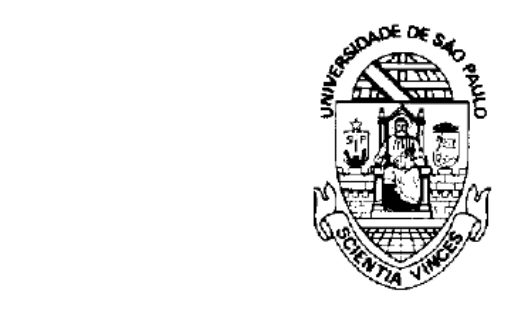

UNIVERSIDADE DE SÃO PAULO

Instituto de Física

\title{
Método de Espectroscopia de Mistura de Níveis para Medida de Momentos de Quadrupolo Nucleares
}

Marcus Kliewer

Dissertação submetida ao Instituto de Física da Universidade de São Paulo para obtenção do título de Mestre em Ciências

Comissão Examinadora:

Profa. Dra. Alinka Lépine-Szily - Orientadora

Prof. Dr. Nilberto Heder Medina - IFUSP

Prof. Dr. Rajendra N. Saxena - IPEN

SÃO PAULO

1999 


\section{Agradecimentos}

Gostaria de expressar os meus sinceros agradecimentos a todas as pessoas que contribuíram na realização deste trabalho, em particular,

à Profa. Dr. Alinka Lépine-Szily, pelo entusiasmo, motivação e competência na orientação deste trabalho.

aos colegas de grupo: Prof. Rubens Lichtenthäler, Gilberto F. Lima, Vanessa Chisté e José Martins (JJ) pela amizade, incentivo e inestimável colaboração .

aos colegas e colaboradores do grupo $\gamma$ : Juan, Flor, Marcia e Prof. ${ }^{e s}$ Wayne, Rao, Ewa, Ribas, pela solidariedade e ajuda na tomada de dados e em especial aos Prof. ${ }^{\text {es }}$ Medina e José Roberto (Zero), pelas proveitosas e esclarecedoras discussões.

ao grupo de Leuven (Bélgica): Prof. Romain Coussement, Gerda Neyens, Sonja Ternier e Katrien Vyvey pela colaboração .

ao Jorge e a Wanda do Laboratório de alvos pela disposição em fazer o "annealing" e "plasma glow" dos alvos.

aos Prof. ${ }^{e s}$ : Hercílio Rechenberg e Frank Missel pela medida de magnetização .

à minha esposa Silvana, por toda compreensão, dedicação, carinho e amor que foram fundamentais para a conclusão deste trabalho.

aos meus queridos pais, irmãos e demais familiares pelo eterno apoio.

aos amigos que me receberam e apoiaram nesta jornada em São Paulo.

a todos os funcionários do laboratório pelo suporte indispensável para a realização deste trabalho.

à FAPESP pelo apoio financeiro. 


\section{Resumo}

Momentos de quadrupolo elétricos de estados isoméricos nucleares com vidas médias entre 10 nanosegundos e 100 milisegundos podem ser medidos com o método Espectroscopia de Mistura de Níveis (Level Mixing Spectroscopy - LEMS), utilizando campos magnéticos variáveis aplicados em núcleos implantados em materias hospedeiros que possuam gradientes de campo elétrico.

O campo magnético externo pode ser substituido pelo campo hiperfino de materiais ferromagnéticos e sua variação poderia ser controlada variando a temperatura. O objetivo deste trabalho é verificar a viabilidade desta substituição .

Implementamos o método LEMS no Laboratório Pelletron usando como caso teste o estado isomérico de $398 \mathrm{keV}$ do ${ }^{69} \mathrm{Ge}$ que possui todas as suas propriedades nucleares conhecidas (meia vida, spin, momento magnético, momento de quadrupolo elétrico). Ele foi produzido pela reação ${ }^{56} \mathrm{Fe}\left({ }^{16} \mathrm{O}, 2 \mathrm{pn}\right){ }^{69} \mathrm{Ge}$ com o feixe de ${ }^{16} \mathrm{O}$ a $53 \mathrm{MeV}$ (LAB) de energia, e depois implantado em Gadolínio que é ferromagnético abaixo de $\mathrm{T}_{c}=289 \mathrm{~K}$. Medimos a anisotropia da radiação $\gamma$ emitida por esse núcleo em função da temperatura. A comparação entre as medidas da anisotropia em função da temperatura, com medidas da anisotropia em função de campo magnético externo, feita pelo grupo de Leuven/Bélgica, nos levou a duas interpretações possíveis. Na primeira, supondo a interação elétrica constante e independente da temperatura, obtemos um campo magnético hiperfino anômalo para o Gd. Na segunda análise, obtivemos o campo hiperfino variando linearmente com a magnetização, admitindo gradientes de campo elétrico dependentes da temperatura. Medidas futuras usando monocristal de Gd poderão resolver esta ambiguidade, bem como medidas TDPAD (Time Diferencial Perturbed Angular Distribution) em função da temperatura, na qual se mede diretamente o campo hiperfino. 


\section{Abstract}

The Level Mixing Spectroscopy method allows to measure the eletric quadrupole moments of high spin isomeric nuclear states (10 $\mathrm{ns} \leq \tau \leq 100 \mathrm{~ms}$ ) produced in nuclear reactions. The magnetic interaction is usualy created by an intense external magnetic field. The eletric quadrupole interaction can be created by recoi-implantation of the nuclei in non-cubic crystals, used as host.

The external magnetic field can be replaced by the hyperfine fields of ferromagnetic materials, controling its intensity by temperature variation. The purpose of the research performed for this work is to verify the viability in this replacement.

We adapt the LEMS method to be used in the Pelletron Laboratory. We choose the isomeric state at $398 \mathrm{keV}$ exitation energy in the ${ }^{69} \mathrm{Ge}$ nucleus as a test case, because it has all nuclear properties well known (half-life, spin, magnetic moment, eletric quarupole moment). It was produced by the ${ }^{56} \mathrm{Fe}\left({ }^{16} \mathrm{O}, 2 \mathrm{pn}\right){ }^{69} \mathrm{Ge}$ reaction, with a ${ }^{16} \mathrm{O}$ beam at 53 $\mathrm{MeV}$, and implanted and stopped in a Gadolinium host, which is a ferromagnet from low temperatures up to $T_{c}=289 \mathrm{~K}$.

We measure the anisotropy of the emitted $\gamma$ ray as a function of the temperature of the host. The comparison of this measurement with another of the anisotropy as a function of an external magnetic field strength, done by the Leuven/Belgium group, show us two possibilities. In the first, we suppose that the eletric interaction is constant and independent of temperature and we obtain an anomalous magnetic hyperfine field for Gd. In the second one, we obtain a hyperfine field that follows the magnetization if we assume eletric field gradients that are temperature dependent. New measurements by using Gd monocrystal and the TDPAD (Time Diferencial Perturbed Angular Distribution) method may solve this ambiguity. 


\section{Introdução}

As medidas de momentos multipolares como momentos de quadrupolo elétricos e momentos de dipolo magnéticos, fornecem contribuições significativas ao desenvolvimento de modelos teóricos da estrutura nuclear. As propriedades eletromagnéticas nucleares são sensíveis às funções de onda do estado, e suas medidas podem fornecer informações decisivas para o teste desses modelos, pois, modelos distintos podem predizer valores diferentes para os momentos eletromagnéticos, mesmo concordando nas previsões de outros parâmetros nucleares, como energia, spin e paridade dos estados nucleares.

O fenômeno de "mistura de níveis" no esquema de níveis hiperfinos, embora conhecido há longa data, só recentemente teve seu potencial melhor aproveitado, nos trabalhos do grupo de R. Coussement [1,3]. Este grupo adaptou e utiliza o método Ressonância de Mistura de Níveis (Level Mixing Resonance - LMR) para a medida de momentos de quadrupolo elétrico de estados isoméricos nucleares, com vidas médias entre 10 nanosegundos e 100 milisegundos, produzidos por reações de fusão-evaporação.

As experiências de LMR e Espectroscopia de Mistura de Níveis (Level Mixing Spectroscopy - LEMS) pertencem à categoria de medidas de distribuições angulares perturbadas integradas no tempo. Neste método, núcleos são produzidos e orientados num estado isomérico, e submetidos a uma interação hiperfina elétrica e magnética estática. O resultado da perturbação é observado por uma medida integrada no tempo da distribuição angular da radiação $\gamma$ emitida no decaimento do isômero.

A característca principal do método LMR é uma perturbação muito especial no estado intermediário: é uma interação magnética produzida por um campo magnético externo paralelo (ou perpendicular) ao feixe, e uma interação quadrupolar axialmente simétrica produzida pelo material, no qual o núcleo isomérico é implantado pelo recuo. A orientação inicial é, em geral, produzida pela reação nuclear e portanto é simétrica em torno da 
direção do feixe.

Se o eixo de simetria do gradiente de campo elétrico (Eletric Field Gradient - EFG) é apenas ligeiramente desalinhado, com um pequeno ângulo $\beta$, em relação à direção do campo magnético, a interação continua sendo aproximadamente axial em torno do eixo de simetria do alinhamento inicial, e espera-se ter pouco efeito na orientação do núcleo. No entanto, para certos valores de campo magnético onde ocorre uma degenerescência nos níveis hiperfinos, a pequena parte não-axial da interação perturba fortemente a orientação, de uma forma ressonante. Medindo-se a distribuição angular integrada no tempo do decaimento do estado isomérico como função da intensidade do campo magnético, estes pontos degenerados podem ser detectados com precisão, devido ao seu caráter ressonante, e permitem determinar com precisão a razão das interações elétrica e magnética.

Se continuarmos a aumentar o ângulo $\beta$ entre o gradiente de campo elétrico e o campo magnético, cada vez mais níveis vão se misturar, e o espaçamento entre os pontos de mistura ficam menores e as ressonâncias começam a se alargar. Quanto maior o ângulo $\beta$, mais misturas tendem a ocorrer e conseqüentemente, mais os níveis se repelem uns dos outros.

No caso de usar um policristal em vez de um monocristal para implantar o núcleo de interesse, devemos realizar uma integração sobre todos os ângulos possíveis entre as direções do EFG ao acaso no policristal e a direção do campo magnético. Isto dá um resultado semelhante ao caso de se ter um ângulo $\beta$ grande. Neste caso não se observam as ressonâncias individuais que passam a se superpôr, mas o que se observa é uma variação na anisotropia da radiação $\gamma$ emitida pelo estado isomérico em função do campo magnético externo. Quando o spin do estado isomérico é alto e tem muitos subestados magnéticos também não é possível resolver as ressonâncias individuais. Quando as ressonâncias individuais não são separadas e se observa uma variação da anisotropia em função da razão das interações elétroca e magnética $\omega_{B} / \omega_{Q}$, trata-se do método LEMS.

No LEMS usam-se policristais ou monocristais e os núcleos no estado isomérico também são submetidos simultaneamente à interação hiperfina magnética e elétrica. A interação quadrupolar elétrica pode ser criada por gradientes de campo elétricos (EFG) estáticos de policristais que não possuam simetria cúbica, ou por EFG de defeitos criados pelo núcleo implantado, no material hospedeiro ("host"), onde é parado. Já a interação magnética 
é usualmente criada por um campo magnético externo intenso (até 5 Tesla) de um imã supercondutor.

Uma alternativa para substituir os campos magnéticos externos é usar os campos magnéticos hiperfinos de materiais ferromagnéticos. Em geral, esses campos variam linearmente com a magnetização e, variando a temperatura do material ferromagnético, é possível variar o valor do campo hiperfino. Esta substituição teria grande interesse prático, pois permite a miniaturização dos equipamentos, e usar o método LMR ou LEMS com os sistemas de detectores $\gamma$ de geometria 4 $\pi$, como "Euroball" ou "Gammas Sphere”. Também o campo magnético intenso do imã externo afeta os detetores Ge(HP) e anti-Compton.

Nesse trabalho adaptamos o método LEMS no Laboratório Pelletron, usando como caso teste o estado isomérico de $398 \mathrm{keV}$ do ${ }^{69} \mathrm{Ge}$. Este estado do ${ }^{69} \mathrm{Ge}$ possui suas propriedades nucleares como spin, meia vida, momento de quadrupolo elétrico e momento magnético, conhecidas.

Para produzir o ${ }^{69} \mathrm{Ge}$ utilizamos a reação ${ }^{56} \mathrm{Fe}\left({ }^{16} \mathrm{O}, 2 p n\right){ }^{69} \mathrm{Ge}$ com o feixe de ${ }^{16} \mathrm{O}$ à $53 \mathrm{MeV}$ de energia incidente. $\mathrm{O}{ }^{69} \mathrm{Ge}$ então foi implantado numa folha de gadolínio natural que serviu de material hospedeiro. O gadolínio é ferromagnético para temperaturas abaixo de $T_{C}=289 \mathrm{~K}$. Além disso, ele possui uma assimetria na distribuição de cargas que permite ter um gradiente de campo elétrico. Medimos a anisotropia da radiação $\gamma$ proveniente do estado isomérico de $398 \mathrm{keV}$ do ${ }^{69} \mathrm{Ge}$, em função da temperatura. Como não se conhece a dependência do $B_{\text {hiperfino }}$ e do gradiente de campo elétrico com a temperatura, os resultados não podem ser interpretados sem ambiguidade.

No entanto, medidas complementares podem resolver estas ambiguidades. Uma medida complementar deste tipo foi realizada no Instituut voor Kern en Stralingsfysica (IKS) da Universidade Católica de Leuven, Bélgica, medindo a anisotropia da radiação $\gamma$, implantando o ${ }^{69} \mathrm{Ge}$ em $\mathrm{Gd}$, usando campo magnético externo B variável e mantendo o alvo a uma temperatura fixa $(\mathrm{T}=450 \mathrm{~K})$, ou seja, garantindo que o gradiente de campo elétrico seja fixo e que não haja campo magnético hiperfino. Neste caso, separou-se a variação do B, da variação do EFG. Nas medidas de Leuven verificou-se a existência de 2 sítios de implantação, provávelmente um substitucional e outro intersticial, com EFG muito diferentes. 
Devido a grande diferença entre os EFG, o desacoplamento das interações elétricas ocorre também em regiões de campo B bem diferentes. Com campos B baixos ( $\mathrm{B} \leq 1 \mathrm{~T})$ desacopla-se o EFG criado pelos defeitos, no entanto para desacoplar o EFG intrínseco precisa de campos $\mathrm{B}$ mais intensos $(1 \mathrm{~T} \leq \mathrm{B} \leq 4 \mathrm{~T})$.

Já nas nossas medidas, tanto o campo hiperfino magnético B como o elétrico EFG podem variar com a temperatura. Assumímos uma dependência razoável para o campo hiperfino elétrico $\left(\mathrm{EFG}(\mathrm{T}) \approx T^{3 / 2}\right)$ e com esta hipótese de trabalho conseguimos obter $\mathrm{B}(\mathrm{T})$. A dependência que obtivemos para o campo hiperfino $\mathrm{B}(\mathrm{T})$ é bastante próxima à variação da magnetização com a temperatura, resultando numa função aproximadamente linear entre o campo hiperfino B e a magnetização .

Este resultado precisa de medidas complementares adicionais para sua confirmação. O grupo de Leuven está muito interessado em nossos resultados e na confirmação da nossa interpretação. Se nossa interpretação estiver correta e o campo hiperfino for linear à magnetização e seu comportamento com a temperatura for conhecida, então uma enorme gama de aplicações se abre diante dos métodos LMR/LEMS.

Através da miniaturização, o método pode ser incorporado em vários sistemas de detecção, usando em sistemas de detetores tipo EUROBALL, espectrógrafos, em seletores junto com feixe radioativos, etc. 


\section{Conteúdo}

$\begin{array}{ll}\text { Introdução } & 1\end{array}$

1 Teoria de Espectroscopia de Mistura de Níveis (Level Mixing Spectroscopy - LEMS) 5

1.1 Conceito geral . . . . . . . . . . . . . . . . . 5

1.2 Hamiltoniana de mistura de níveis . . . . . . . . . . . . . . . . . . . . 6

1.3 Espectroscopia de Mistura de Níveis . . . . . . . . . . . . . . . . . . . . . . 12

1.3.1 Observação da mistura de níveis . . . . . . . . . . . . . . . . . 14

1.3.2 Distribuição Angular de raios $\gamma$ e Perturbações Hiperfinas . . . . . 16

1.4 A geometria para LEMS . . . . . . . . . . . . . . . . . . . . . . . 19

1.4.1 Geometria paralela . . . . . . . . . . . . . . . 19

1.4.2 Geometria perpendicular . . . . . . . . . . . . 20

1.5 Duas Perturbações . . . . . . . . . . . . . . . . . . . 22

2 Materiais Ferromagnéticos $\quad 23$

2.1 Implantação em materiais hospedeiros . . . . . . . . . . . . . . 25

2.2 Materiais Ferromagnéticos . . . . . . . . . . . . . . . . . 27

2.2.1 Ferromagnetismo em $\mathrm{Gd}$. . . . . . . . . . . . . . . . . . . . 29

3 Interações hiperfinas $\quad 31$

3.1 Interação magnética hiperfina no Gd . . . . . . . . . . . . . . . . . . 31

3.1 .1 Dependência do campo hiperfino com a magnetização . . . . . . . . 32

3.2 Interações quadrupolares estáticas . . . . . . . . . . . . . . . . 33

4 Dispositivo Experimental $\quad 36$

4.1 Montagem experimental . . . . . . . . . . . . . . . . 36

4.2 A câmara . . . . . . . . . . . . . . . . . . . 37

4.3 Criostato de Fluxo Contínuo . . . . . . . . . . . . . . . . . . 38

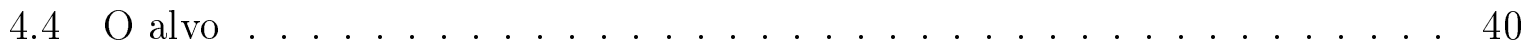


4.4 Laminação . . . . . . . . . . . . . . . . . . . . . . 40

4.4 .2 Recozimento (Annealing) . . . . . . . . . . . . . . 41

4.4.3 "Plasma Glow" . . . . . . . . . . . . . . . . . . . . . . 41

4.4.4 Evaporação do Ferro . . . . . . . . . . . . . . . . . . 42

4.5 Os imãs . . . . . . . . . . . . . . . . . . . . . 42

4.5.1 Medida da magnetização . . . . . . . . . . . . . . 44

4.6 Detectores . . . . . . . . . . . . . . . . . . 45

4.7 Eletrônica de aquisição . . . . . . . . . . . . . . . . . . 46

5 Descrição da experiência $\quad 49$

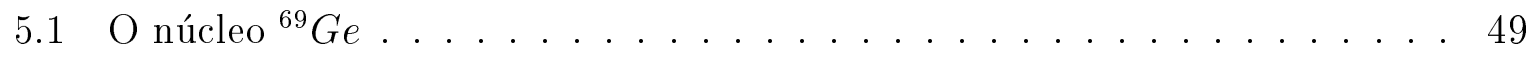

5.2 Reação de fusão-evaporação . . . . . . . . . . . . . . . . . . 50

5.3 Redução de Dados . . . . . . . . . . . . . . . . . . . . . . 50

5.4 Procedimento da análise . . . . . . . . . . . . . . . . . . 51

5.4 .1 Identificação dos picos . . . . . . . . . . . . . 51

5.4 .2 Extração das áreas dos picos do espectro $\gamma$. . . . . . . . . . . 52

5.4 .3 Normalização dos picos com a transição de $788 \mathrm{keV}$. . . . . . . . . 54

6 Análise e interpretação dos resultados $\quad 57$

6.1 Anisotropia X Temperatura .................. 57

6.2 Comparação de resultados . . . . . . . . . . . . . . . . . . . 58

6.3 Campo hiperfino anômalo em $\mathrm{Gd}$. . . . . . . . . . . . . . . . . . . 60

6.4 Duas frequências quadrupolares . . . . . . . . . . . . . . . . 63

6.5 Interações quadrupolares dependentes de temperatura . . . . . . . . . . . 64

6.6 Desacoplamento das interações . . . . . . . . . . . . . . . . 65

7 Conclusão e perspectivas $\quad 72$

$\begin{array}{ll}\text { Bibliografia } & 75\end{array}$ 


\section{Introdução}

As medidas de momentos multipolares como momentos de quadrupolo elétricos e momentos de dipolo magnéticos, fornecem contribuições significativas ao desenvolvimento de modelos teóricos da estrutura nuclear. As propriedades eletromagnéticas nucleares são sensíveis às funções de onda do estado, e suas medidas podem fornecer informações decisivas para o teste desses modelos, pois, modelos distintos podem predizer valores diferentes para os momentos eletromagnéticos, mesmo concordando nas previsões de outros parâmetros nucleares, como energia, spin e paridade dos estados nucleares.

O fenômeno de "mistura de níveis" no esquema de níveis hiperfinos, embora conhecido há longa data, só recentemente teve seu potencial melhor aproveitado, nos trabalhos do grupo de R. Coussement [1,3]. Este grupo adaptou e utiliza o método Ressonância de Mistura de Níveis (Level Mixing Resonance - LMR) para a medida de momentos de quadrupolo elétrico de estados isoméricos nucleares, com vidas médias entre 10 nanosegundos e 100 milisegundos, produzidos por reações de fusão-evaporação.

As experiências de LMR e Espectroscopia de Mistura de Níveis (Level Mixing Spectroscopy - LEMS) pertencem à categoria de medidas de distribuições angulares perturbadas integradas no tempo. Neste método, núcleos são produzidos e orientados num estado isomérico, e submetidos a uma interação hiperfina elétrica e magnética estática. O resultado da perturbação é observado por uma medida integrada no tempo da distribuição angular da radiação $\gamma$ emitida no decaimento do isômero.

A característca principal do método LMR é uma perturbação muito especial no estado intermediário: é uma interação magnética produzida por um campo magnético externo paralelo (ou perpendicular) ao feixe, e uma interação quadrupolar axialmente simétrica

produzida pelo material, no qual o núcleo isomérico é implantado pelo recuo. A orientação inicial é, em geral, produzida pela reação nuclear e portanto é simétrica em torno da 
direção do feixe.

Se o eixo de simetria do gradiente de campo elétrico (Eletric Field Gradient - EFG) é apenas ligeiramente desalinhado, com um pequeno ângulo $\beta$, em relação à direção do campo magnético, a interação continua sendo aproximadamente axial em torno do eixo de simetria do alinhamento inicial, e espera-se ter pouco efeito na orientação do núcleo. No entanto, para certos valores de campo magnético onde ocorre uma degenerescência nos níveis hiperfinos, a pequena parte não-axial da interação perturba fortemente a orientação, de uma forma ressonante. Medindo-se a distribuição angular integrada no tempo do decaimento do estado isomérico como função da intensidade do campo magnético, estes pontos degenerados podem ser detectados com precisão, devido ao seu caráter ressonante, e permitem determinar com precisão a razão das interações elétrica e magnética.

Se continuarmos a aumentar o ângulo $\beta$ entre o gradiente de campo elétrico e o campo magnético, cada vez mais níveis vão se misturar, e o espaçamento entre os pontos de mistura ficam menores e as ressonâncias começam a se alargar. Quanto maior o ângulo $\beta$, mais misturas tendem a ocorrer e conseqüentemente, mais os níveis se repelem uns dos outros.

No caso de usar um policristal em vez de um monocristal para implantar o núcleo de interesse, devemos realizar uma integração sobre todos os ângulos possíveis entre as direções do EFG ao acaso no policristal e a direção do campo magnético. Isto dá um resultado semelhante ao caso de se ter um ângulo $\beta$ grande. Neste caso não se observam as ressonâncias individuais que passam a se superpôr, mas o que se observa é uma variação na anisotropia da radiação $\gamma$ emitida pelo estado isomérico em função do campo magnético externo. Quando o spin do estado isomérico é alto e tem muitos subestados magnéticos também não é possível resolver as ressonâncias individuais. Quando as ressonâncias individuais não são separadas e se observa uma variação da anisotropia em função da razão das interações elétroca e magnética $\omega_{B} / \omega_{Q}$, trata-se do método LEMS.

No LEMS usam-se policristais ou monocristais e os núcleos no estado isomérico também são submetidos simultaneamente à interação hiperfina magnética e elétrica. A interação quadrupolar elétrica pode ser criada por gradientes de campo elétricos (EFG) estáticos de policristais que não possuam simetria cúbica, ou por EFG de defeitos criados pelo núcleo implantado, no material hospedeiro ("host"), onde é parado. Já a interação magnética 
é usualmente criada por um campo magnético externo intenso (até 5 Tesla) de um imã supercondutor.

Uma alternativa para substituir os campos magnéticos externos é usar os campos magnéticos hiperfinos de materiais ferromagnéticos. Em geral, esses campos variam linearmente com a magnetização e, variando a temperatura do material ferromagnético, é possível variar o valor do campo hiperfino. Esta substituição teria grande interesse prático, pois permite a miniaturização dos equipamentos, e usar o método LMR ou LEMS com os sistemas de detectores $\gamma$ de geometria $4 \pi$, como "Euroball" ou "Gammas Sphere". Também o campo magnético intenso do imã externo afeta os detetores Ge(HP) e anti-Compton.

Nesse trabalho adaptamos o método LEMS no Laboratório Pelletron, usando como caso teste o estado isomérico de $398 \mathrm{keV}$ do ${ }^{69} \mathrm{Ge}$. Este estado do ${ }^{69} \mathrm{Ge}$ possui suas propriedades nucleares como spin, meia vida, momento de quadrupolo elétrico e momento magnético, conhecidas.

Para produzir o ${ }^{69} \mathrm{Ge}$ utilizamos a reação ${ }^{56} \mathrm{Fe}\left({ }^{16} \mathrm{O}, 2 p n\right){ }^{69} \mathrm{Ge}$ com o feixe de ${ }^{16} \mathrm{O}$ à $53 \mathrm{MeV}$ de energia incidente. O ${ }^{69} \mathrm{Ge}$ então foi implantado numa folha de gadolínio natural que serviu de material hospedeiro. O gadolínio é ferromagnético para temperaturas abaixo de $T_{C}=289 \mathrm{~K}$. Além disso, ele possui uma assimetria na distribuição de cargas que permite ter um gradiente de campo elétrico. Medimos a anisotropia da radiação $\gamma$ proveniente do estado isomérico de $398 \mathrm{keV}$ do ${ }^{69} \mathrm{Ge}$, em função da temperatura. Como não se conhece a dependência do $B_{\text {hiperfino }}$ e do gradiente de campo elétrico com a temperatura, os resultados não podem ser interpretados sem ambiguidade.

No entanto, medidas complementares podem resolver estas ambiguidades. Uma medida complementar deste tipo foi realizada no Instituut voor Kern en Stralingsfysica (IKS) da Universidade Católica de Leuven, Bélgica, medindo a anisotropia da radiação $\gamma$, implantando o ${ }^{69} \mathrm{Ge}$ em Gd, usando campo magnético externo B variável e mantendo o alvo a uma temperatura fixa $(\mathrm{T}=450 \mathrm{~K})$, ou seja, garantindo que o gradiente de campo elétrico seja fixo e que não haja campo magnético hiperfino. Neste caso, separou-se a variação do B, da variação do EFG. Nas medidas de Leuven verificou-se a existência de 2 sítios de implantação, provávelmente um substitucional e outro intersticial, com EFG muito diferentes. 
Devido a grande diferença entre os EFG, o desacoplamento das interações elétricas ocorre também em regiões de campo B bem diferentes. Com campos B baixos $(\mathrm{B} \leq 1 \mathrm{~T})$ desacopla-se o EFG criado pelos defeitos, no entanto para desacoplar o EFG intrínseco precisa de campos $\mathrm{B}$ mais intensos $(1 \mathrm{~T} \leq \mathrm{B} \leq 4 \mathrm{~T})$.

Já nas nossas medidas, tanto o campo hiperfino magnético B como o elétrico EFG podem variar com a temperatura. Assumímos uma dependência razoável para o campo hiperfino elétrico $\left(\operatorname{EFG}(\mathrm{T}) \approx T^{3 / 2}\right)$ e com esta hipótese de trabalho conseguimos obter $\mathrm{B}(\mathrm{T})$. A dependência que obtivemos para o campo hiperfino $\mathrm{B}(\mathrm{T})$ é bastante próxima à variação da magnetização com a temperatura, resultando numa função aproximadamente linear entre o campo hiperfino B e a magnetização .

Este resultado precisa de medidas complementares adicionais para sua confirmação. O grupo de Leuven está muito interessado em nossos resultados e na confirmação da nossa interpretação. Se nossa interpretação estiver correta e o campo hiperfino for linear à magnetização e seu comportamento com a temperatura for conhecida, então uma enorme gama de aplicações se abre diante dos métodos LMR/LEMS.

Através da miniaturização, o método pode ser incorporado em vários sistemas de detecção, usando em sistemas de detetores tipo EUROBALL, espectrógrafos, em seletores junto com feixe radioativos, etc. 


\section{Capítulo 1}

\section{Teoria de Espectroscopia de Mistura de Níveis (Level Mixing Spectroscopy - LEMS)}

\subsection{Conceito geral}

Num experimento de Espectroscopia de Mistura de Níveis (Level Mixing Spectroscopy

- LEMS), núcleos são produzidos num estado isomérico e submetidos a uma interação hiperfina estática. O resultado da perturbação é observado por uma medida integrada no tempo da distribuição angular da radiação $\gamma$ emitida no decaimento do isômero, em função da intensidade do campo magnético.

A ocorrência de mistura de níveis está relacionada com a quebra ou restauração de simetrias. Uma interação quadrupolar axialmente simétrica e um campo magnético aplicado ao longo do mesmo eixo, não destróem a simetria. Mas, uma pequeno ângulo entre as duas interações vai destruir essa simetria. Quando os subestados magnéticos se cruzam, o efeito da quebra de simetria é então de misturar os autoestados correspondentes, e repelir os níveis de energia [1]. O que se mede é a curva da variação da distribuição angular em funcão do campo magnético aplicado. Neste trabalho, tratamos da situação em que um núcleo sofre um interação quadrupolar elétrica axialmente simétrica e uma interação magnética estática. 
CAPíTUlO 1. TEORIA DE ESPECTROSCOPIA DE MISTURA DE NíVEIS (LEVEL MIXING SPECTROSCOPY - LEMS)

\subsection{Hamiltoniana de mistura de níveis}

A Hamiltoniana de interação hiperfina contém dois termos, a Hamiltoniana magnética e a elétrica:

$$
H=H_{B}+H_{Q}
$$

Escolhemos a direção $Z$ do sistema de referencial do laboratório ao longo da direção do campo magnético estático $B$. Neste referencial, a interação magnética entre o campo magnético estático $B$ e o momento magnético $\mu$ do estado nuclear isomérico se escreve como:

$$
H_{B}=-\vec{\mu} \cdot \overrightarrow{\mathbf{B}}=\frac{-g \mu_{N} B_{Z}}{\hbar} \mathbf{I}_{\mathbf{Z}}=-\omega_{B} \mathbf{I}_{\mathbf{Z}}
$$

onde $\omega_{B}$ é chamada frequência de Larmor magnética.

Na presença de um gradiente de campo elétrico induzido, por exemplo, por uma assimetria na distribuição de cargas da rede cristalina de um monocristal no qual o núcleo é implantado, o estado nuclear isomérico com momento de quadrupolo elétrico $Q$ sofre uma interação elétrica (que se mostra sob um torque que resulta na precessão do spin I em torno de um eixo de simetria, que definiremos ser na direção $Z_{P A S}$ ) (Fig. 1.1). Assim,

podemos caracterizar o gradiente de campo elétrico por $V_{z z}=\frac{\partial^{2} V}{\partial Z_{P A S}^{2}}$. A Hamiltoniana que descreve a interação quadrupolar no sistema de coordenadas PAS (ligado a simetria do cristal) é dada por [2]:

$$
H_{Q}=\frac{\hbar \omega_{Q}}{\hbar^{2}}\left(3 I_{Z_{P A S}}^{2}-I_{P A S}^{2}\right)
$$

onde

$$
\omega_{Q}=\frac{e Q V_{z z}}{4 I(2 I-1) \hbar}
$$

é a chamada frequência de Larmor elétrica.

Se o campo magnético aplicado $\vec{B}$ está alinhado com o eixo de simetria do gradiente de campo elétrico, ou seja, se $Z_{L A B}$ coincide com $Z_{P A S}$, a Hamiltoniana total de interação será axialmente simétrica e, 


$$
H_{T O T}=-\omega_{B} I_{Z_{P A S}}+\frac{\omega_{Q}}{\hbar}\left(3 I_{Z_{P A S}}^{2}-I_{P A S}^{2}\right)
$$

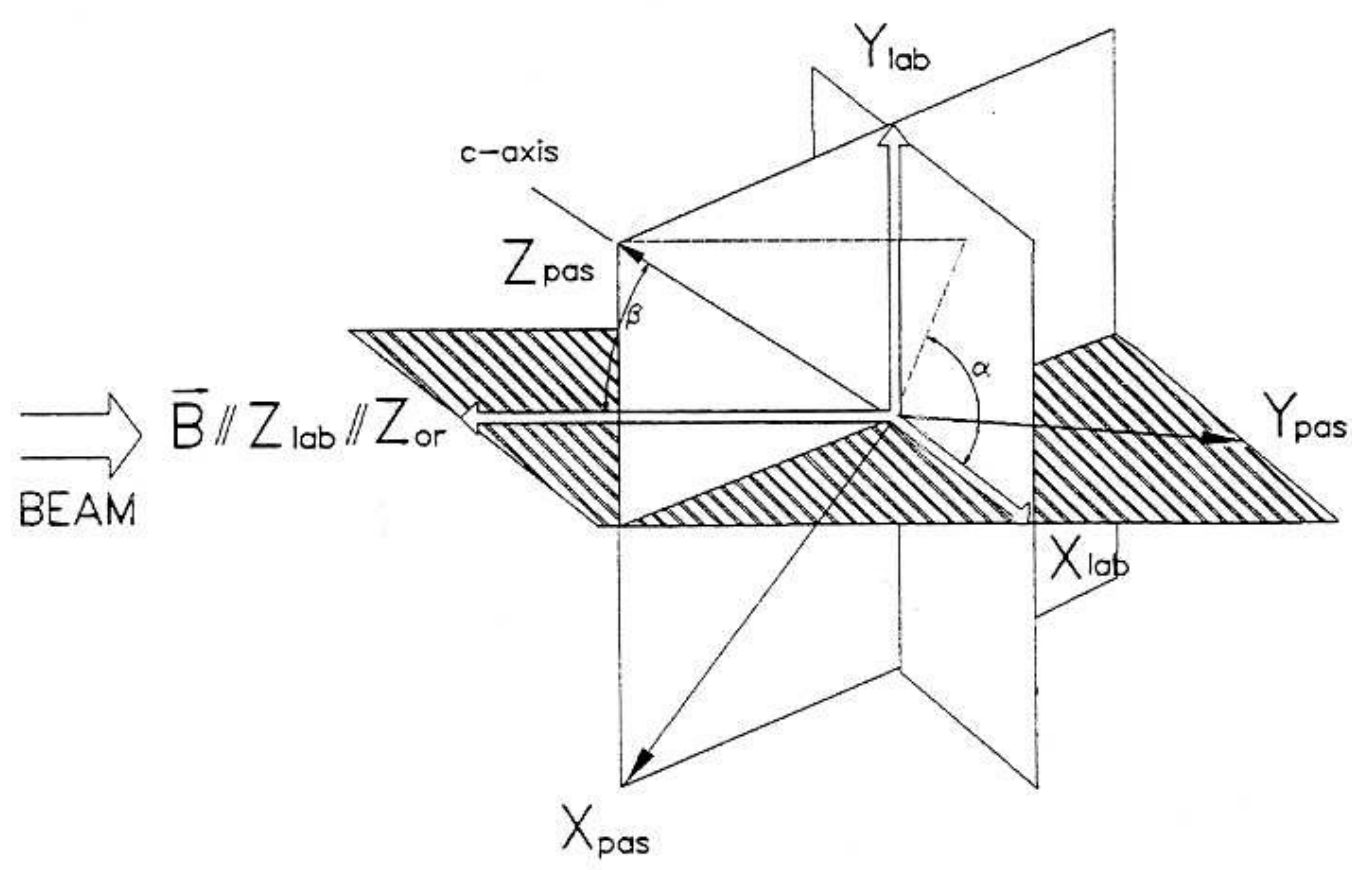

Figura 1.1: Definição dos sistemas de coordenadas LAB e PAS. Usamos $\beta$ para denotar a diferença angular entre os eixos do campo magnético e do eixo de simetria do gradiente de campo elétrico [3].

Expressando isso em termos da base $\mid I, m>$, onde $\mid I, m>$ são autoestados do operador de momento angular $I_{Z_{P A S}}$, temos

$$
\begin{aligned}
E_{m}=<I, m\left|H_{t o t}\right| I, m> & =<I, m\left|H_{Q}\right| I, m>+<I, m\left|H_{B}\right| I, m> \\
& =\hbar \omega_{Q}\left[3 m^{2}-I(I+1)\right]-\hbar \omega_{B} m
\end{aligned}
$$

onde $E_{m}$ é o autovalor da energia para cada subnível magnético. Na ausência de campo magnético, sobra apenas o termo da interação quadrupolar e a energia dos níveis mostrase degenerada em $\mid \pm m>$. Quando o campo magnético é aplicado, a degenerescência é removida, exceto para alguns valores de campo magnético, em pontos equidistantes, nos quais os níveis com valores diferentes $m$ e $m^{\prime}$ se cruzam, apresentando o mesmo valor de energia $E_{m}$ (Fig. 1.2). Isto decorre quando: 


$$
\frac{\omega_{B}}{\omega_{Q}}=3\left(m+m^{\prime}\right)
$$

Esse efeito é chamado de cruzamento de níveis, e pode dar origem às chamadas ressonâncias de cruzamento de níveis (Level Crossing Resonances), descritos pela primeira vez em 1983 [4]. Para valores altos de campo magnético, a interação quadrupolar se torna desprezível e se desacopla, tornando o desdobramento em energia igual ao desdobramento Zeeman nuclear [5].

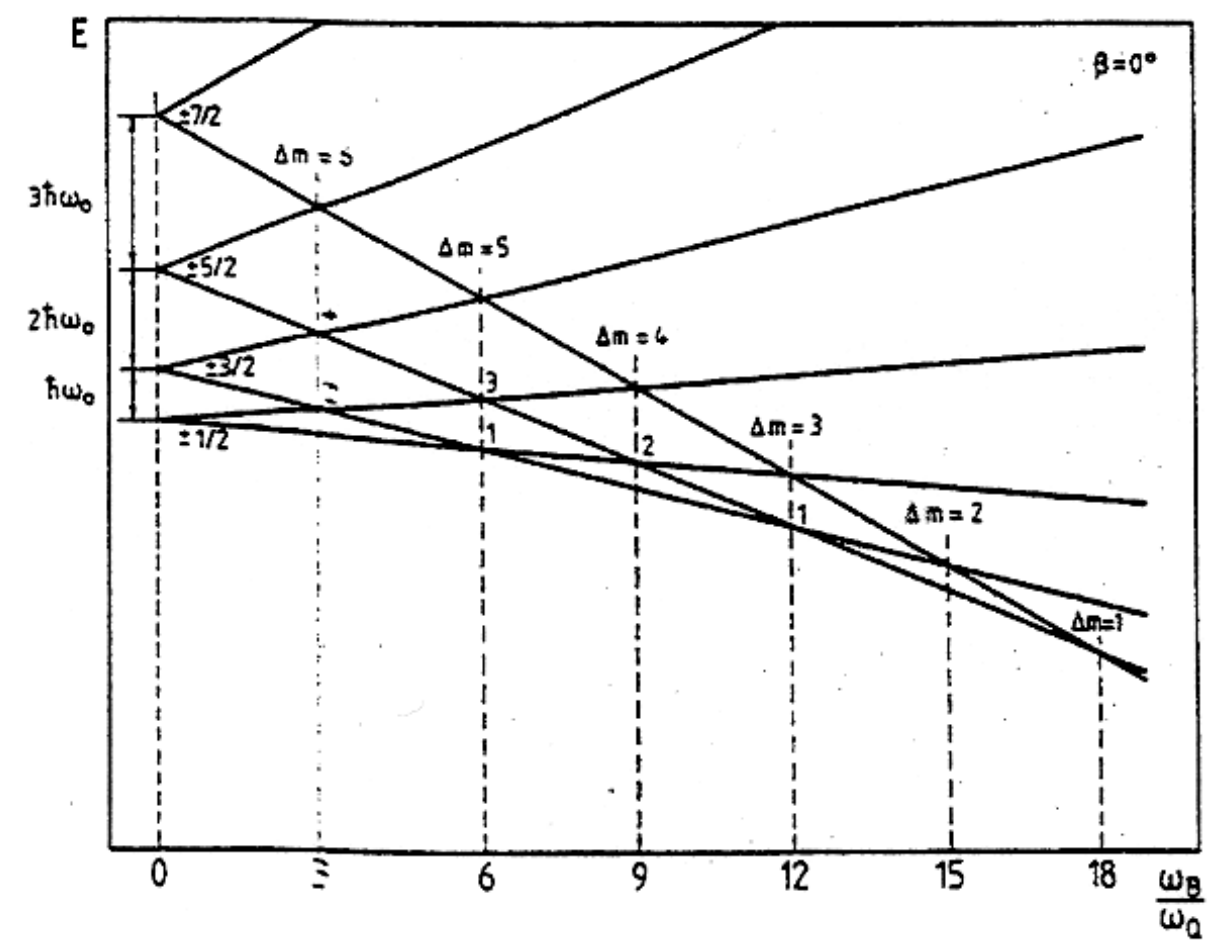

Figura 1.2: Esquema dos níveis de energia hiperfinos em função de $\frac{\omega_{B}}{\omega_{Q}}$ para $\beta=0$, ou seja, quando o campo magnético está perfeitamente alinhado com o eixo de simetria do gradiente de campo elétrico.[5]

Se agora, considerarmos um pequeno desvio entre os eixos das interações elétrica e magnética, ou seja um pequeno ângulo $\beta$, então os sistemas de coordenadas LAB e PAS não coincidem mais. Isto induz a uma pequena quebra de simetria da Hamiltoniana. Podemos decompor o campo magnético em relação ao referencial PAS em componentes paralelas e perpendiculares à $Z_{P A S}$

$$
B_{\|}=B \cos \beta \quad \text { e } B_{\perp}=B \operatorname{sen} \beta
$$


Podemos escolher a direção de x-LAB de tal maneira que o eixo de orientação da interação elétrica permaneca no plano (x-LAB, z-LAB). Rescrevemos então a Hamiltoniana dividida em uma parte axialmente simétrica e uma perturbação não axial determinada pela componente perpendicular do campo magnético:

$$
\begin{aligned}
H_{m a g} & =H_{\|}+H_{\perp} \\
H_{\|} & =-\omega_{B} \cos \beta I_{z}+\frac{\omega_{Q}}{\hbar}\left(3 I_{z}^{2}-I^{2}\right) \\
H_{\perp} & =+\omega_{B} \operatorname{sen} \beta I_{x}
\end{aligned}
$$

Portanto, os elementos de matriz de $H_{m a g}$ podem ser escritas como:

$$
\begin{aligned}
<m\left|H_{\text {mag }}\right| m> & =-\hbar \omega_{B} m \cos \beta \\
<m\left|H_{\text {mag }}\right| m-1> & =\frac{\hbar \omega_{B}}{2} \operatorname{sen} \beta[(I+m)(I-m+1)]^{1 / 2}
\end{aligned}
$$

A pequena componente transversa do campo magnético induz transições entre subestados magnéticos, isto é, produz uma pequena perturbação na orientação. Contudo, longe dos pontos de cruzamento o efeito do pequeno campo transverso é desprezível comparado ao efeito dos campos longitudinais. Podemos entender isso classicamente como spins nucleares precessionando rapidamente em torno do eixo de orientação (que são os campos longitudinais) e uma precessão lenta em torno de um eixo perpendicular ao eixo de orientação (campos transversos). Durante um período da precessão rápida, o ângulo entre o spin e o campo transverso muda de tal maneira que o efeito integrado da precessão lenta é cancelada. Podemos dizer que a precessão rápida restaura a simetria axial. No entanto, perto dos pontos de cruzamento, a precessão longitudinal fica muito pequena e a restauração não acontece mais [7].

O resultado é uma mistura de níveis que se torna importante em pequenos ângulos $\beta$, e onde os níveis não-perturbados se aproximam muito um do outro (Fig. 1.3)[3]. Se medirmos observáveis que são sensíveis à simetria espacial da Hamiltoniana, podemos esperar sinais ressonantes nesses pontos (a distribuição angular da radiação $\gamma$ que desexcita o estado nuclear é um exemplo de uma observável deste tipo). Essa condição é satisfeita se a Hamiltoniana agir perturbativamente num estado intermediário em uma medida da distribuição angular [1]. Isto dá origem às ressonâncias de mistura de níveis (LMR), que 
CAPíTUlO 1. TEORIA DE ESPECTROSCOPIA DE MISTURA DE NíVEIS (LEVEL MIXING SPECTROSCOPY - LEMS)
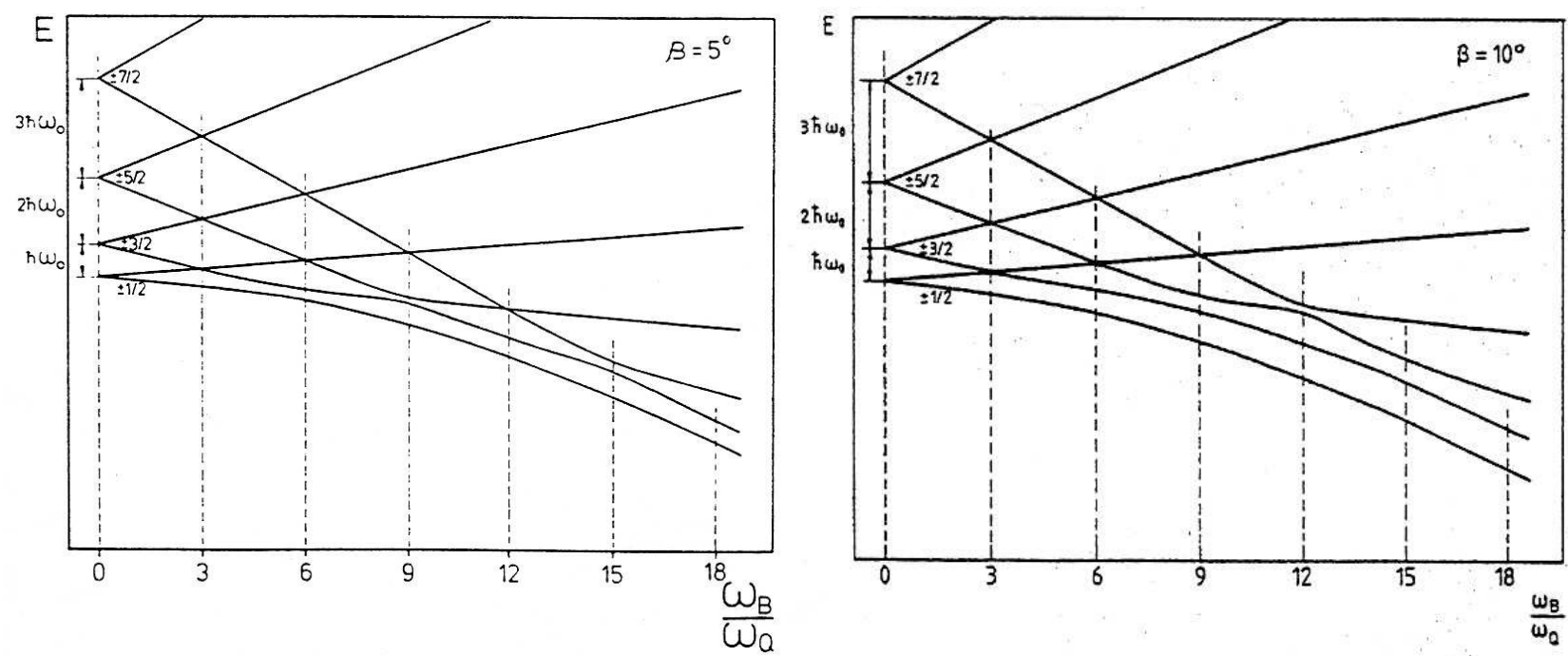

Figura 1.3: Diagramas de Breit-Rabi para ângulos $\beta=5$ e 10. Quando $\beta$ aumenta, cada vez mais níveis se misturam.

são observadas quando medimos a distribuição angular da radiação $\gamma$ em função do campo magnético aplicado $[7,8,9]$. Em uma aproximação para dois níveis, os estados misturados e os níveis de energia do sistema perturbado podem ser calculados com a teoria de perturbação quasi-degenerada [11]. Essas expressões e outras são colocadas nesse trabalho de forma resumida e o tratamento completo pode ser encontrado nas referências $[1,3]$ e em outras referências citadas ao longo do texto.

Fora das regiões de cruzamento, a influência do desalinhamento das duas interações é muito pequena. Nos pontos de cruzamento, o efeito de $\beta$ é de levantar a degenerescência; os níveis de energia coincidentes se repelem e os autoestados correspondentes são misturados. Podemos dividir a Hamiltoniana em duas partes e isolar a influência do angulo $\beta$ do termo perturbativo [1]:

$$
H=H(\beta=0)+V(\beta)
$$

e os elementos de matriz são :

$$
\begin{aligned}
<m|H(\beta=0)| m> & =-\hbar \omega_{B} m+\hbar \omega_{Q}\left[3 m^{2}-I(I+1)\right] \\
<m|V| m> & =\hbar \omega_{B} m(1-\cos \beta)
\end{aligned}
$$


CAPíTUlO 1. TEORIA DE ESPECTROSCOPIA DE MISTURA DE NíVEIS (LEVEL MIXING SPECTROSCOPY - LEMS)

$$
<m|V| m-1>=\frac{\hbar \omega_{B}}{2} \operatorname{sen} \beta[(I+m)(I-m+1)]^{1 / 2}
$$

Vamos supor que o campo magnético tem o valor tal que dois níveis com números quanticos $m$ e $m^{\prime}=m-1$ se aproximam. Os elementos de matriz $H(\beta=0)_{m, m}$ e $H(\beta=0)_{m^{\prime}, m^{\prime}}$ são iguais. Nos pontos de cruzamento temos que aplicar a teoria de perturbação para o caso degenerado, que significa diagonalizar a submatriz (2 X 2) de V que corresponde aos níveis cruzados. Se $\beta$ é pequeno, podemos numa primeira aproximação desprezar os elementos de matriz diagonais de V. Desta maneira, a diferença de energia entre dois níveis que se repelem é de $2 V_{m m^{\prime}}$, que é proporcional a $\operatorname{sen} \beta$. Como estamos interessados não apenas no ponto do cruzamento, mas também na vizinhança desses pontos, um estudo mais elaborado usando a teoria de perturbação quasi-degenerada deve ser usado. Devemos então diagonalizar a submatriz ( 2 X 2) de toda a Hamiltoniana, e não somente de V [6]. Também não é mais possível utilizar a teoria de perturbação apenas até a primeira ordem. Para tanto, vamos utilizar uma expansão da perturbação $V=\sum_{n} V^{(n)}$ [1].

Escrevendo os novos estados misturados como:

$$
\begin{aligned}
\mid \mathbf{N}> & =\frac{1}{\sqrt{1+R^{2}}}\left(|m>-R| m^{\prime}>\right) \\
\mid \mathbf{N}^{\prime}> & =\frac{1}{\sqrt{1+R^{2}}}\left(R|m>+| m^{\prime}>\right)
\end{aligned}
$$

onde R é o parâmetro de mistura e é dado por

$$
R=\frac{E_{m}^{0}-E_{m^{\prime}}^{0}+V_{m m}-V_{m^{\prime} m^{\prime}}}{2 V_{m m^{\prime}}^{\Delta m}}+\sqrt{\left(\frac{E_{m}^{0}-E_{m^{\prime}}^{0}+V_{m m}-V_{m^{\prime} m^{\prime}}}{2 V_{m m^{\prime}}^{\Delta m}}\right)^{2}+1}
$$

Os autovalores correspondentes são :

$$
\begin{aligned}
E_{N, N^{\prime}} & =\frac{E_{m}^{0}+E_{m^{\prime}}^{0}+V_{m m}+V_{m^{\prime} m^{\prime}}}{2} \\
& \pm \frac{1}{2}\left[\left(E_{m}-E_{m^{\prime}}+V_{m m}-V_{m^{\prime} m^{\prime}}\right)^{2}+\left(2 V_{m m^{\prime}}^{\Delta m}\right)^{2}\right]^{1 / 2}
\end{aligned}
$$

Longe dos pontos de mistura os elementos de matriz da perturbação são muito pequenos comparados com a diferença de energia entre os níveis misturados e conseqüentemente temos que $|N>=| m>$ e $\left|N^{\prime}>=\right| m^{\prime}>[1]$. 


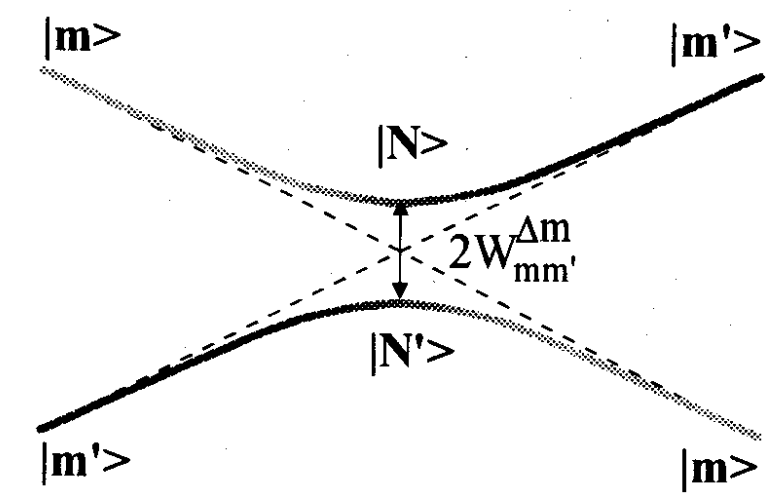

Figura 1.4: Os níveis $\mid m>$ e $\mid m^{\prime}>$ são misturados por uma quebra de simetria axial no sistema. Seguindo de um lado da região de mistura, as populações dos níveis puros ficam trocados.

Na maioria dos casos, o efeito dos elementos diagonais de $\mathrm{V}$ é de deslocar o ponto de maior aproximação entre dois níveis enquanto o efeito dos elementos não diagonais é gerar a repulsão dos níveis. O acoplamento da perturbação tem uma dependência $(\operatorname{sen} \beta)^{\Delta m}$ e consequentemente, a largura da região misturada depende fortemente do ângulo de desalinhamento $\beta$, especialmente para misturas de ordens maiores ( $\Delta m$ grande). Como o deslocamento do ponto de mistura é proporcional à $(\operatorname{sen} \beta)^{2 \Delta m}$, ele em geral é desprezível quando comparado com a largura da região de mistura.

Importante ressaltar que a técnica da ressonância de mistura de níveis é possível apenas para baixos valores de spin, já que a população de cada nível decresce com o aumento do número de níveis, e a amplitude da ressonância é proporcional à diferença de população entre níveis misturados [10]. Assim, para estados de alto spin, as amplitudes das ressonâncias se tornam demasiadamente pequenas, e já não é mais possível resolver umas das outras.

\subsection{Espectroscopia de Mistura de Níveis}

Se continuarmos a aumentar o ângulo $\beta$ entre o gradiente de campo elétrico e o campo magnético, cada vez mais níveis vão se misturar e começar a ganhar importância. O espaçamento entre os pontos de mistura fica menor, de acordo com $\frac{\omega_{B}}{\omega_{Q}} \cos \beta=3\left(m+m^{\prime}\right)$ [11] e as ressonâncias começam a se alargar [9], resultando em curvas como mostradas na Fig.1.3. Quanto maior o ângulo $\beta$, mais misturas tendem a ocorrer e conseqüentemente, mais os níveis se repelem uns dos outros. A medida da 
CAPíTUlO 1. TEORIA DE ESPECTROSCOPIA DE MISTURA DE NíVEIS (LEVEL MIXING SPECTROSCOPY - LEMS)

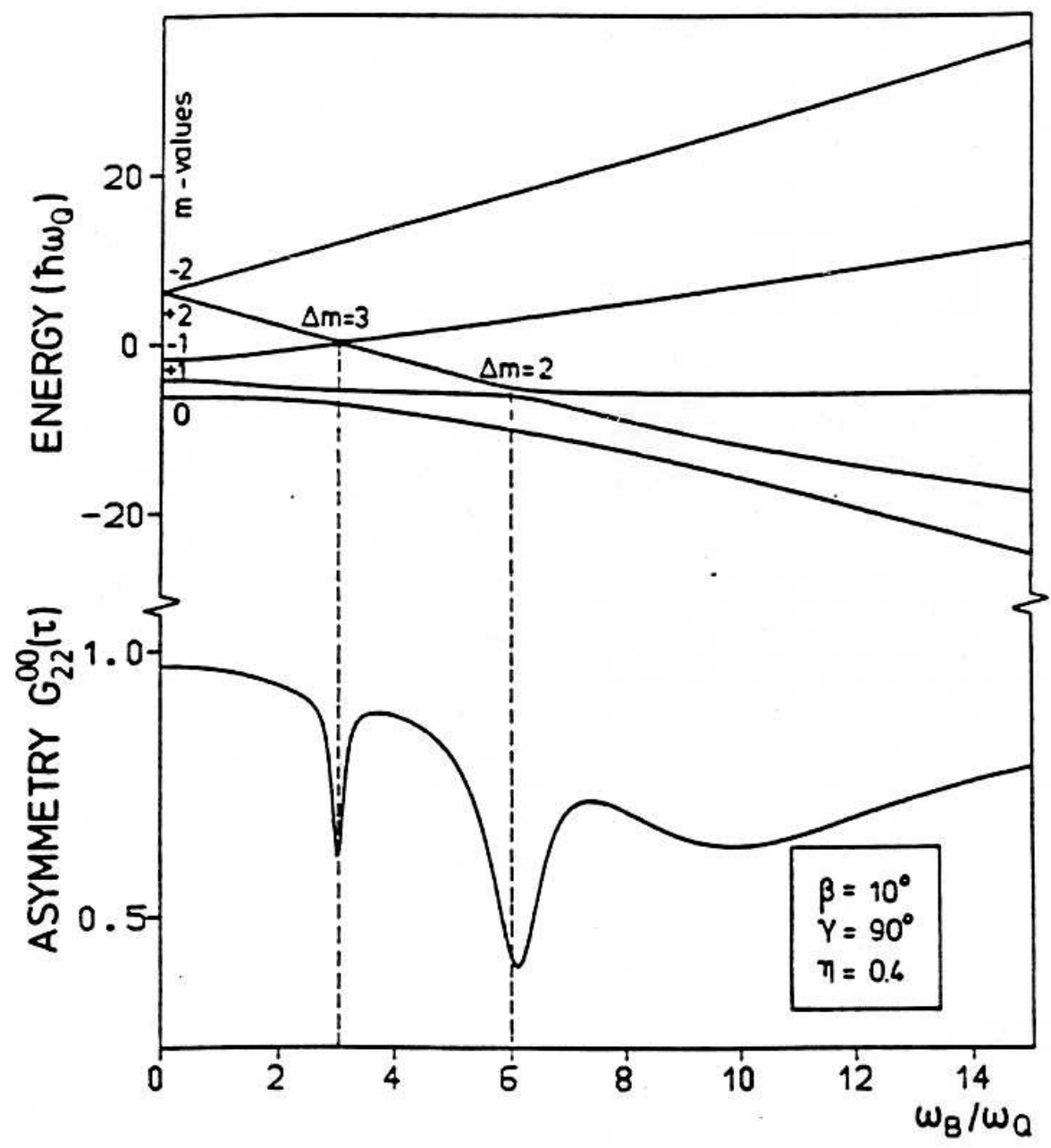

Figura 1.5: Níveis de energia hiperfinos (em cima) e o fator de perturbação integrado no tempo (em baixo) como função do campo magnético para um estado com $\mathrm{I}=2$.

anisotropia da radiação $\gamma$ emitida em função da intensidade do campo magnético aplicado é chamada curva "LEMS". Devido à combinação entre as interações magnética e elétrica, as misturas dos níveis de energia ocorrem e por isso esse método é chamado de Espectroscopia de Mistura de Níveis ou de experimento de "desacoplamento".

Lembramos que se a interação elétrica criada, por exemplo, pela assimetria na distribuição de cargas de um monocristal, no qual o núcleo implantado, temos um único valor de ângulo $\beta$. Se ao invés de monocristais usarmos policristais, devemos integrar sobre todos os possíveis ângulos entre $Z_{P A S}$ e o campo magnético. O resultado é semelhante a quando temos um caso de $\beta$ grande (Fig. 1.6). 
CAPítUlO 1. TEORIA DE ESPECTROSCOPIA DE MISTURA DE NíVEIS (LEVEL MIXING SPECTROSCOPY - LEMS)

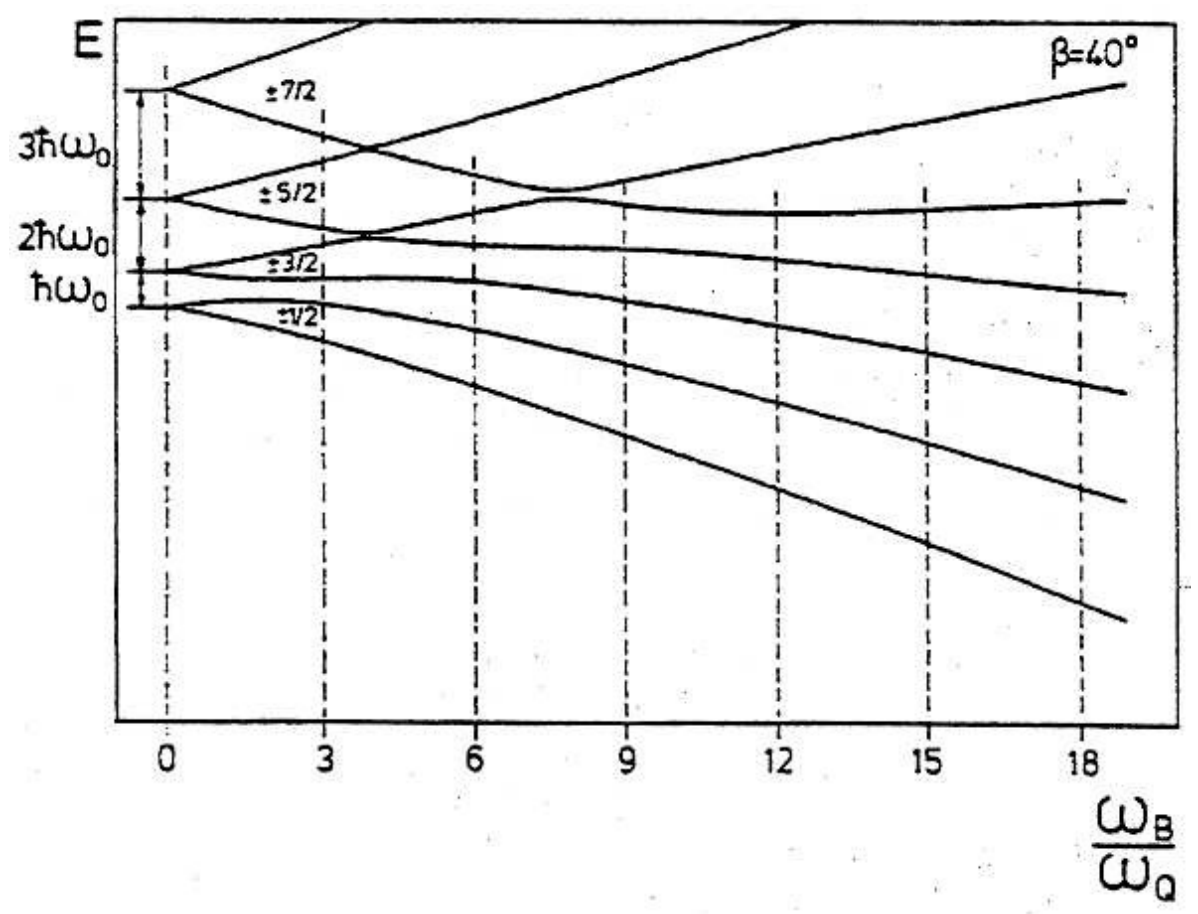

Figura 1.6: Diagrama Breit-Rabi mostrando a mistura dos níveis para $\beta$ grande.

\subsubsection{Observação da mistura de níveis}

Estados excitados formados em reações nucleares são em geral, orientados de acordo com a direção do feixe. [12]. É possível produzir e orientar um núcleo que seja de interesse, por exemplo, através de uma reação de fusão -evaporação [3]. Na fusão do projétil com o núcleo-alvo, todo momento angular é transferido do projétil para o núcleo composto. Devido a isto, o momento angular é orientado preferencialmente perpendicular ao eixo de entrada do projétil, ou seja, perpendicular à linha do feixe. O núcleo composto fica num estado altamente excitado e vai perdendo energia através da emissão de partículas como prótons, nêutrons, alfas e da emissão de raios gama.

Em geral, o momento angular $j$ de um estado tem $2 j+1$ componentes $m$ ao longo do eixo de quantização . Precisamos tratar, não de um único núcleo com uma componente definida mas, de um conjunto de núcleos que possamos descrever estatísticamente. Vamos adotar a definição de que todo o conjunto é composto de estados puros com probabilidade $P(m)$ quando projetados num eixo de quantização. No nosso caso, vamos chamar esse eixo de $Z_{O R}$, denotando o eixo de orientação (Fig. 1.1). $P(m)$ é também conhecido como 
CAPíTUlO 1. TEORIA DE ESPECTROSCOPIA DE MISTURA DE NíVEIS (LEVEL MIXING SPECTROSCOPY - LEMS)
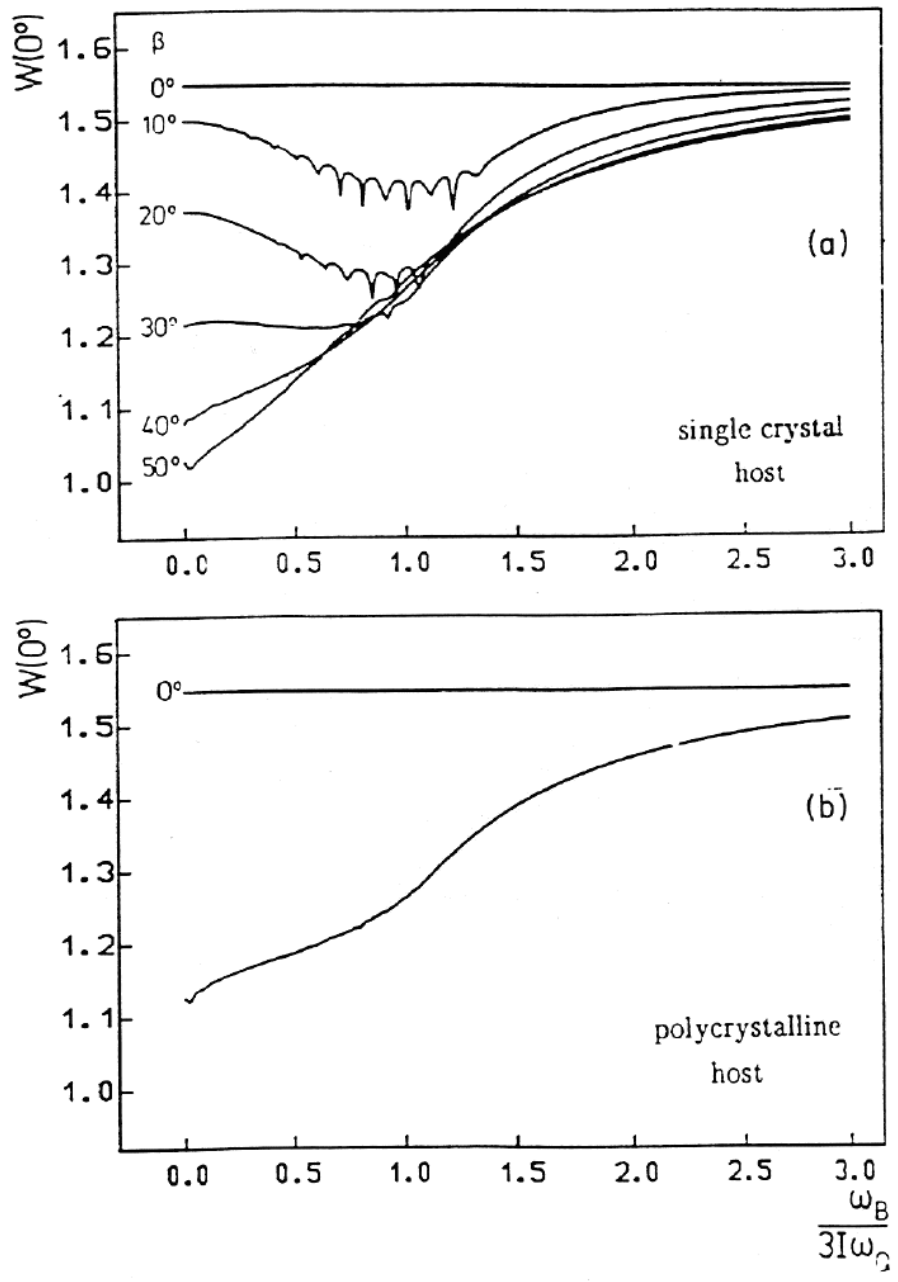

Figura 1.7: Simulação de curvas LEMS para varios angulos $\beta$ de um isômero com spin 10. $W\left(0^{\circ}\right)$ é o numero de contagens a $0^{\circ}$ graus em relação a campo magnético.

o parâmetro de população, e podemos supor uma distribuição gaussiana para os spins em torno de $m=0$ [13] de forma que

$$
P(m)=\frac{\exp \left(-m^{2} / 2 \sigma^{2}\right)}{\sum_{m^{\prime}=-j}^{j} \exp \left(-m^{\prime 2} / 2 \sigma^{2}\right)}
$$

$P(m)$ é a probabilidade de ocupação de um estado com $I_{Z}=m$ e $\sigma$ é um parâmetro que caracteriza a quantidade de orientação do sistema ou seja, a largura da Gaussiana. A razão $\sigma / I$ é experimentalmente determinada com sendo entre 0.3 e 0.4 para reações com íons pesados [12]. 
CAPíTUlO 1. TEORIA DE ESPECTROSCOPIA DE MISTURA DE NíVEIS (LEVEL MIXING SPECTROSCOPY - LEMS)

\subsubsection{Distribuição Angular de raios $\gamma$ e Perturbações Hiperfinas}

Vamos definir a matriz densidade como sendo a quantidade que especifica a população de subestados $m$, onde

$$
<m|\rho| m>=\rho_{m m}=P(m)
$$

são os elementos da matriz densidade que descrevem a ocupação dos subníveis do momento angular. Definindo as componentes esféricas de tensores como sendo as projeções da matriz densidade numa base tensorial esférica $<U_{k}^{n} \mid$, podemos simplificar a transformação entre sistemas de coordenadas, já que é simples fazer uma rotação espacial nesses tensores [3].

$$
\rho_{k}^{n}=\left\langle U_{k}^{n}\left|\rho>=\sqrt{2 k+1} \sum_{m}(-1)^{I+m}\left[\begin{array}{ccc}
I & I & k \\
-m & m^{\prime} & n
\end{array}\right]<m\right| \rho\right| m^{\prime}>
$$

Em se tratando de simetrias espaciais, podemos reduzir as componentes tensoriais mudando para um sistema de coordenadas adequado [14]. Num sistema orientado axialmente, $<m|\rho| m^{\prime}>=0$ e segue que $\rho_{k}^{n} \neq 0$ apenas se $n=0$. Como o sistema é invariante a uma rotação de $180^{\circ}$ em $X_{L A B}$ e $Y_{L A B}$, ou de uma transformação de $\mid+m>$ para $\mid-m>$, apenas componentes com $k$ par ocorrem [3]. Neste formalismo, podemos agora definir os tensores de orientação como sendo proporcionais aos tensores densidade:

$$
B_{k}^{n}=\sqrt{2 I+1} \rho_{k}^{n}
$$

No nosso caso, estamos interessados na distribuição angular de raios $\gamma$ emitidos no decaimento de um estado isomérico. A probabilidade de um desses raios $\gamma$ ser emitido numa dada direção depende da orientação do spin nuclear e é dada por [29]:

$$
W(\theta, \phi, t)=\sqrt{4 \pi} \sum_{k, n} \frac{1}{\sqrt{2 k+1}} A_{k}(\gamma) U_{k} B_{k}^{n}(I, t) Y_{k}^{n}(\theta, \phi)
$$

onde $k$ é par (no caso de deteç̧ão $\gamma$ ), $A_{k}(\gamma)$ é o parâmetro de radiação que contêm a informação acerca do tipo de transição $\gamma$, e $U_{k}$ são os coeficientes de desorientação 
que descrevem a perda de orientação da radiação não detectada, proveniente do estado isomérico de interesse. $Y_{k}^{n}(\theta, \phi)$ são os tensores esféricos harmonicos e $\theta$ e $\phi$ os ângulos de detecção, expressos no referencial LAB.

A evolução temporal do tensor de orientação $B_{k}^{n}(t)$ pode ser escrita como [15]:

$$
B_{k}^{n}(I, t)=\sum_{k^{\prime}, n^{\prime}} G_{k, k^{\prime}}^{n, n^{\prime}}(t) B_{k}^{n}(I, t=0)
$$

onde toda a informação sobre a interação hiperfina esta contida no fator de perturbação,

$$
\begin{gathered}
G_{k, k^{\prime}}^{n, n^{\prime}}(t)=\sqrt{2 k+1} \sqrt{2 k^{\prime}+1} \sum_{m, \mu, N, N^{\prime}}(-1)^{m-\mu}\left[\begin{array}{ccc}
I & I & k \\
-m & m^{\prime} & n
\end{array}\right]\left[\begin{array}{ccc}
I & I & k^{\prime} \\
-\mu & \mu^{\prime} & n^{\prime}
\end{array}\right] e^{-i \omega_{N N^{\prime}} t} \\
\times<m|N><N| \mu><m^{\prime}\left|N^{\prime}>^{*}<N^{\prime}\right| \mu^{\prime}>^{*}
\end{gathered}
$$

onde $|m>,| m^{\prime}>,|\mu>,| \mu^{\prime}>$ são, respectivamente, autovetores dos operadores de momento angular $I^{2}$ e $I_{z}$ no sistema de coordenadas PAS. $\mid N>$ e $\mid N^{\prime}>$ são autovetores da Hamiltoniana de interação hiperfina e $\omega_{N N^{\prime}}=\frac{E_{N}-E_{N^{\prime}}}{\hbar}$

Cada termo no fator de perturbação contém três importantes fatores:

- Os fatores geométricos: $\left[\begin{array}{ccc}I & I & k \\ -m & m^{\prime} & n\end{array}\right]\left[\begin{array}{ccc}I & I & k^{\prime} \\ -\mu & \mu^{\prime} & n^{\prime}\end{array}\right]$

- Os fatores de mistura: $C_{N N^{\prime}}^{m m^{\prime} \mu}=<m|N><N| \mu><m^{\prime}\left|N^{\prime}>^{*}<N^{\prime}\right| \mu^{\prime}>^{*}$

- Os fatores de energia: $e^{-i \omega_{N N^{\prime}} t}$

A perturbação que a componente transversa do campo magnético exerce nos pontos onde ocorrem as misturas, produz uma mudança na distribuição angular da radiação.

No caso de LEMS, o que se tem é uma medida da distribuição angular integrada no tempo. Como essa integração é feita num perodo infinitamente maior do que a meia vida $\tau$ do isômero, podemos reduzir os tensores perturbativos a uma média temporal [3]

$$
G_{k, k^{\prime}}^{n, n^{\prime}}(\tau, \beta)=\frac{\int_{0}^{\infty} G_{k, k^{\prime}}^{n, n^{\prime}} e^{-t / \tau} d t}{\int_{0}^{\infty} e^{-t / \tau} d t}
$$


CAPíTulo 1. TEORIA DE ESPECTROSCOPIA DE MiSTURA DE NíVEIS (LEVEL MIXING SPECTROSCOPY - LEMS)

onde a integração leva em conta a meia vida $\tau$ do isômero. Assim, a distribuição angular de um experimento LEMS com um monocristal ( $\beta$ bem definido) pode ser descrita como:

$$
W(\theta, \phi, \tau, \beta)=\sum_{(k=0,2,4 \ldots)}^{\infty} \sum_{n=-k}^{k} A_{k}(\gamma) Y_{k}^{n}(\theta, \phi) e^{i n \phi} \sum_{k^{\prime}, n^{\prime}} G_{k, k^{\prime}}^{n, n^{\prime}}(\tau, \beta) B_{k^{\prime}}^{n^{\prime}}(I, t=0)
$$

No caso de usar policristais como material hospedeiro, devemos integrar sobre todas as direções espaciais possíveis $(\alpha, \beta)$ para o gradiente de campo elétrico [10]. A dependência com $\phi$ desaparece após integrar em $\alpha$ [34] e apenas termos com $n=0$ contribuem para a distribuição angular, de maneira que

$$
G_{k, k^{\prime}}^{0, n^{\prime}}(\tau)_{P O L Y}=\frac{\sum_{\beta} \operatorname{sen} \beta G_{k, k^{\prime}}^{0, n^{\prime}}(\tau, \beta)}{\sum_{\beta} \operatorname{sen} \beta}
$$

Alguns termos interessantes da expressão (1.24) podem ser selecionados apenas adequando a geometria entre as direcões do campo, do eixo de orientação e da disposição dos detectores. Isso será discutido na próxima seção . 
CAPítUlO 1. TEORIA DE ESPECTROSCOPIA DE MISTURA DE NíVEIS (LEVEL MIXING SPECTROSCOPY - LEMS)

\subsection{A geometria para LEMS}

A expressão 1.24 é bastante genérica e pode ser reduzida se escolhermos apropriadamente os ângulos $(\theta, \phi)$ para os detectores e também a geometria dos campos. Duas geometrias envolvendo o feixe e o campo magnético são importantes. A geometria paralela que define um campo magnético paralelo ao feixe e a perpendicular onde o campo magnético é perpendicularmente orientado em relação ao feixe. Também são chamadas de geometrias longitudinal e transversal, respectivamente.

\subsubsection{Geometria paralela}

Em reações nucleares de fusão-evaporação são populados estados nucleares de alto spin e que são bastante alinhados. É conhecido que os spins desses estados estão alinhados perpendicularmente em relação ao feixe incidente. Esse é o eixo de simetria da orientação. Para reações com ons pesados, os isótopos produzidos e orientados dessa maneira podem ser implantados pelo recúo num monocristal ou num policristal. O monocristal deve estar com o eixo-c levemente desalinhado em relação ao campo magnético para se obter as condições da mistura de níveis.

Se escolhermos o eixo Z da orientação do sistema (que é a direção do campo magético) paralelo ao feixe temos que,

- $n^{\prime}=0$ pois a orientação inicial do estado isomérico produzido numa reação de fusãoevaporação é perpendicular ao eixo $Z$ (do feixe incidente). Isto reduz o tensor de orientação $B_{k^{\prime}}^{n^{\prime}}(I, t=0)$ à componente $n^{\prime}=0$.

- Como o sistema inicial é alinhado (devido à reação nuclear) apenas componentes $k^{\prime}=$ par serão diferentes de zero. Também é suficiente considerar termos até $k^{\prime} \leq 4$, já que a contribuição de ordens maiores é muito pequena. A mesma aproximação pode ser feita para $k \leq 4$, desde que $\left|A_{2}\right|>>\left|A_{4}\right|>>\ldots$

- No caso de policristais, somamos apenas termos com $n=0$ devido à integração em todas as direções $\alpha$ possíveis. Para monocristais, a soma em $n \neq 0$ não é desprezível e a distribuição angular é dependente de $\phi$. Simulações mostraram que essa dependência é especialmente importante nas áreas onde a interação quadrupolar é dominante, uma vez que ela não é axialmente simétrica [3]. 
CAPíTUlo 1. TEORIA DE ESPECTROSCOPIA DE MISTURA DE NíVEIS (LEVEL MIXING SPECTROSCOPY - LEMS)

Se usarmos uma geometria apropriada para os detectores, podemos novamente selecionar apenas alguns termos da expressão 1.24. As posições mais interessantes são com um detector apontando na direção do campo magnético $\left(\theta=0^{0}\right)$ e o outro fazendo $90^{0}$ com o campo magnético.

Esse tipo de geometria foi bastante utilizado pelo grupo do Prof. Coussement, do IKS (Instituut vor Kern- en Stralingsfysica, da Univ. Católica de Leuven/Bélgica), que possui um imã supercondutor (com duas bobinas) para produzir o campo magnético. Uma razão para usar a geometria paralela é que os fatores de perturbação produzem uma variação maior na anisotropia, comparado com outras geometrias [1]. Outra vantagem é que o feixe não é desviado de seu trajeto pelo campo magnético intenso (Força de Lorentz). Fazem parte das desvantagens o fundo muito grande, como também os raios $\mathrm{X}$ e fluxo de nêutrons, devido a um dos detectores se encontrar a $0^{\circ}$ graus ou seja, na linha do feixe.

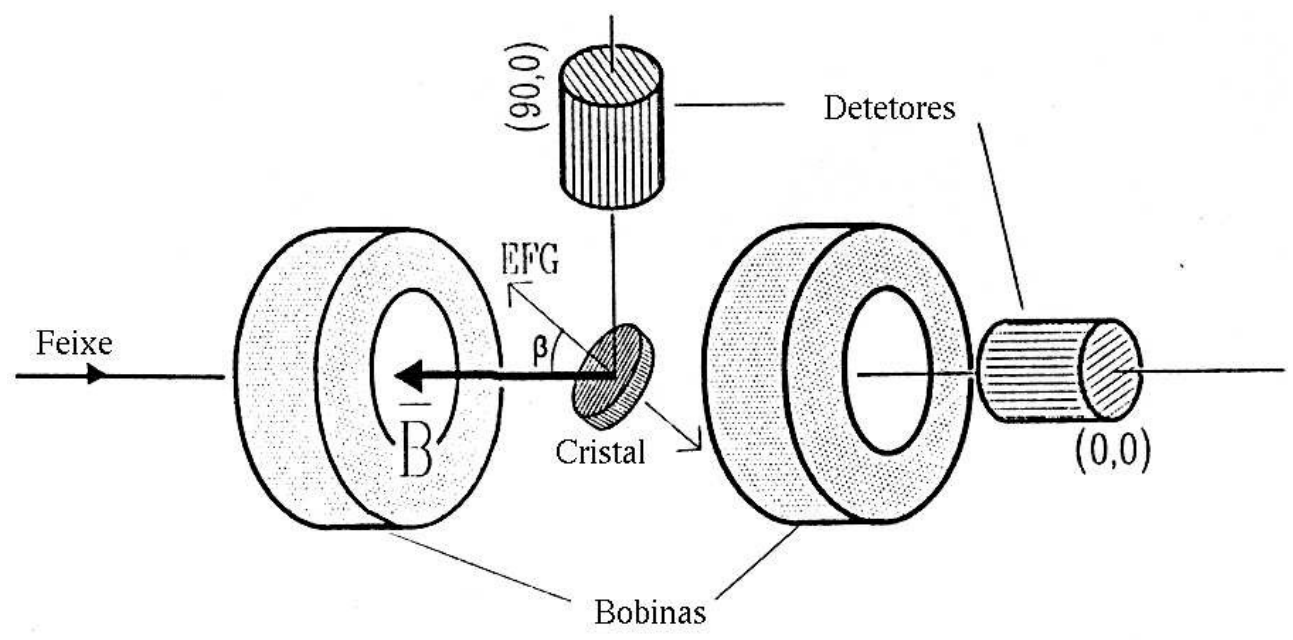

Figura 1.8: Dispositivo experimental para geometria paralela usado em Leuven,Bélgica

\subsubsection{Geometria perpendicular}

Uma outra opção é usar a geometria perpendicular. A vantagem dessa geometria é poder colocar os dois detectores fora da linha do feixe, produzindo um espectro muito mais limpo. O grupo de Leuven obtem essa geometria simplesmente rotacionando em $90^{\circ}$ graus toda base dos imãs supercondutores. Foi mostrado [10] que no caso de ímãs supercondutores o desvio causado no feixe pelo campo central é compensado pelo campo 
externo, de sinal contrário e grande alcance, sendo que no fim o feixe retorna à posição central, só com direção modificada.

No nosso caso, usamos imãs permanentes para polarizar o material ferromagnético. Para isso um campo de 0.3 Tesla é suficiente e o desvio de feixe se torna desprezível. Os detectores de Ge(HP) que usamos, estão localizados sobre uma mesa horizontal, obrigando a um deles ficar na linha do feixe. No entanto, os detectores usados não são muito sensíveis a nêutrons. A comparação de espectros de cada detector mostra que não há aumento do fundo devido a um dos detectores estar na linha do feixe.

Por causa da simetria axial da orientação inicial, podemos escolher $X_{O R}$ ao longo do campo magnético $Z_{L A B}$. O desenho esquemático pode ser visto na Figura 1.9. Temos então apenas um ângulo $\gamma(\mathrm{B})$ entre o eixo do feixe incidente e o eixo de orientação $Z_{O R}$, que mostra a dependência do campo nos tensores de orientação . De acordo com [15], $\gamma$ nunca vai ser maior que $\pm 20^{\circ}$ e simulações feitas para curvas LEMS com $\gamma=0$,mostram o mesmo resultado do que se levarmos em conta a dependência explícita do campo com $\gamma$

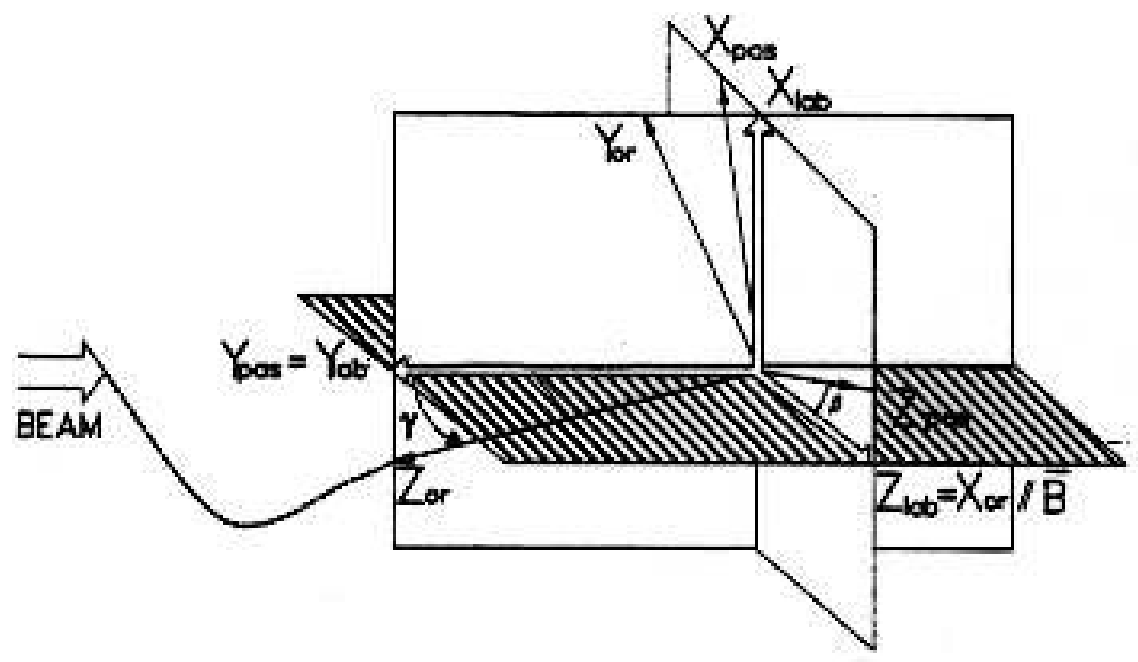

Figura 1.9: Definição dos sistemas PAS, LAB e OR para a geometria perpendicular. 
CAPítUlO 1. TEORIA DE ESPECTROSCOPIA DE MISTURA DE NíVEIS (LEVEL MIXING SPECTROSCOPY - LEMS)

\subsection{Duas Perturbações}

Se um estado inicial $I_{1}$ está orientado, então o estado $I_{2}$ populado depois da emissão de um raio- $\gamma$ por $I_{1}$, também estará orientado, mesmo que o raio- $\gamma$ não tenha sido observado. Em uma reação de fusão-evaporação é possível popular estados isoméricos com altos spins. Eles podem decair para o estado fundamental, passando por outros estados isoméricos abaixo dele. Para estudar esses estados mais baixos, é necessário levar em conta a perturbação gerada no estado isomérico superior.

Mas não apenas as energias mais altas são populadas na reação nuclear. Também energias baixas podem ser populadas continuamente. Isto quer dizer que nem todos os isômeros $I_{2}$ são populados por $I_{1}$. Existe uma fração do total que vem sendo populada diretamente da reação nuclear e outra através de $I_{1}$. Isto torna necessário levar em conta duas classes de isômeros $I_{2}$ : As que foram perturbadas uma vez e as que foram perturbadas duplamente. Um tratamento mais completo pode ser encontrado em [3]. 


\section{Capítulo 2}

\section{Materiais Ferromagnéticos}

Pela necessidade de haver uma interação quadrupolar elétrica, além da interação magnética, para realizar medidas LEMS, os núcleos de interesse devem ser implantados em materiais cuja estrutura cristalina ofereça um gradiente de campo elétrico. De acordo com a estrutura do material hospedeiro e do núcleo a ser implantado, existem dois processos pelos quais a interação elétrica é obtida.

Num experimento LEMS, o núcleo de interesse é produzido e orientado pela reação nuclear num dado material que chamamos de alvo. O núcleo de interesse que sai dessa reação, recua com uma energia da ordem de MeV's, e pode ser freado e implantado de duas maneiras: Ou no próprio alvo ou num segundo material posto atrás do alvo.

A vantagem de colocar um outro material para servir como hospedeiro, é que inúmeros alvos de produção podem ser usados e, a princípio, qualquer núcleo pode ser produzido. Cuidado especial deve se ter para escolher a espessura das folhas a serem usadas, tanto para o alvo de produção como para o hospedeiro.

O alvo de produção deve ser fino o suficiente para que o núcleo composto produzido possa sair e ser implantado no outro material. Mas, por outro lado, para alvos de produção finos o número de reações ocorridas também vão diminuir proporcionalmente. Um aspecto importante, é o fato de ser preferível que esse alvo tenha baixo Z. Quanto maior o Z do material, maior é o poder de freamento [16].

Outro ponto importante no método de implantação pelo recuo, é garantir que quando o feixe passa pelo material hospedeiro, ele não tenha energia suficiente para ali induzir reações nucleares, pois isto poderia contaminar o escpectro $\gamma$. Para reduzir essa contaminação, é preferível usar materiais hospedeiros com Z grande, aumentando a barreira 
coulombiana entre os núcleos do feixe e do material hospedeiro. Mesmo assim, o espectro ainda pode ser contaminado pela exitação Coulombiana dos núcleos do feixe e introduzir um fundo grande no espectro [3]. Esses problemas não ocorrem quando o alvo de produção também é o próprio material hospedeiro.

A localização do íon implantado também é um ponto importante. Ele pode ocupar uma posição substitucional ou intersticial. A posição substitucional é quando o íon incidente colide com um átomo do material hospedeiro, e não tem energia suficiente para deixar a vacância produzida, e então, fica nessa posição substitucional. Outra posição que ele pode assumir é a intersticial. Isso geralmente ocorre quando o material hospedeiro tem um $\mathrm{Z}$ muito maior do que o núcleo em recuo. $\mathrm{O}$ atomo fica aprisionado em meio a alguns íons da rede cristalina. Esse assunto será melhor discutido mais adiante.

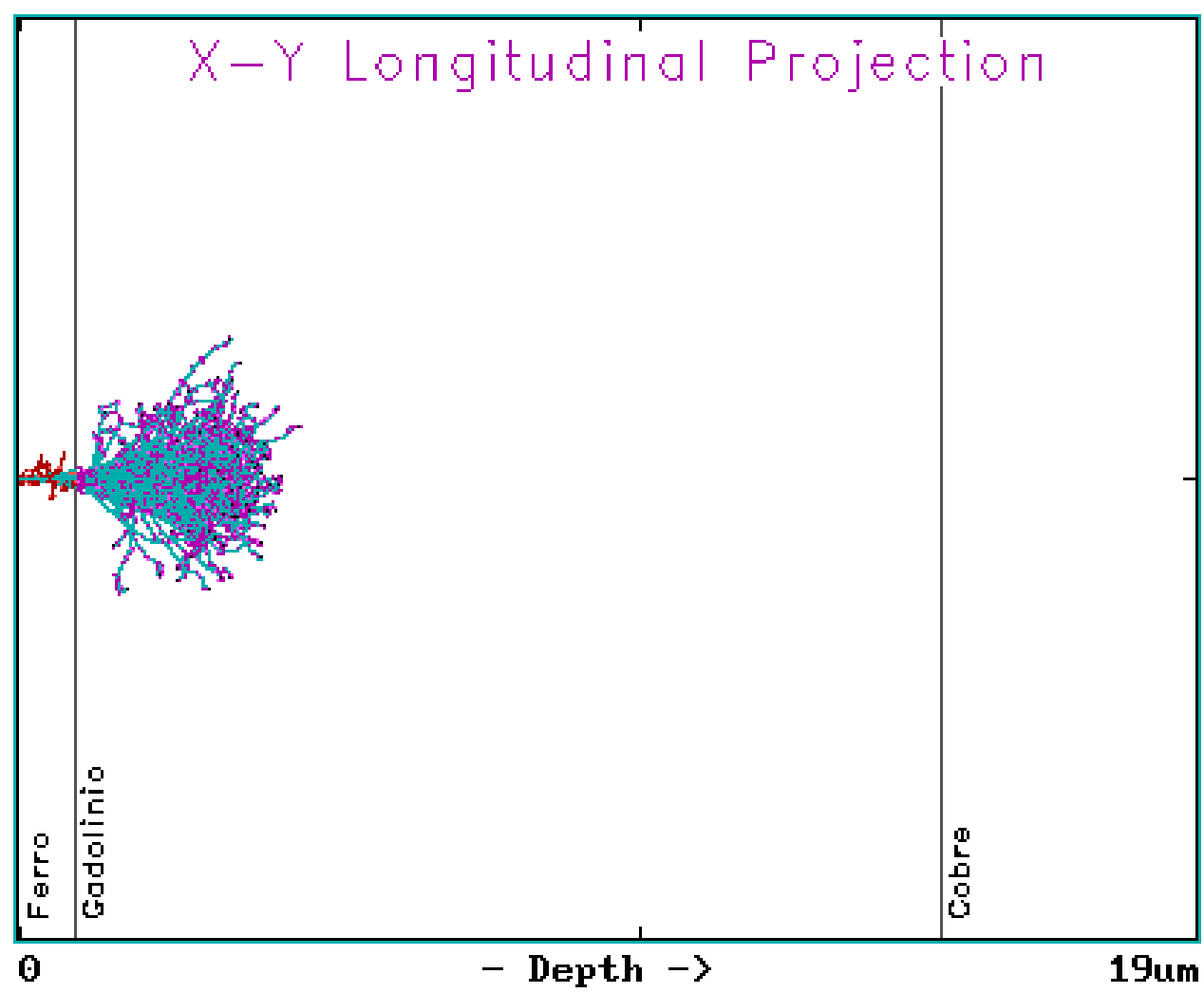

Figura 2.1: Simulação da implantação de ${ }^{69} \mathrm{Ge}$ a $13 \mathrm{MeV}$ em Gd. Cálculos feitos com o programa TRIM. 


\subsection{Implantação em materiais hospedeiros}

A maior restrição ao uso de materias como hospedeiros, é a necessidade de haver um gradiente de campo elétrico. Esse gradiente precisa ser definido por um eixo que geralmente é dado por uma simetria da estrutura cristalina do material, ou melhor, pela assimetria da distribuição de cargas em torno do núcleo implantado para o caso de implantações substitucionais. Esse tipo de assimetria se consegue em estruturas não cúbicas. Em particular, no caso de estruturas do tipo hcp (close-packed-hexagonal) a presença dos núcleos vizinhos define um eixo com um gradiente de campo elétrico. No caso do Gd, esse eixo aponta na direção do eixo $c$ do cristal (Figura 2.2).

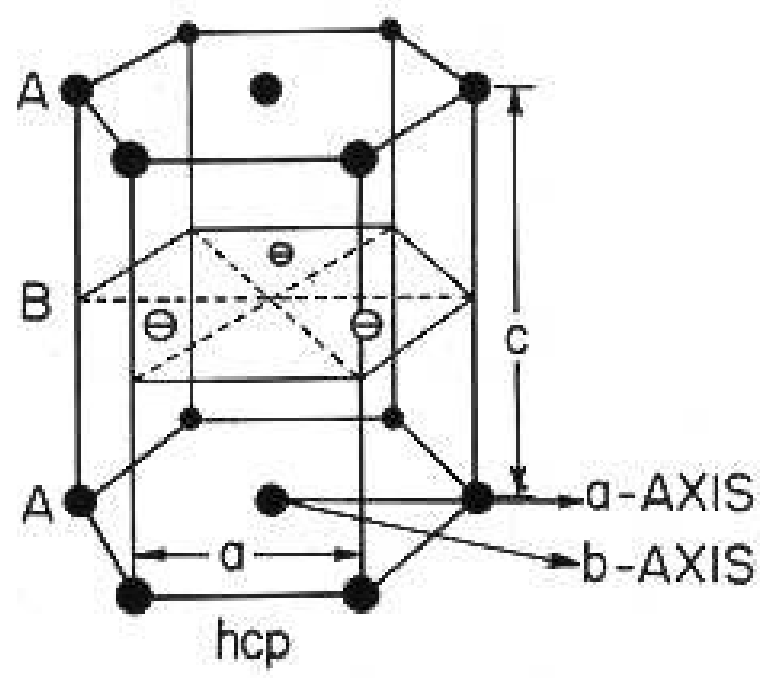

Figura 2.2: Estrutura cristalina do Gd.

Os materiais com estrutura cúbica não têm essa assimetria. Se um núcleo é implantado numa posição substitucional de um cristal cúbico, todas as direções oferecem o mesmo gradiente de campo elétrico dado pelos íons vizinhos. Na há uma direção preferencial e portanto, não é possível se definir um eixo de simetria (vide Figura 2.3).

No entanto, é possível se criar um gradiente de campo elétrico devido a defeitos no cristal. O núcleo implantado pode atrair algumas vacâncias produzidas durante a implantação e a simetria de cargas é quebrada. Os defeitos que vão induzir o gradiente de campo elétrico necessário são criados apenas em colisões do núcleo em recuo com os átomos do material hospedeiro [17]. 
Em implantações a baixas energias, o dano causado na vizinhança do núcleo implantado depende do tipo de feixe inicial e da energia. No entanto, para nossa faixa de energia, as colisões elásticas se tornam importantes apenas depois do processo de freamento do núcleo em recuo. Consequentemente, o dano criado não é tão dependente da energia do feixe inicial para a região de energia usada. Para doses baixas de implantação como as nossas, a chance de um núcleo parar numa vizinhança danificada por outro núcleo é desprezível. Pode-se concluir que os danos nos arredores desse núcleo são induzidos apenas por ele mesmo e não dependem do tipo de feixe inicial, da energia desse feixe nem da intensidade [3].

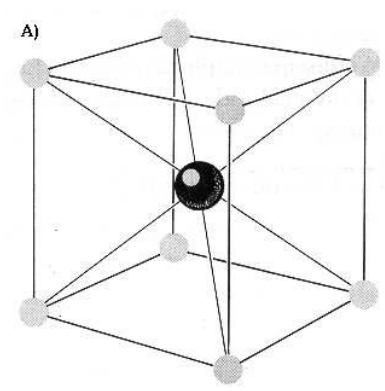

B)

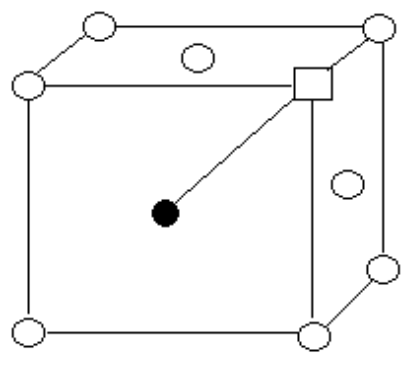

C)

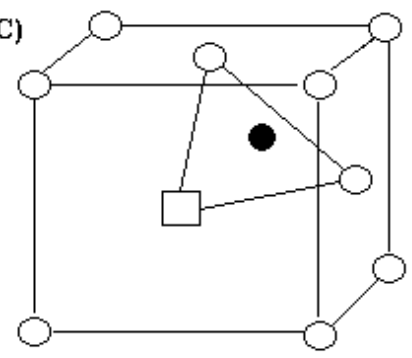

Figura 2.3: A) Estrutura interna de um cristal cúbico, onde não existe uma direção preferencial de EFG. B)Posição das vacâncias num cristal cúbico para os caso de implantação substitucional. C)Implantação intersticial.

Quando um núcleo do material hospedeiro é atingido e tirado de sua posição de equilibrio, ele pode deslocar outros átomos da rede cristalina, originando uma cascata de deslocamentos [18]. A posição final desse núcleo, que pode conter vacâncias, fica rodeado à distância por uma área cheia de átomos em posições intersticiais [17, 19, 20]. A grande distância relativa entre esses átomos e o núcleo implantado garante que não haverá nenhum efeito induzido.

Ainda devido à colisão, pode haver um aquecimento local da rede cristalina que tenha um $\mathrm{Z}$ alto, que é conhecido como faísca térmica. Após alguns nanosegundos (tempo de vida da faísca), a estrutura ao redor do núcleo implantado se rearranja e algumas vacâncias podem se deslocar para bem próximo [17, 20, 21]. Isto cria a assimetria na distribuição de cargas e consequentemente, um gradiente de campo elétrico.

Também a densidade do material hospedeiro é importante. Para metais mais leves (Z baixo), uma maior concentração de implantações substitucionais pode ser observada 
[20]. Medidas feitas com monocristais, comprovaram que os defeitos criam gradientes de campo elétrico similares àqueles dados pela assimetria do cristal [22, 23].

\subsection{Materiais Ferromagnéticos}

Outra limitação imposta no uso de materiais hospedeiros, é a necessidade de usar campos magnéticos altos. O grupo de Leuven faz medidas usando ímãs supercondutores. Esses imãs, além de serem equipamentos caros e pesados, de mobilidade reduzida, apresentam uma limitação no valor máximo de campos magnéticos (máximo 4.4 Tesla). Outros imãs supercondutores chegam até 10 Tesla. Em vista disso, apresentou-se a idéia de usar os campos hiperfinos de materiais ferromagnéticos. Esses campos chegam a intensidade da ordem de dezenas de Tesla.

A variação do campo hiperfino, condição necessária para a realização de medidas LEMS, seria realizada neste caso através da variação da temperatura do material ferromagnético.

O magnetismo decorre de pequenas correntes circulatórias causadas pelo movimento dos elétrons em pequenas órbitas ao redor do núcleo. Podemos caracterizar o ferromagnetismo como sendo a existência de uma magnetização espontânea em pequenas regiões de um material, magnetização essa que persiste mesmo na ausência de um campo de indução externo [24]. Esses materiais apresentam momentos magnéticos espontâneos o que sugere que os spins dos elétrons e os momentos magnéticos dos átomos são dispostos de uma maneira regular. Mas esse ordenamento pode ser destruido pela agitação térmica a elevadas temperaturas [25]. A magnetização induzida por um campo externo num material ferromagnético como Ni, Fe, Co e Gd entre outros, está relacionada de uma maneira complexa à forma, à histereze e ao campo aplicado [26].

A magnetização de um material ferromagnético só é observada se for aplicado previamente um campo magnético externo. Embora exista a magnetização espontântea, a magnetização de uma pequena região ou domínio de um material ferromagnético pode estar orientada em uma direção diferente da de outro domínio, de modo que a magnetização macroscópica resultante será zero. Os domínios aparecem porque a energia de um cristal grande não é mínima quando ele está magnetizado uniformemente [24]. O tamanho específico e a forma de um domínio são determinados por um processo que minimiza a 


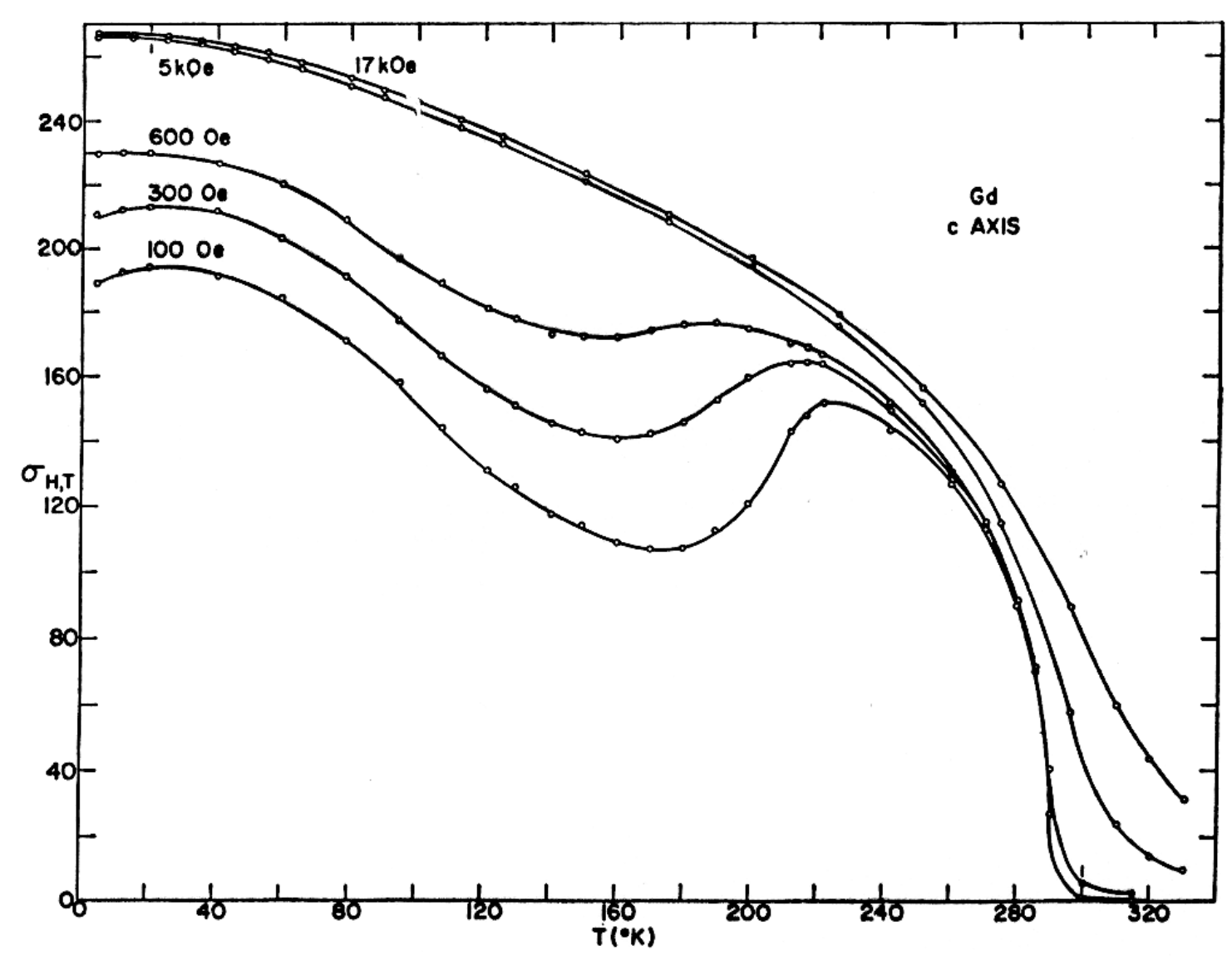

Figura 2.4: Manetização para o $\mathrm{Gd}$ momcristal na direção do eixo $c$ para vários valores de campo externo [32].

energia.

Os domínios individuais, dentro dos quais os momentos de dipolo magnético estão alinhados, se encontram orientados ao acaso. Quando o material é magnetizado pela aplicação de um campo magnético externo, ocorrem dois efeitos. O primeiro deles é o crescimento do tamanho dos domínios que se encontram orientados favoravelmente ao campo aplicado. O outro é uma rotação da direção de magnetização dentro de um domínio, no sentido da direção do campo externo. A energia que direciona a magnetização ao longo de um certo eixo cristalográfico é chamada de energia de anisotropia magnetocristalina $[25,27]$. 


\subsubsection{Ferromagnetismo em Gd}

O elemento Gadolínio pertence, assim como outros elementos de terras raras ou lantanídeos, aos chamados metais de transição da camada $4 f$. As suas propriedades magnéticas se originam de elétrons desemparelhados na camada $4 f$. O Gd, de número atômico 64, tem sete elétrons completando a metade da camada $4 f$. Ele é o único elemento de terra rara que é um ferromagnético simples.

A temperatura de Curie $T_{C}$ (que é a temperatura abaixo da qual, o material se torna ferromagnético) para o $\mathrm{Gd}$ é a $289 \mathrm{~K}$ e a direção de fácil magnetização abaixo de $T_{C}$, em se tratando de um monocristal, é ao longo do eixo $c$ do cristal. A dependência do momento magnético em função da temperatura num monocristal pode ser vista na figura 2.5. Com um campo aplicado de 100 Oe, o momento magnético observado cresce rapidamente quando a temperatura decresce abaixo de $T_{C}$. Abaixo de $240 \mathrm{~K}$ a direção de fácil magnetização deixa de ser o eixo $\underline{c}$ e o momento cai para um valor mínimo em $170 \mathrm{~K}$ e depois novamente cresce. Esses resultados estão de acordo com observações feitas com difração de nêutrons por Will et al. (1964) e por Cable e Wollan (1968) que também descobriram que o ângulo $\theta_{c}$ entre o eixo $\underline{c}$ e o eixo de fácil magnetização muda com a temperatura [31]. A magnetização segue a lei de Bloch

$$
M_{S}=M_{o}\left(1-a T^{3 / 2}\right)
$$

desde $50 K$ até $200 K[32]$.

Para orientar os campos hiperfinos internos, é necessário aplicar um campo magnético externo. No caso do Gd, o tratamento feito (laminação, recozimento) pode ser um fator importante para obter uma boa magnetização que possa ser orientada numa única direção (ver seção 4.4). Um campo de $0.27 T$ é suficiente para orientar completamente os domínios magnéticos ao longo da direção de fácil magnetização no caso de um monocristal [32, 33].

Para um policristal de Gd, a aplicação de cerca de 300 Gauss são suficientes para polarizar os domínios magnéticos. Na ausência de um ímã supercondutor, usamos ímãs permanentes de SmCo, que separados por uma distância de $8 \mathrm{~mm}$, produzem um campo magnético da ordem de 3200 Gauss (0.32 Tesla), o que é mais do que suficiente para polarizar o $\mathrm{Gd}$. 


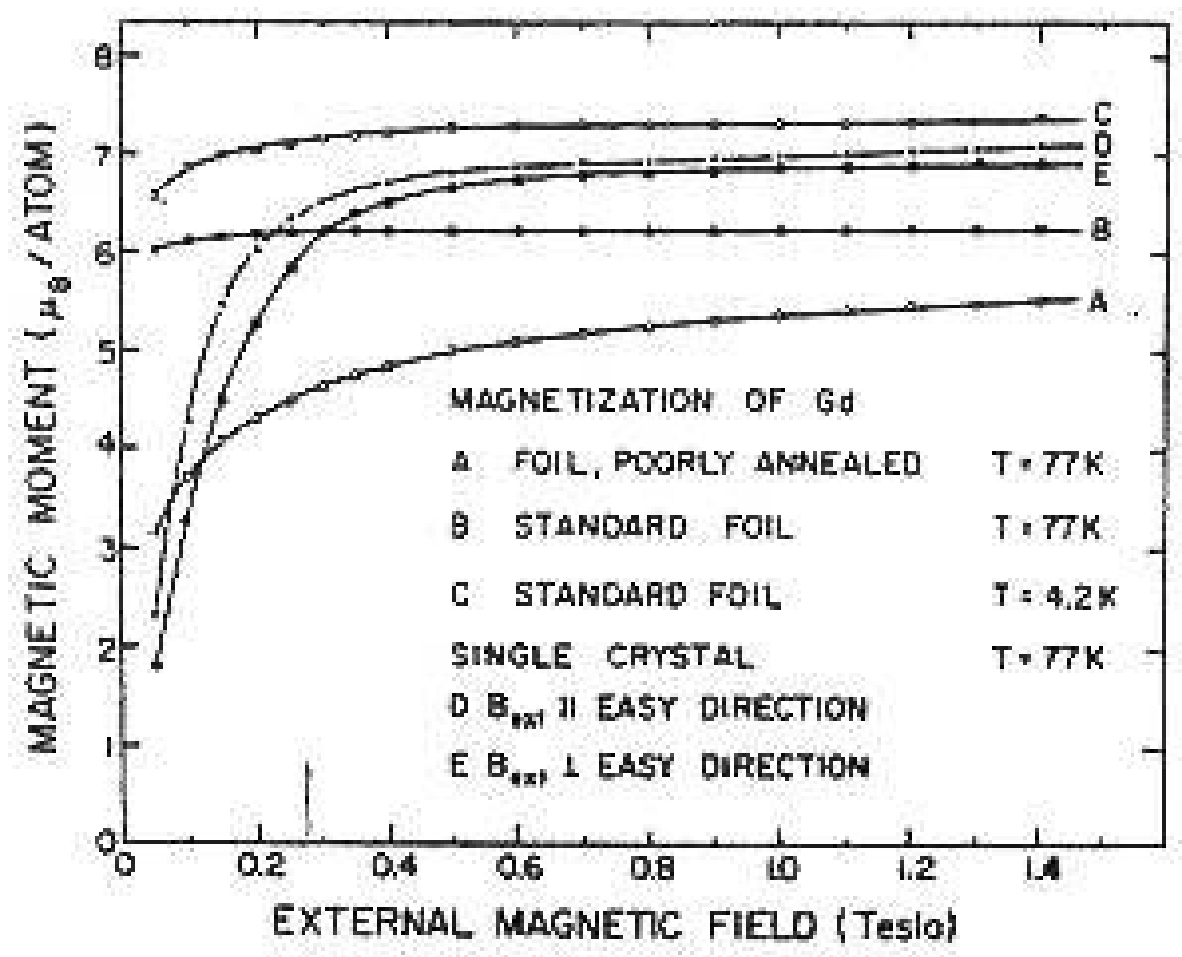

Figura 2.5: Magnetização por átomo versus campo aplicado em Gd. A magnetização satura somente a 0.27 Tesla para monocristais [33] Este valor é mais baixo para folhas policristalinas. 


\section{Capítulo 3}

\section{Interações hiperfinas}

Como a proposta deste trabalho é realizar medidas LEMS como função de campos hiperfinos para medir momentos de quadrupolo elétricos nucleares, é importante conhecer as propriedades desses campos e principalmente sua dependência com a temperatura.

\subsection{Interação magnética hiperfina no Gd}

As contribuições para as interações hiperfinas de núcleos implantados em terras raras como o Gd, são produzidas em geral, pelo "ambiente" dos íons dessas terras taras. Tem-se uma interação elétrica produzida pelo distribuição de cargas e uma interação magnética.

Em particular para as interações magnéticas, se o material hospedeiro for ferromagnético e estiver com seus domínios magnéticos orientados (magnetizado), a polarização do spin dos elétrons de condução e o caroço de elétrons induzem um campo chamado de campo magnético hiperfino.

O sinal e a magnitude desses campos magnéticos hiperfinos no sítio em um material ferromagnético onde está localizada uma "impureza " (núcleo implantado), são determinados por um combinação de três possíveis efeitos [42]:

- a polarização do spin dos elétrons de condução do material hospedeiro.

- a polarização do caroço de elétrons da "impureza " por um momento magnético localizado.

- e a polarização superposta, que é importante nos caso quando a impureza tem um raio atômico muito maior do que o hospedeiro. 
Cada uma delas contribui mais ou menos dependendo de do par impureza-hospedeiro.

\subsubsection{Dependência do campo hiperfino com a magnetização}

Cada núcleo atômico em um sólido contendo íons ou elétrons com momentos magnéticos desbalanceados, está sujeito a um campo magnético. Medidas desses campos geralmente representam médias temporais dos valores de campo. Portanto, campos hiperfinos não nulos podem ser encontrados em materiais ordenados magneticamente e indicam a média temporal do grau de polarização magnética dos elétrons que estão perto do núcleo em questão [26].

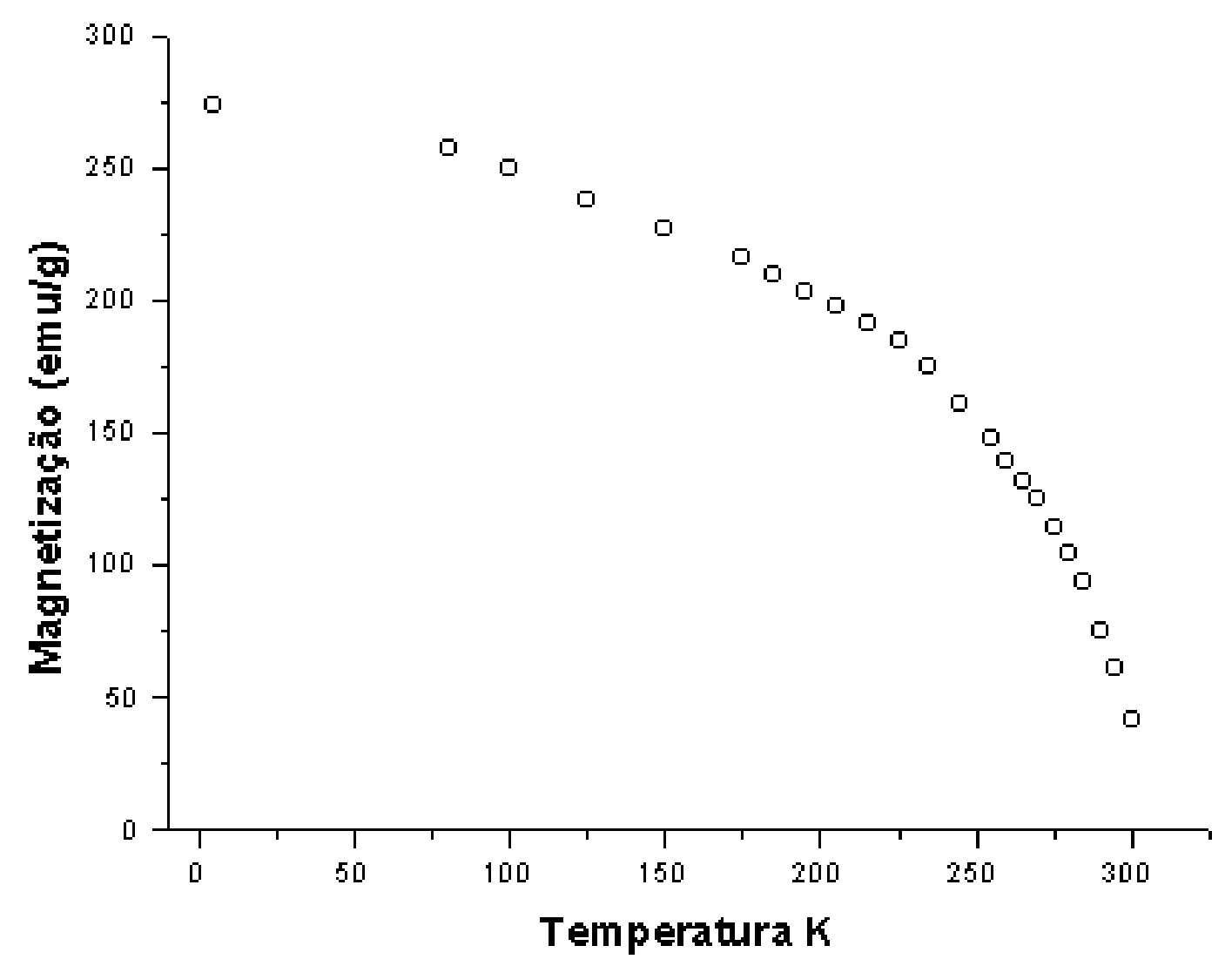

Figura 3.1: Variação da magnetização numa amostra de nossas folhas de Gd recozidas, sob um campo de 3000 Gauss. 
Como nós queremos fazer medidas LEMS usando o campo hiperfino do Gadolínio, é necessário conhecer a dependência desse campo com a temperatura. No entanto sabemos que o campo magnético hiperfino é proporcional à magnetização. A dependência dos campos hiperfinos com a temperatura é usualmente expressa em termos da magnetização $\mathrm{M}(\mathrm{T})$ do material ferromagnético, pois essas curvas variam de forma análoga [25, 26, 28].

$$
\frac{B_{\text {hiper. }}(T)}{B_{\text {hiper. }}(0)}=A_{T} \frac{M(T)}{M(0)}
$$

onde $A_{T}$ é chamada de constante de acoplamento hiperfino. Em geral essa constante é em torno de $A_{T} \sim 1$ para temperaturas que vão até $T_{C} / 2$ [30].

A magnetização em geral obedece à equação:

$$
M_{s}=M_{o}\left(1-a T^{3 / 2}\right)
$$

onde $M_{o}$ é a magnetização à $0 \mathrm{~K}$ e $a$ é uma constante [26]. Foi experimentalmente determinado que essa equação descreve bem a magnetização em até $86 \%$ de $T_{c}$, onde $T_{c}$ é a temperatura de Curie e é determinada como sendo $289 \mathrm{~K}$ para o Gadolínio.

Em um campo magnético estático $B_{z}$, o núcleo com momento magnético $\mu$ vai interagir com $B_{z}$, dando início a uma precessão com uma velocidade angular dada pela equação :

$$
\omega_{B}=\frac{-g \mu_{N} B_{Z}}{\hbar}
$$

A frequência $\omega_{B}$ é a chamada frequência de Larmor.

Observando a figura 3.1, vemos que cerca de $75 \%$ dos domínios magnéticos se alinham na região de temperatura entre 200 e $300 \mathrm{~K}$. Como a variação do campo hiperfino é supostamente linear com a magnetização, podemos esperar que a sua variação máxima também

seja nessa região de temperaturas. É claro que o valor absoluto do campo hiperfino precisa ser determinado para cada impureza e hospedeiro separadamente.

\subsection{Interações quadrupolares estáticas}

Perturbações quadrupolares estáticas são causadas pela interação do momento de quadrupolo elétrico nuclear $Q$ do estado intermediário $I$ com um gradiente de campo ele- 
trostático que pode ser escrito como:

$$
V_{z z}=-\frac{\partial E_{z}}{\partial z}=\frac{\partial^{2} V}{\partial z^{2}}
$$

onde $V$ é o potencial eletrostático.

Ainda não é possível criar artificialmente gradientes eletrostáticos suficientemente intensos para perturbar a distribuição angular (como consequencia da interaçãop elétrica). No entanto, os gradientes de distribuições de cargas em estruturas que não sejam cúbicas podem ser usados na interação quadrupolar [43].

Muitos mecanismos contribuem, em geral, para o gradiente eletrostático. Além dos íons em um cristal não cúbico, as camadas eletrônicas dos átomos, que também estão acoplados aos campos elétricos do cristral, contribuem para os gradientes eletrostáticos. Para o caso particular de metais, a contribuição dos elétrons de condução num cristal não cúbico também devem ser levados em conta [43].

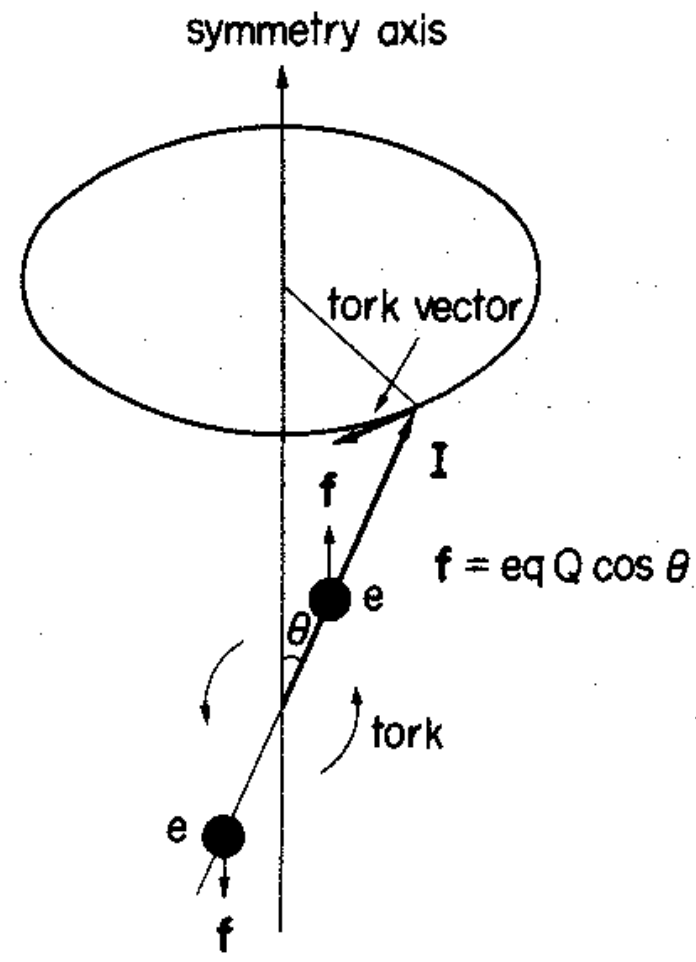

Figura 3.2: Esquema ilustrativo mostrando a interação quadrupolar estática. 
Os gradientes eletrostáticos que são originados em cristais não cúbicos podem frequentemente, como uma boa aproximação, serem descritos classicamente. Podemos pensar que, na presença de um gradiente de campo elétrico $V_{z z}$ ao longo de um eixo (por simplicidade suposto simétrico), um núcleo com momento de quadrupolo $Q$ esta sujeito a um torque, dando início a uma precessão do spin $I$ em torno do eixo de simetria (veja figura 3.2). Em contraste com a interação magnética, a frequência de precessão não é única, mas depende da direção de $I$ [12]. A interação quadrupolar leva a um desdobramento dos subníveis de energias e a precessão em $I$ tem várias frequências. A frequência básica é

$$
\omega_{Q}=\left\{\begin{array}{l}
-\frac{3}{4 I(2 I-1)} \cdot \frac{e Q V_{z z}}{\hbar} \quad \text { se } I \text { é inteiro, } \\
-\frac{3}{2 I(2 I-1)} \cdot \frac{e Q V_{z z}}{\hbar} \quad \text { se } I \text { é meio inteiro. }
\end{array}\right.
$$

O sinal de $\omega_{Q}$ refere-se à direção de $I$. A distribuição angular dos raios $\gamma$ emitidos no decaimento dos estado isomérico com spin I é então sujeita a uma mudança periódica de frequência $\omega_{Q}$.

O efeito de um gradiente de campo elétrico orientado aleatoriamente (esse é o caso do Gd policristalino), é representado pelos fatores de atenuação $G_{k}(t)$ na expressão 1.24, que são funções que variam periodicamente no tempo com frequência $\omega_{Q}$, e dependem do spin nuclear $I$. Na realidade, não existe um eixo de simetria bem definido, e o gradiente de campo elétrico se mostra assimétrico e também distribuído (muitas frequencias quadrupolares próximas) [12]. 


\section{Capítulo 4}

\section{Dispositivo Experimental}

O estado excitado de $398 \mathrm{keV}$ de energia do núcleo ${ }^{69} G e$ é populado através da reação de fusão-evaporação ${ }^{56} \mathrm{Fe}\left({ }^{16} \mathrm{O}, 2 p n\right){ }^{69} \mathrm{Ge}$. O feixe de ${ }^{16} \mathrm{O}$ atinge o alvo, onde a primeira camada é de ferro natural $\left(\approx 1 \mathrm{mg} / \mathrm{cm}^{2}\right)$ e pode ocorrer a reação. O núcleo de ${ }^{69} \mathrm{Ge}$ excitado, produzido na reação, recua até uma camada de Gd natural $\left(\approx 11 \mathrm{mg} / \mathrm{cm}^{2}\right)$, onde é totalmente freado.

O ${ }^{69} \mathrm{Ge}$ pára numa posição substitucional dentro do cristal de Gd, onde interage com o gradiente de campo elétrico. Por ser ferromagnético, o Gd cria campos magnéticos internos muito intensos (campos hiperfinos) quando diminuimos sua temperatura abaixo da temperatura de Curie $\left(T_{C}\right)$. Variando a temperatura, variamos o campo magnético interno e consequentemente a distribuição angular do raio $\gamma$ de $398 \mathrm{keV}$.

\subsection{Montagem experimental}

Todas as experiências feitas para este trabalho foram realizadas no Laboratório Pelletron, do Instituto de Física da Universidade de São Paulo - IFUSP. As experiências foram realizadas na canalização à $30^{\circ}$ da sala experimental $\mathbf{A}$ que é usualmente utilizada pelo Grupo $\gamma$ do laboratório, e já se encontram instaladas mesas de apoio próprias para os detectores de Ge(HP).

Para realizar a experiência, utilizamos o acelerador tipo Tandem do Laboratório Pelletron. O feixe de ${ }^{16} O$ foi acelerado através do terminal usando uma tensão de $6.61 \mathrm{MV}$. $\mathrm{O}$ estado de carga selecionado foi o $7^{+}$, e a energia obtida foi de $53 \mathrm{MeV}$.

Reduzimos bastante a intensidade do feixe usando as fendas e os parâmetros de foca- 
lização. Por fim, com o feixe alinhado, tínhamos cerca de 6 nA de corrente medidos num copo de Faraday localizado na canalização, a cerca de 3 metros do alvo.

\subsection{A câmara}

Desenvolvemos uma câmara de aço-inox em forma de " $\mathrm{T}^{*}$ (Figura 4.1), a qual acoplamos à canalização, o criostato de fluxo contínuo (ver seção 4.3) juntamente com o alvo. A câmara consiste de um tubo de 2 polegadas de diâmetro que é perpendicular a um tubo menor de 5/8 de polegadas por onde passa o feixe. Neste último estão instalados dois colimadores de tântalo separados por uma distância de 18 centímetros, o primeiro com um orifício de 9 milímetros de diâmetro e o segundo com 3 milímetros. Isto garante que o feixe não venha a bater nas paredes internas do tubo antes de chegar ao alvo. O segundo colimador fica à $1 \mathrm{~cm}$ do alvo, o que mantém a precisão na hora de incidir o feixe no alvo.

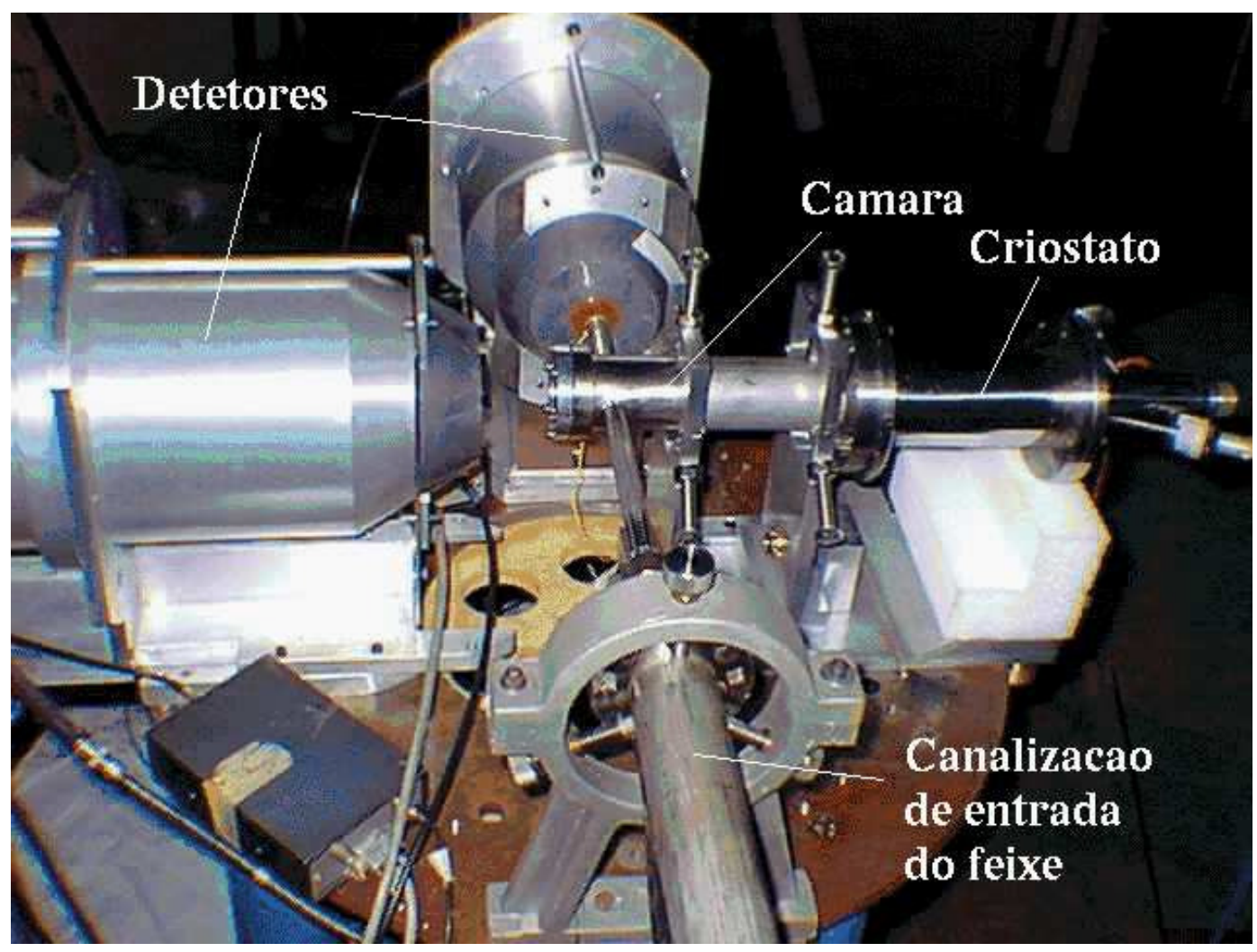

Figura 4.1: Fotografias do posicionamento dos detetores (com anti-Compton), do criostato e da câmara na canalização $30 \mathrm{~A}$.

Após atravessar o alvo e o material hospedeiro, o feixe de ${ }^{16} O$ é parado num copo 


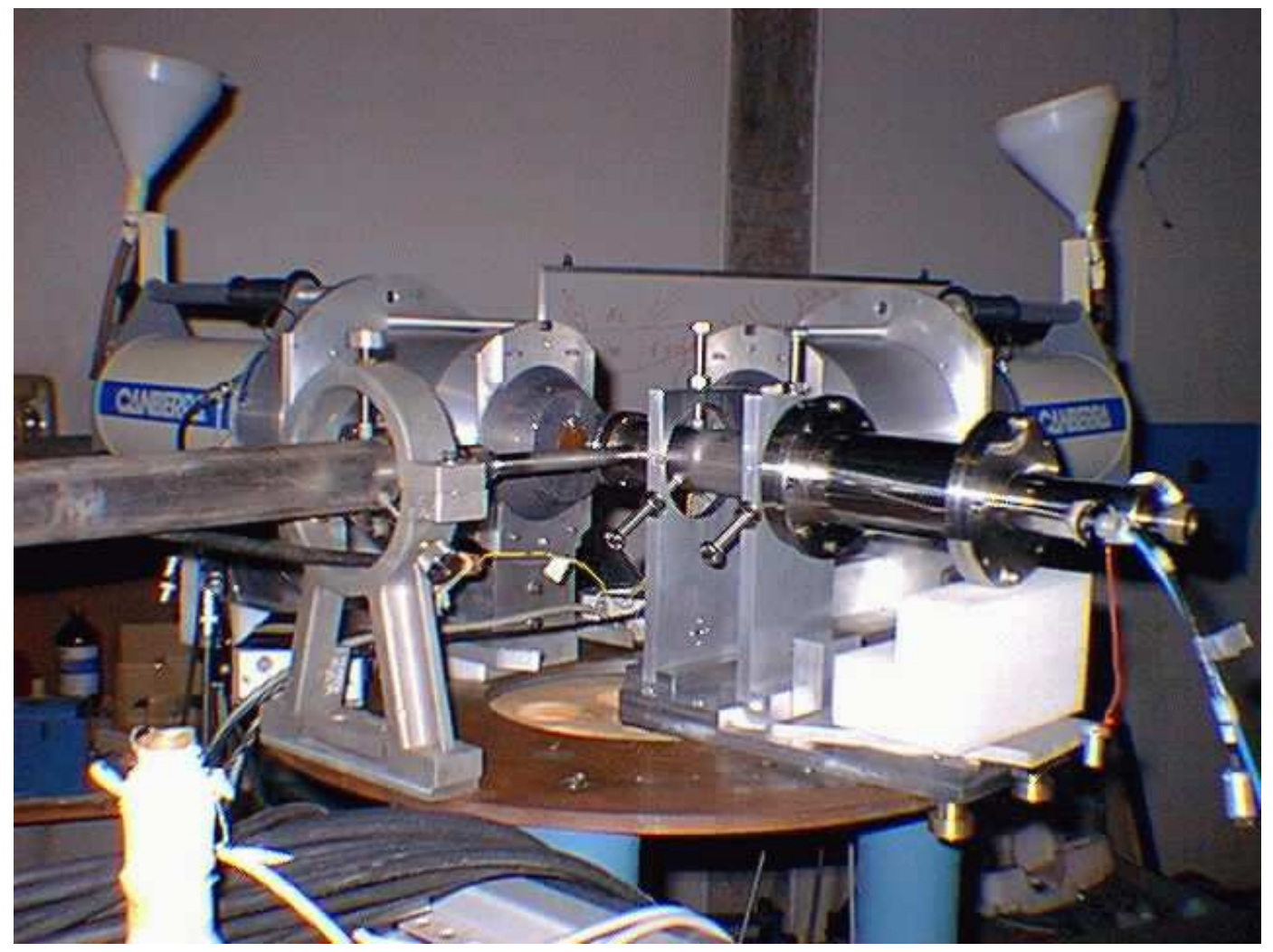

Figura 4.2: Vista horizontal da montagem dos detetores e do criostato.

de Faraday no final da câmara. Esse copo é formado de cobre e internamente revestido com chumbo. No entanto, por ser o alvo relativamente grosso $\left(1 \mathrm{mg} / \mathrm{cm}^{2}+11 \mathrm{mg} / \mathrm{cm}^{2}\right.$ de $\mathrm{Gd}$ ), o espalhamento do feixe (straggling) que é em torno de $6^{\circ}$, é muito maior do que o diâmetro do copo. Em consequência, não medimos o valor absoluto do feixe. Usamos a medida deste copo apenas para passar e regular o feixe.

\subsection{Criostato de Fluxo Contínuo}

Devido à temperatura de Curie do Gadolínio ser baixa $\left(T_{C}=289 \mathrm{~K}\right)$, as medidas com campo magnético variável entre zero e $B_{\text {hiperfino }}$ máximo devem ser realizadas com temperaturas abaixo da ambiente. Para isso, usamos um sistema de refrigeração chamado Criostato de Fluxo Contínuo (vide Figura 4.3). Ele tem um sistema completo de controle de temperatura, que permite variar desde a temperatura do hélio $(4 \mathrm{~K})$ ou do nitrogênio liquido (77K), até a centenas de graus Celsius. Basicamente, este sistema é composto pelo 
"dedo frio", por um tubo de transferência e um controlador eletrônico de temperatura.

Para o nosso caso, é suficiente usar nitrogênio líquido para resfriar o alvo de gadolínio. O nitrogênio, inicialmente num reservatório separado (Dewar) é levado ao "dedo frio" através do tubo de transferência, que possui uma válvula para regular a vazão inicial. O nitrogênio passa pelo tubo de transferência e chega até o dedo frio, onde está fixado nosso alvo, impulsionado pela diferença de pressão produzida por uma bomba mecânica de vácuo, acoplada na saída do dedo frio. Após resfriar o alvo, o nitrogênio, agora já em forma de gás, sai do dedo frio, passa pela bomba mecânica e é liberado.

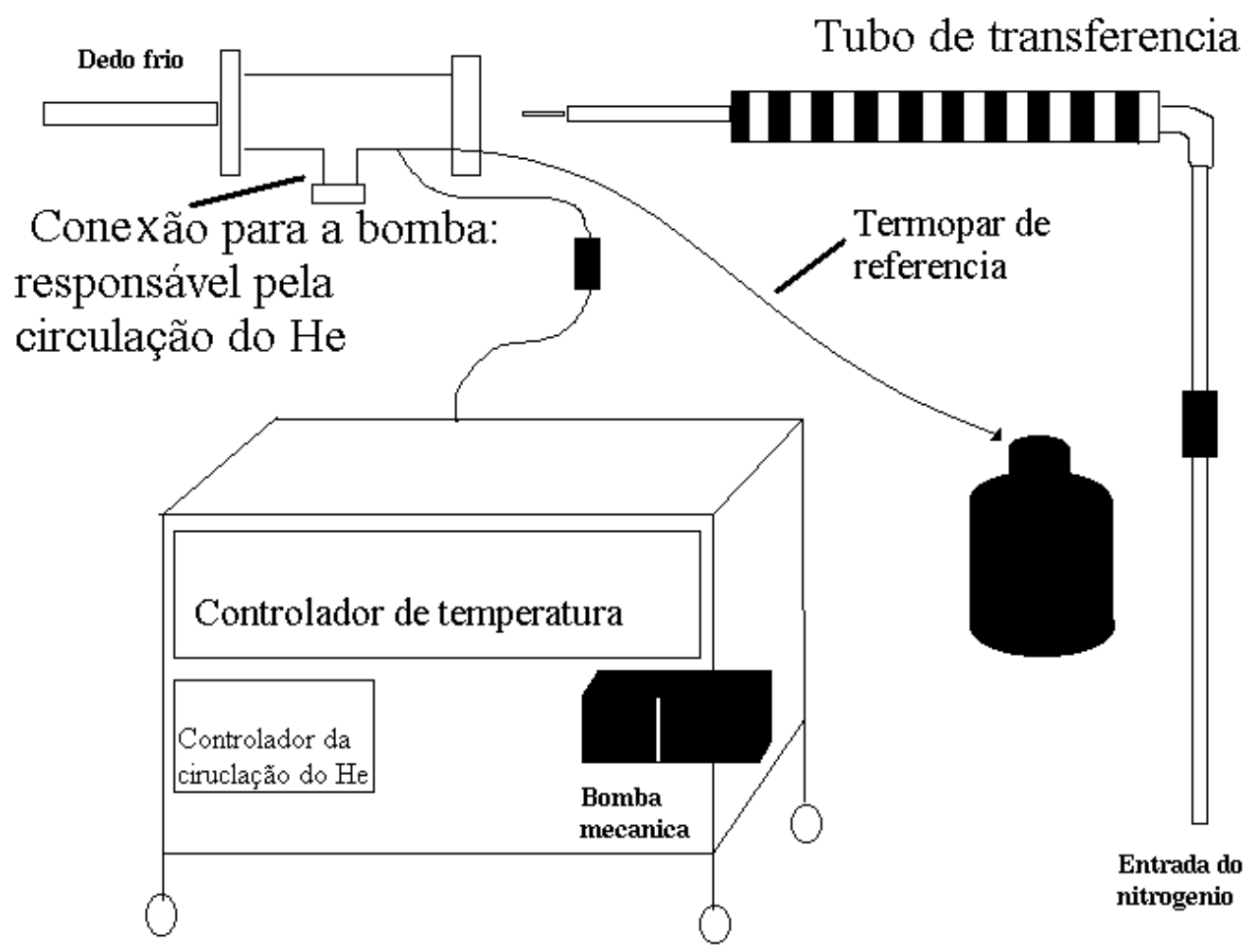

Figura 4.3: Esquema do Criostato de Fluxo Continuo.

Para aquecer o alvo, utiliza-se uma resistência própria em volta do dedo frio. Assim, aquecemos ou resfriamos o alvo apenas regulando a passagem de corrente na resistência. O contato feito entre o alvo e o dedo frio é através de um porta-alvos. Este porta-alvos é feito de cobre (assim como o dedo frio) e é parafusado no dedo frio garantindo um bom contato térmico. O alvo por sua vez, é prensado por pequenas placas no porta alvos. 
Para controlar todos esses parâmetros (aquecimento, resfriamento), o sistema tem um controlador automático de temperatura. O que o controlador faz é regular automaticamente o fluxo de nitrogênio por um controle acoplado à bomba mecânica e também a intensidade de corrente da resistência no dedo frio, de maneira a manter estável a temperatura que escolhemos. A leitura da temperatura é feita por um termopar de FerroConstantan preso na ponta do dedo frio e ligado ao controlador. É necessário ainda fornecer ao controlador, uma referência fixa de temperatura por um outro termopar de Ferro-Constantan. Essa referência é dada mergulhando a ponta do termopar num outro recipiente com nitrogênio líquido $(77 \mathrm{~K})$.

O controlador permite realizar medidas com variações muito pequenas de temperatura, uma vez que todo o sistema é automatizado. Isto é bastante útil para medir com boa precisão a curva LEMS, pois sabemos que variando a temperatura $T$, estamos variando a magnetização, e que esta é proporcional ao campo magnético hiperfino $B_{\text {hiperfino. Logo, }}$ variando T estaremos variando $B_{\text {hiperfino. }}$.

\subsection{O alvo}

A técnica para implantar os núcleos de ${ }^{69} \mathrm{Ge}$ no $\mathrm{Gd}$ exigiu que fossem observadas e realizadas algumas etapas na preparação dos alvos. Essas etapas estão descritas a seguir:

\subsubsection{Laminação}

Em primeiro lugar algumas folhas de gadolínio natural foram laminadas até as espessuras desejadas $\left(\approx 11 \mathrm{mg} / \mathrm{cm}^{2}\right)$, determinadas por medidas de área e massa. Essa espessura é suficientemente grande para que o ${ }^{69} \mathrm{Ge}$ perca toda sua energia de recuo (cerca de 12 $\mathrm{MeV}$ ) e permaneça dentro do Gd. Ao mesmo tempo essa espessura não impede que o feixe do ${ }^{16} \mathrm{O}$ atravesse toda a folha de Gd. O material em forma de folha é colocado entre 2 folhas grossas de aço inox e passado entre os rolos do laminador diversas vezes, aumentando-se gradualmente a pressão entre os rolos de modo que, aos poucos, o alvo vai se aproximando da espessura desejada. A posição do alvo dentro das folhas de inox é sucessivamente alterada, para manter a sua uniformidade. 


\subsubsection{Recozimento (Annealing)}

O processo de laminação provoca deformações nas redes cristalinas do Gadolínio, e que se mostram sob tensões mecânicas internas. Como essas tensões provocadas pelo processo de laminação podem diminuir a magnetização de materiais ferromagnéticos, as folhas de Gadolínio foram submetidas a um processo de recozimento. O recozimento nada mais é do que elevar a temperatura do material suficientemente para que as redes cristalinas possam se rearranjar. A agitação térmica desloca os defeitos ou vacâncias para a superfície onde são eliminadas. Assim, o material, no caso o Gadolínio, recupera todas as propriedades ferromagnéticas.

O Gadolínio foi aquecido pelo processo chamado de "passagem de corrente". Nesse processo o material é submetido a uma passagem de corrente elétrica em vácuo de $10^{-5}$ torr. A intensidade da corrente necessária é variável e depende de diversas propriedades do material e da montagem experimental. Como não existe um critério claro para fazer o recozimento do gadolínio, adotamos um no qual aumentamos a intensidade da corrente até tornar a folha de gadolínio incandescente, de um aspecto alaranjado. Deixamos ela assim durante cerca de 3 minutos. Medidas de magnetização feitas após o recozimento em uma amostra desses alvos num magnetômetro no Departamento de Física dos Materiais e de Mecânica do IFUSP, confirmaram a recuperação da magnetização. A folha apresentou uma magnetização de $\sigma=270 \mathrm{emu} / \mathrm{g}$ quando submetido a um campo de 3000 Oe, indicando que o processo de recozimento restaurou toda a magnetização esperada para uma folha de gadolinio policristalino (vide Figura 3.1).

\subsection{3 "Plasma Glow"}

Após o recozimento, a superfície das folhas de Gadolínio foram limpas através da técnica do "Plasma Glow". Nessa técnica, o material a ser limpo é deitado num suporte que está à uma alta tensão $(\approx 1 \mathrm{kV})$ e numa pressão de $10^{-5}$ torr sob uma campânula. Usa-se o evaporador do laboratório de alvos para este fim. Injeta-se continuamente um pouco de gás argônio na campânula. As partículas carregadas são aceleradas em direção ao suporte e ionizam o gás, provocando pequenas fagulhas que limpam toda a superfície do material. Feito isso por cerca de 3 minutos, a folha de Gadolínio está pronta para que seja feita a evaporação do ferro. 


\subsubsection{Evaporação do Ferro}

Para a evaporação do ferro, usamos o método da passagem de corrente no evaporador do Laboratório Pelletron. Esse método, consiste em aquecer o material colocando-o sobre um cadinho metálico, que é atravessado por uma corrente elétrica adequada. A corrente elétrica necessária depende de vários parâmetros como condutibilidade térmica, ponto de evaporação, contato térmico, entre outros [35]. No caso do ferro, usamos um cadinho de tântalo pré-aquecido por 2 minutos para degaseificar todo o sistema. Logo depois, foi colocado o ferro dentro do cadinho e feitas varias evaporações com a pressão de $10^{-5}$ torr, durante 90 segundos cada, com intervalos de 5 minutos para resfriamento do sistema. Determinamos a espessura de ferro $\left(1 \mathrm{mg} / \mathrm{cm}^{2}\right)$ por medidas de área evaporada e da massa evaporada. Cálculos feitos em STOPX (um programa que simula a perda de energia de um núcleo qualquer em um meio metálico ou gasoso) revelaram que a espessura do ferro não deveria ultrapassar o máximo de $2 \mathrm{mg} / \mathrm{cm}^{2}$ de modo que o Ge formado na reação tenha energia suficiente para sair da camada de ferro e ser implantado no Gadolínio.

\subsection{Os imãs}

Medidas de magnetização do Gadolínio feitas em uma amostra do nosso alvo (sem a camada de ferro) indicaram que são necessários aproximadamente 3000 Gauss (0.3 Tesla) para alinhar os domínios magnéticos existentes à temperatura de $80 \mathrm{~K}$. Para isso optamos por usar imãs permanentes de Samário-Cobalto (SmCo). Esses imãs, de dimensões reduzidas $(6 \times 14 \times 24 \mathrm{~mm})$, produzem um campo magnético de 3200 Gauss, quando separados por um distância de $8 \mathrm{~mm}$. Quanto à variação de temperatura, ao contrário dos imãs de Neodímio-Ferro-Boro (NdFeBo) que tem uma transição de fase a 150K, os ímãs de SmCo não perdem suas propriedades magnéticas para temperaturas abaixo da ambiente.

Para diminuir a dispersão das linhas de campo nas bordas dos imãs, construímos um pequeno circuito magnético em forma de $C$, feito de ferro armco. $O$ ferro armco tem baixa concentração de carbono na sua composição, tornando-o excelente condutor magnético. Esse circuito magnético tem a dupla função de conduzir as linhas até a região do alvo e blindar as linhas exteriores, evitando que atinjam os detectores de Ge(HP). 


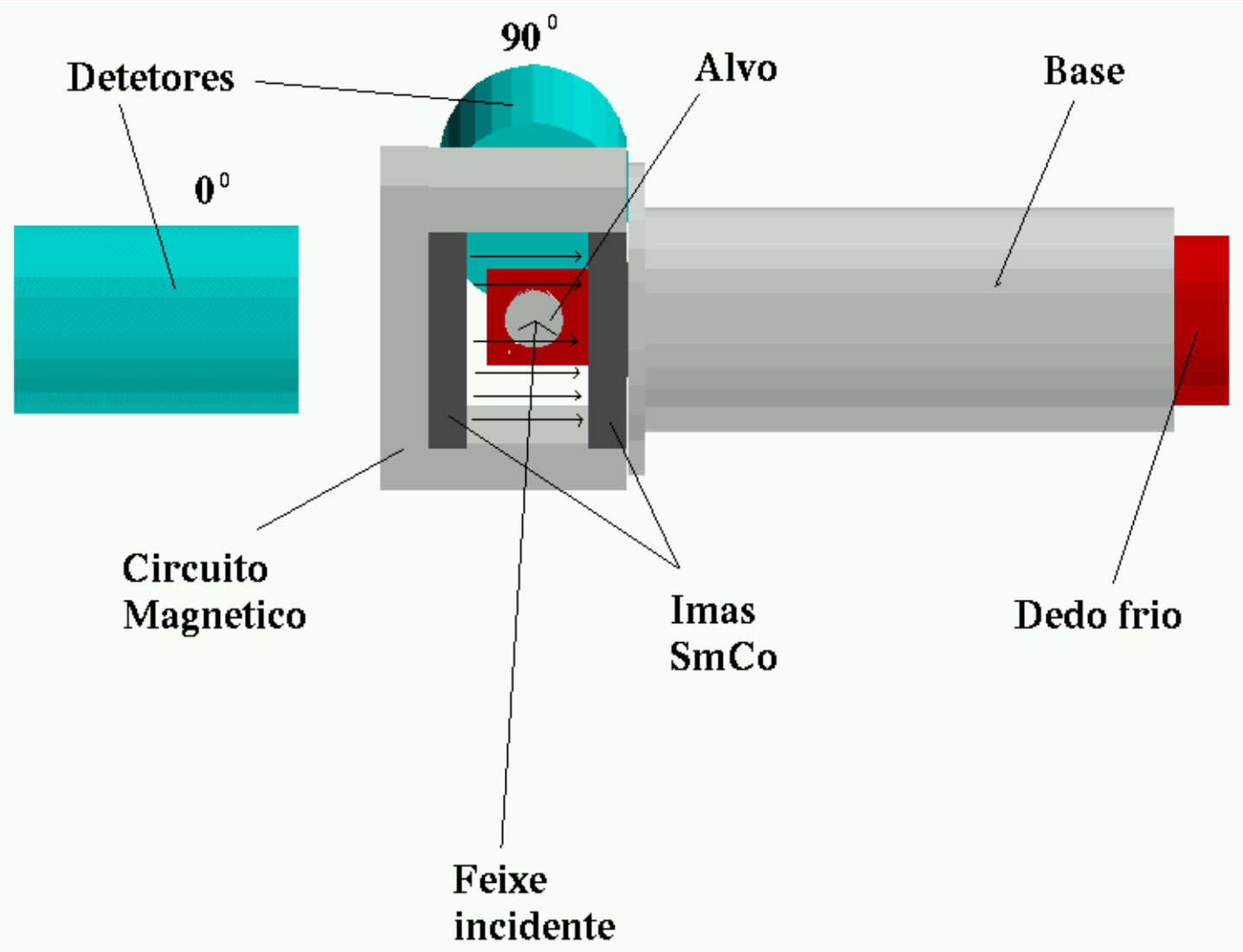

Figura 4.4: Esquema mostrando a montagem dos imãs de SmCo acoplados ao dedo frio. O campo magnético neste sistema é de $\approx 3200$ Gauss.

Uma vez que trabalhamos com imãs permanentes, fica impossível ter campo magnético externo (produzido por eles) na mesma direção do feixe. Portanto, optamos por usar a geometria onde o campo é perpendicular ao feixe, para realizar as experiências. Outro motivo para usar essa configuração é que os domínios magnéticos de qualquer material ferromagnético em forma de folha se alinham preferencialmente paralelos ao plano da folha.

Quando se faz as experiências usuais de LEMS, usando campo magnético externo em vez de materiais ferromagnéticos para desacoplar as interações, o campo externo é da ordem de alguns Tesla, e pode desviar consideravelmente o feixe. No entanto, como o campo magnético gerado pelos imãs permanentes é muito baixo $(\approx 0.3$ Tesla) e atua numa região reduzida do espaço, o desvio é desprezível. 


\subsubsection{Medida da magnetização}

Foi feita uma medida da magnetização em função da temperatura numa amostra de nossas folhas de Gd após passar pelo tratamento térmico e limpeza como descrito na secção 4.4. Essas medidas foram feitas pelo Prof. Dr. Hercilio R. Rechenberg, do Departamento de Física dos Materiais e Mecânica do Instituto de Física - IFUSP. O resultado pode ser visto na figura 3.1 .

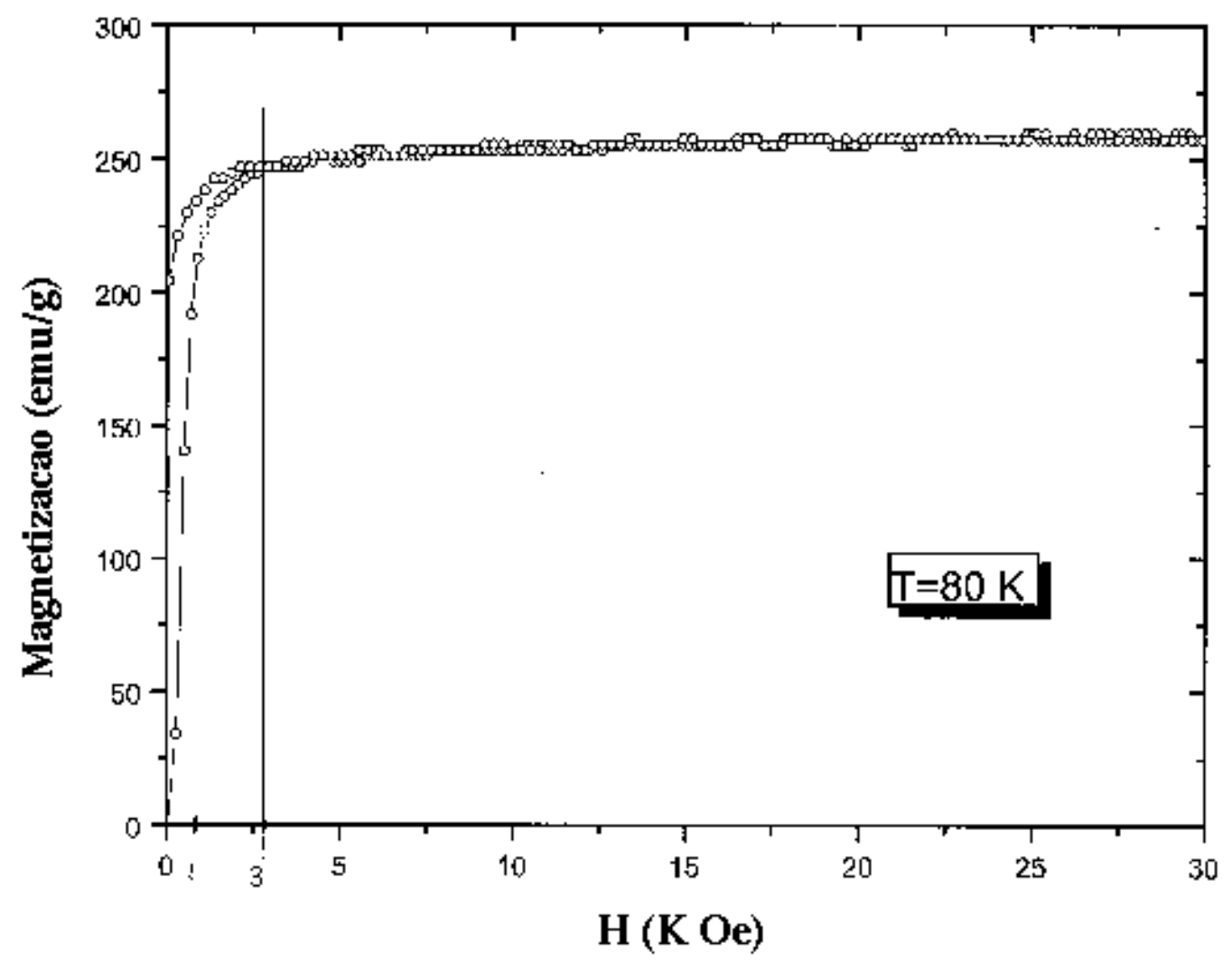

Figura 4.5: Medida da magnetização em função de campo magnético feita em uma amostra de Gd recozido. A linha vertical indica o valor do campo magnético na qual satura a magnetização a $80 \mathrm{~K}$

O valor de saturação da magnetização encontrada é comparável aos valores da literatura $(\approx 270 \mathrm{emu} / \mathrm{g})$, indicando que o processo de recozimento desfez as tensões mecânicas provocadas pela laminação e restaurou a estrutura cristalina inicial.

Para orientar o campo magnético hiperfino, um campo externo precisa ser aplicado. Para saber qual o valor mínimo de campo externo que deve ser aplicado para saturar o valor da magnetização, foram feitas curvas de histerese para várias temperaturas. Podemos ver uma delas na figura 4.5, onde para a temperatura de $80 \mathrm{~K}$ o valor mínimo de 
campo magnético aplicado deve ser de $\approx 3000$ Gauss.

$\mathrm{Na}$ medida da magnetização foi aplicado um campo magnético externo de 3000 Gauss (0.3 Tesla). A escolha desse valor de campo, além do fato de saturar a magnetização a baixas temperaturas, deve-se também ao interesse em se conhecer o comportamento da folha de Gd em função da temperatura quando estiver sujeita ao campo de 0.3 Tesla gerados pelos imãs permanentes.

\subsection{Detectores}

Atualmente, os detectores de germânio hiperpuros Ge(HP) se encontram entre os mais apropriados para medidas em espectroscopia $\gamma$. A principal característica e motivação para seu uso é a excelente resolução em energia $(\approx 2.4 \mathrm{keV}$ para o pico de $1332 \mathrm{keV}$ do ${ }^{60} \mathrm{Co}$ ) e uma eficiência de $60 \%$. Detectores de Germânio são diodos semicondutores com uma estrutura P-I-N na qual uma região intrínseca é sensível à radiação ionizante, particularmente raios $\mathrm{X}$ e raios $\gamma$. Sob uma tensão reversa de polarização (bias), um campo elétrico se estende por toda a região de depleção. Quando fótons interagem com o material dentro dessa região no detetor, portadores de carga (buracos ou elétrons) são produzidos e acelerados pelo campo elétrico para os eletrodos P e N. Essa carga, que é proporcional a energia depositada no detetor pelo fóton incidente, é convertida em um pulso de voltagem por um pré-amplificador sensível à carga.

Por causa do baixo "gap" da banda do germânio, esses detectores devem ficar resfriados para reduzir a geração térmica de portadores de carga a um nível aceitável [38]. O nitrogênio líquido é colocado num recipiente próprio para resfriar os detectores.

O pico de interesse $(398 \mathrm{keV})$ está numa região onde já temos uma razoável contribuição do efeito Compton devido aos numerosos picos de energias mais altas. Acrescentamos então os Supressores Compton que ficam em volta dos detectores de Ge(HP) e servem para fazer a supressão de eventos que não provenham de algum fotopico. Isso aumenta de um fator 2.25 a razão pico/fundo do nosso pico de interesse.

Para medidas LEMS, usamos dois desses detectores, colocados a $0^{\circ}$ e $90^{\circ}$ em relação ao campo magnético (fig. 4.1). Devido ao seus reservatórios de nitrogênio, os dois detectores estão limitados a ficarem na posição horizontal o que nos obriga a ter um deles na linha do feixe $\left(90^{\circ}\right)$. Felizmente esse detetor não chega a ser prejudicado pelo fluxo de nêutrons, 
uma vez que tem o copo de Faraday e o aço inox da câmara a blindá-lo, e também, os detectores sendo do tipo n, são menos sensíveis a nêutrons [38]. Também para não sobrecarregar os detectores com contagens na região de raios X, colocamos placas de cobre em frente a eles (fig. 4.1).

Testes feitos com feixe pulsado limparam enormemente o espectro mas a taxa de eventos por segundo decresce demasiadamente. Seria então necessário um tempo de aquisição muito maior do que tínhamos disponível para obter boas estatísticas.

\subsection{Eletrônica de aquisição}

Para o controle, coleta e armazenagem dos dados pertinentes à medida da anisotropia da distribuição angular da radiação $\gamma$, foi utilizado o sistema de aquisição de dados estocásticos do laboratório Pelletron (SPM_CAMAC)[36], que utiliza a norma de interface de instrumentos CAMAC (Computer Automated Measurement and Control)[37].

Para o tratamento dos pulsos dos detetores de raios $\gamma$, usamos uma eletrônica convencional de anti-coincidência, envolvendo apenas dois detetores de Ge e dois detetores anti-Compton. A figura 4.6 mostra em detalhes o esquema da eletrônica utilizada. As amplitudes dos sinais lineares (energia) provenientes dos pré-amplificadores dos detetores de raios $\gamma$ Ge(HP), são amplificadas (Canberra Amplifier Gain 2026), digitalizadas nos conversores analógicos-digitais (ADC) e traduzidas em uma posição de memória (canal).

Os pulsos dos detetores $\gamma$ são também amplificados por um "Timing Filter Amplifier" (TFA - Ortec 863). Esses pulsos passam por um "Constant Fraction Discriminator" (EG\&G-ESN 4000) que gera pulsos rápidos correspondentes ao instânte da ocorrência do evento, independentemente da amplitude do pulso de entrada, para depois serem introduzidos no "Octal Gate Generator" (EG\&G - 8000). Estes pulsos correspondem a uma marca de tempo dos raios $\gamma$ no " 4 fold - 4 input logic" (CO 4000) que é um circuito de coincidência, sendo ajustado para realizar as operações lógicas desejadas. Os sinais fornecidos por este módulo indicam a ocorrência de uma anti-coincidência entre um evento do detector e um evento do anti-Compton. Por exemplo, quando chega um evento do detector Ge(HP) em coincidência com um evento do anti-Compton, o sinal é descartado, pois se trata de um raio $\gamma$ que foi espalhado dentro do detector $\mathrm{Ge}(\mathrm{HP})$ e chegou ao anti-Compton. Isto quer dizer que o raio $\gamma$ perdeu apenas parte de sua energia no detetor 
Ge(HP), resultando numa medida de energia menor do que a real. Assim, se porventura ocorrer um evento vindo somente do detetor anti-Compton, ele é sempre descartado. Se vier somente do detetor $\mathrm{Ge}(\mathrm{HP})$, indica que é um raio $\gamma$ proveniente de um fotopico, e então será sempre aceito.

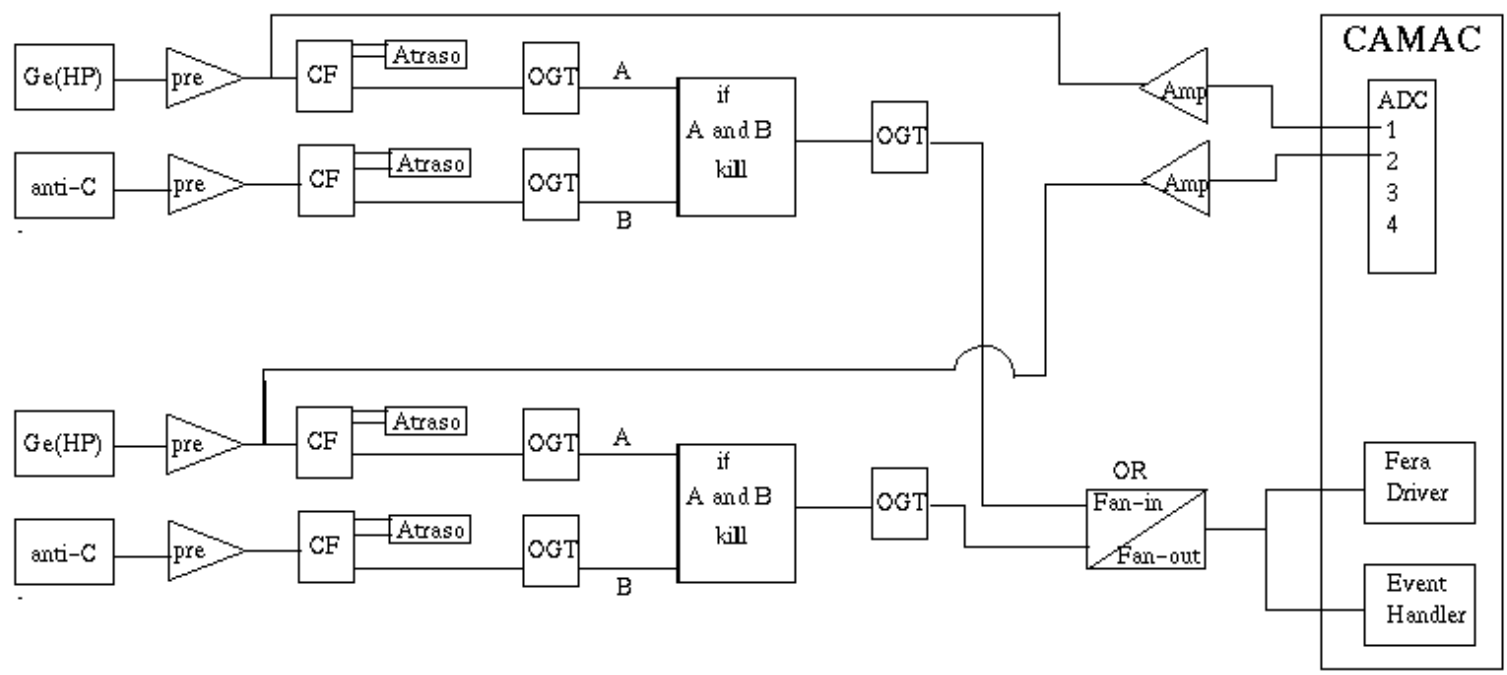

Figura 4.6: Diagrama de blocos so sistema eletrônico analógico de tratamento de pulsos

Feita a anti-coincidência, o sinal é alargado em tempo no "Octal Gate Generator" (EG\&G 8010) e submetido ao "Fan in - Fan out" (LeCroy 429A) (circuito lógico e/ou) a fim de servir como portão de abertura, "gate" para o "Event Handler" e o "Fera Driver" (LeCroy 4301). Quando o módulo "Fera Driver" recebe este pulso (entrada GAI) é aberta uma porta, e assim permanece durante o intervalo de tempo de duração deste pulso $(\approx 50 \mu \mathrm{s})$. Neste intervalo o ADC procura pelo máximo do pico a fim de convertê-lo no canal apropriado. O "Event Handler" ao receber o sinal referente à ocorrência de um evento, e não havendo nenhum impedimento, executa o programa interno, que testa os bits lógicos usados para selecionar diferentes tipos de eventos, lê e zera o ADC, e escreve os parâmetros lidos num "buffer" de memória FIFO. Este "buffer" é programado para enviar um sinal de atenção (LAM) quando estiver com 3/4 de sua capacidade de memória lotada. O sistema de aquisição está preparado para receber um interrupção associada a este LAM, quando então esvazia a memória FIFO e apaga o sinal LAM [39].

A partir daí o programa GERENTE faz o controle geral da aquisição, entre os quais 
estão a alocação de dados na memória, histogramação em arquivos de disco, etc. Isto possibilita uma visualização e análise durante a aquisição (tempo real) como também a análise posterior (off-line). 


\section{Capítulo 5}

\section{Descrição da experiência}

\subsection{O núcleo ${ }^{69} G e$}

Para testar o método LEMS, escolhemos estudar o decaimento $\gamma$ do estado isomérico de meia-vida $2.81 \mu \mathrm{s}$ e $398 \mathrm{keV}$ de energia do núcleo ${ }^{69} \mathrm{Ge}$. Esse estado possui todas as suas propriedades como spin, paridade, momento magnético, momento de quadrupolo elétrico, bem conhecidas apresentados na tabela 5.1.

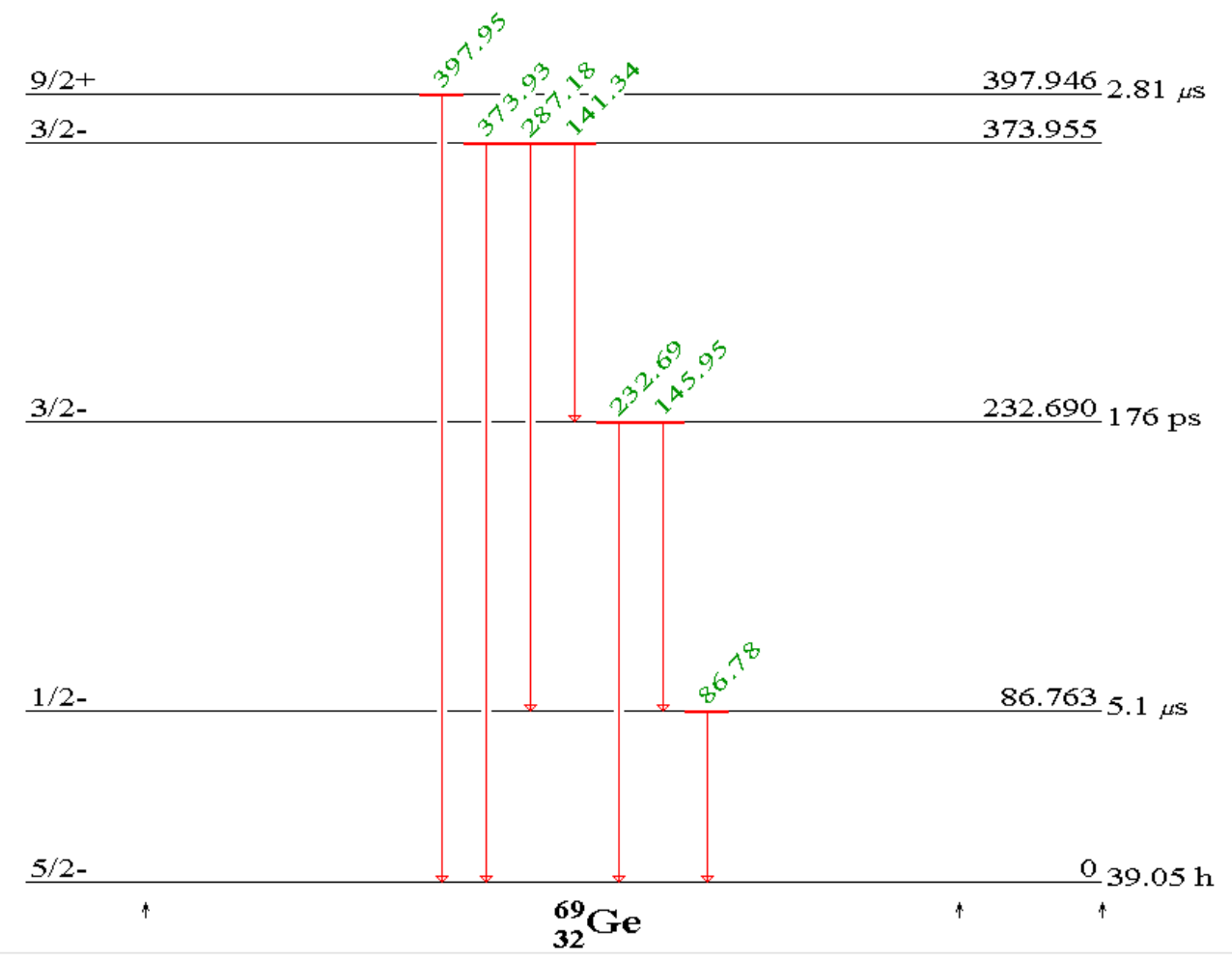

Figura 5.1: Esquema de níveis do ${ }^{69} G e$ produzido na reação . 


\begin{tabular}{lrcccc}
\hline \hline Núcleo & $E_{x}(\mathrm{keV})$ & $T_{1 / 2}$ & $I$ & $\mu(\mathrm{nm})$ & $Q(b)$ \\
\hline${ }_{32}^{69} \mathrm{Ge}$ & 0 & $39.0 \mathrm{~h}$ & $5 / 2-$ & $0.735(7)$ & $0.024(5)$ \\
& 398 & $2.8 \mu \mathrm{s}$ & $9 / 2+$ & $-1.0011(32)$ & $1.00(20)$ \\
\hline \hline
\end{tabular}

Tabela 5.1: Tabela com algumas propriedades nucleares do ${ }^{69} \mathrm{Ge}$

A meia vida de $2.81 \mu \mathrm{s}$ é suficientemente longa para que o estado seja perturbado pela interação quadrupolar. Se isso não acontece, a interação não tem tempo suficiente para reduzir completamente a anisotropia. Por outro lado, a meia vida não pode ser maior do que o tempo de relaxamento da rede de spins, que para baixas temperaturas é da ordem de centenas de milisegundos até segundos.

\subsection{Reação de fusão-evaporação}

$\mathrm{O}{ }^{69} \mathrm{Ge}$ foi produzido por meio da reação de fusão-evaporação ${ }^{56} \mathrm{Fe}\left({ }^{16} \mathrm{O}, 2 p n\right){ }^{69} \mathrm{Ge}$, com um feixe de ${ }^{16} \mathrm{O}$ à $53 \mathrm{MeV}$ de energia incidente. A energia do feixe incidente foi escolhida com a ajuda do programa PACE (Projection Angular-momentum Coupled Evaporation), uma rotina de Monte-Carlo que calcula a secção de choque de produção de um isótopo para uma dada reação nuclear. Um gráfico da secção de choque de produção em função da energia incidente pode ser visto na fig 5.2.

O elemento Fe natural contêm $91 \%$ do isótopo ${ }^{56} \mathrm{Fe}$. Portanto, foi suficiente usar Fe natural para a reação desejada.

\subsection{Redução de Dados}

A histogramação dos dados em espectros de raios $\gamma$ foi feita durante a aquisição com o programa DAMM (Data Analises Manipulation Module), que pertence ao pacote de rotinas VAXPAK [36, 40, 41] e que incorpora também o programa para cálculo de perda de energia (STOPX) entre outros. Os dados foram tirados em etapas (RUN'S) de algumas horas cada, observando-se que o número de contagens nos picos $\gamma$ fosse razoável. Os espectros de cada detector eram gravados em disco toda vez que um RUN terminava. Isso permitiu fazer uma análise em tempo real, para detectar possíveis variações no ganho do 


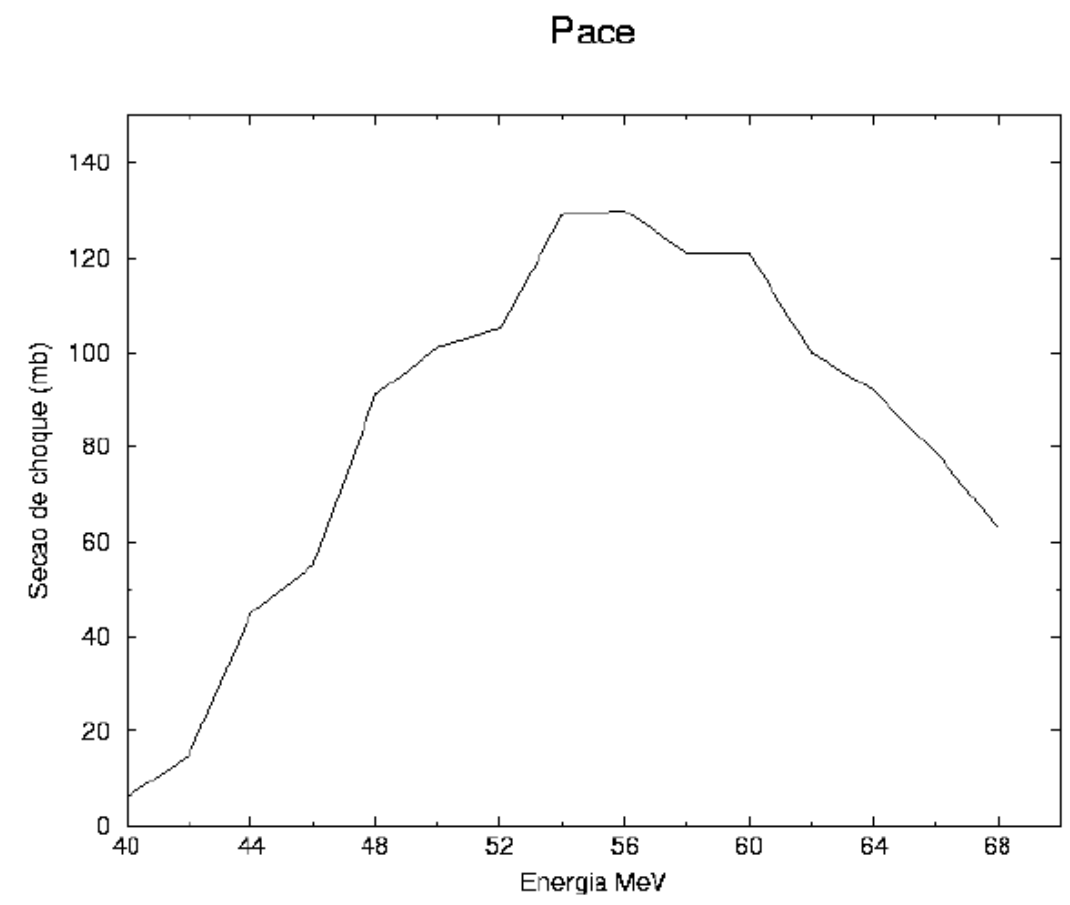

Figura 5.2: Secção de choque total de produção do de ${ }^{69} \mathrm{Ge}$ na reação ${ }^{16} \mathrm{O}+{ }^{56} \mathrm{Fe}$. Cálculos feitos com programa PACE.

amplificador ou até perda de sinal além de, é claro, fazer uma análise prévia do resultado. Um espectro típico obtido nessa reação está mostrado na figura 5.3.

A anisotropia da distribuição angular do raio $\gamma$ emitido no decaimento do estado nuclear do ${ }^{69} \mathrm{Ge}$ é calculada considerando a razão das contagens no pico do raio $\gamma$ de $398 \mathrm{keV}$ entre os dois detectores. Por convenção, essa razão será calculada sempre entre o número de contagens do detector que esta na direção do campo magnético $N\left(0^{0}\right)$ e o que está perpendicularmente colocado $N\left(90^{\circ}\right)$. Desta forma, quando mencionamos a anisotropia da distribuição angular, nos referimos à medir a razão das contagens $N\left(0^{0}\right) / N\left(90^{0}\right)$.

\subsection{Procedimento da análise}

\subsubsection{Identificação dos picos}

Podemos observar na figura 5.3 vários picos interessantes. É possível identificar os picos de transições $\gamma$ provenientes da reação, como o de $398 \mathrm{keV}$ de energia que vem do ${ }^{69} \mathrm{Ge}$. Também podem ser vistos os picos de $321 \mathrm{keV}, 485 \mathrm{keV}$ e $788 \mathrm{keV}$ do ${ }^{70}$ As entre 


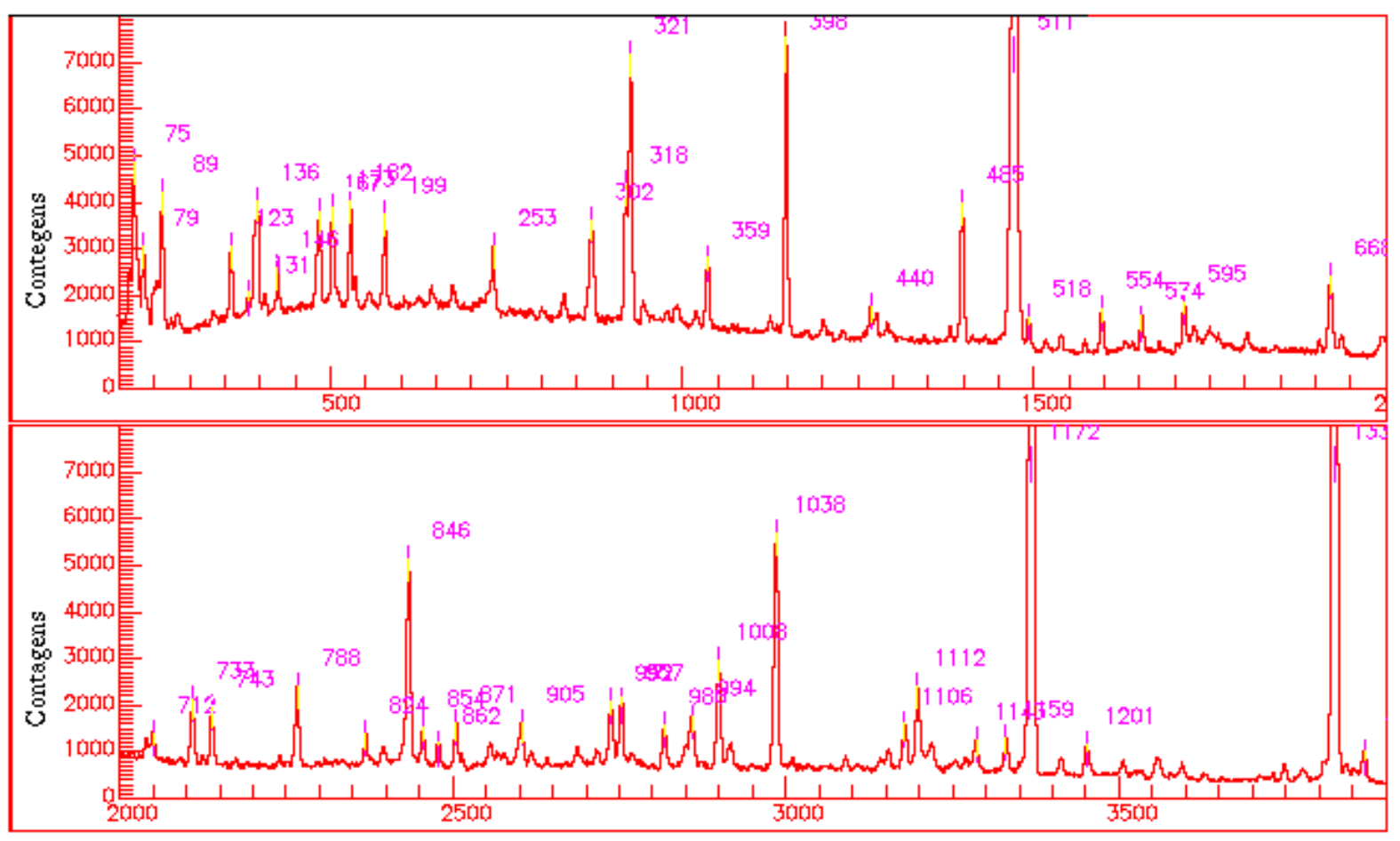

Canal

Figura 5.3: Espectro de raios $\gamma$ da reação de fusão-evaporação ${ }^{56} \mathrm{Fe}\left({ }^{16} \mathrm{O}, 2 p n\right){ }^{69} \mathrm{Ge}$ à $53 \mathrm{MeV}$. Os picos de alta intensidade no final do espectro são de uma fonte de ${ }^{60} \mathrm{Co}$.

outros. Os poucos contaminantes encontrados como o de $440 \mathrm{keV}$ do ${ }^{23} \mathrm{Na}$ (das reações ${ }^{16} \mathrm{O}\left({ }^{16} \mathrm{O}, 2 \alpha p\right){ }^{23} \mathrm{Na}$ e $\left.{ }^{12} \mathrm{C}\left({ }^{16} \mathrm{O}, \alpha p\right){ }^{23} \mathrm{Na}\right)$ mostram, pela baixa intensidade do pico, que o alvo não chegou a oxidar. Também a baixa intensidade dos picos de $136 \mathrm{keV}, 166 \mathrm{keV}$ e $181 \mathrm{keV}$ do Tântalo, usado como colimador, indicam que o feixe era bem focalizado e pouco feixe incidia sobre o colimador.

\subsubsection{Extração das áreas dos picos do espectro $\gamma$}

Na extração das áreas dos picos de raios $\gamma$ não foi necessária a utilização de programas de ajuste de picos, uma vez que o pico de $398 \mathrm{keV}$ estava bem separado de qualquer contaminante e apresentava um fundo estatístico liso. Com isso, evitam-se as incertezas provenientes desses ajustes nos quais são feitas suposições relacionadas à forma dos picos de raios $\gamma$. As àreas dos picos de raios $\gamma$ de interesse foram então obtidas somando-se todas as contagens do pico acima de um fundo estatístico, que é definido através de um ajuste das contagens experimentais próximas ao pico (ver figura 5.4). Este procedimento 
foi feito para cada RUN.

Usamos por final, três métodos diferentes de extração das áreas. Todos esses métodos estão disponíveis no programa DAMM. O primeiro é mais simples, que aqui vamos chamar de método $S$, é escolher um ponto (canal) à esquerda do pico o outro à direita (ver fig. 5.4). A altura do ponto é definido pelo número de contagens nesse canal. O que o programa faz é unir esses dois pontos por uma reta para representar a linha do fundo estatístico, e somar todas as contagens acima dessa linha e entre os dois canais escolhidos. O resultado representa a àrea do pico.

Apesar de esse método ser o mais simples, ele é muito vulnerável a flutuação estatística quando se tem poucas contagens no fundo. Dependendo dos canais escolhidos para representar a linha de fundo, o resultado final pode variar consideravelmente.

No segundo método que chamaremos de método $A$, também se escolhe um ponto à esquerda e outro à direita do pico. Mas nesse caso, o ponto é escolhido com o cursor. Dessa maneira se pode visualizar um fundo médio de cada lado do pico e marcar um ponto nessa região . O que o programa faz então é novamente unir esses dois pontos por uma reta para representar o fundo debaixo do pico.

O terceiro método (chamado de método Ribas), consiste em escolher uma região de cada lado do pico (à esquerda e à direita do pico) como mostra a figura 5.4. Se escolhe uma região de fundo de vários canais à esquerda do pico (que seja desprovida de qualquer outro pico). O que o programa faz é calcular uma média das contagens nos canais da região selecionada, e assumir essa média como sendo a contagem correspondente ao fundo selecionado. O mesmo procedimento é feito para o lado direito do pico.

Encontrada a contagem média que melhor representa o fundo nessas duas regiões, o programa novamente une o ponto médio da esquerda com o da direita e considera essa linha como a linha que separa o fundo estatístico e pico. A região de integração é marcada independentemente pelas linhas verticais ao lado do pico.

Fizemos análises usando os três métodos. Os resultados dos três são muito semelhantes. No entanto, utilizamos o fundo calculado pelo método Ribas por ser menos sujeito a erros sistemáticos. 


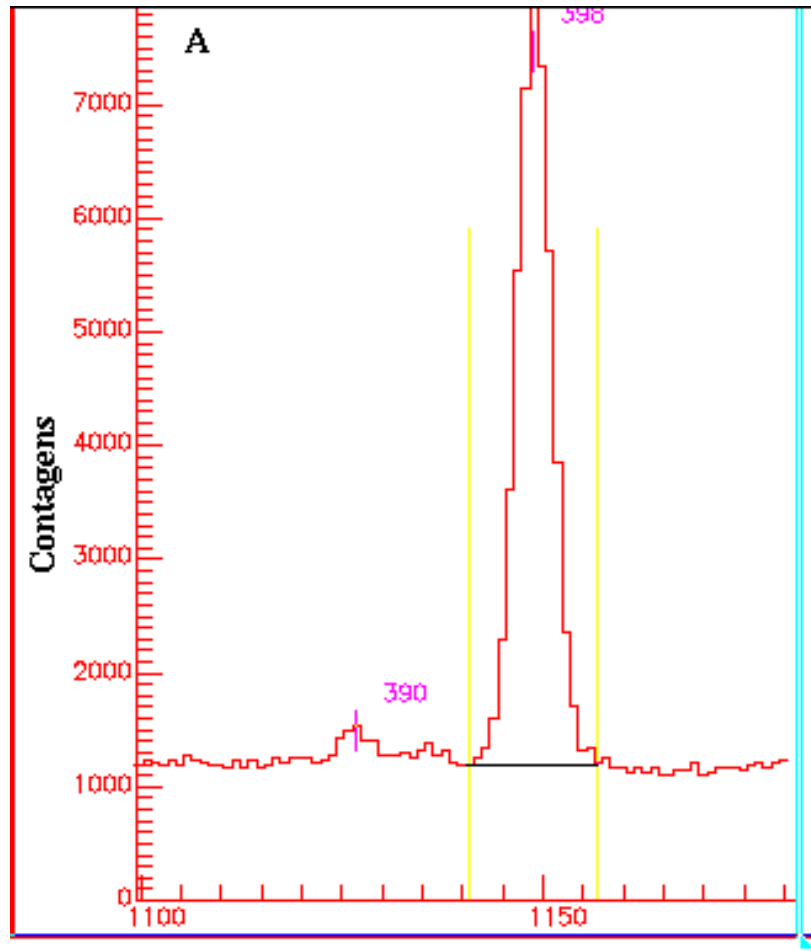

Canal

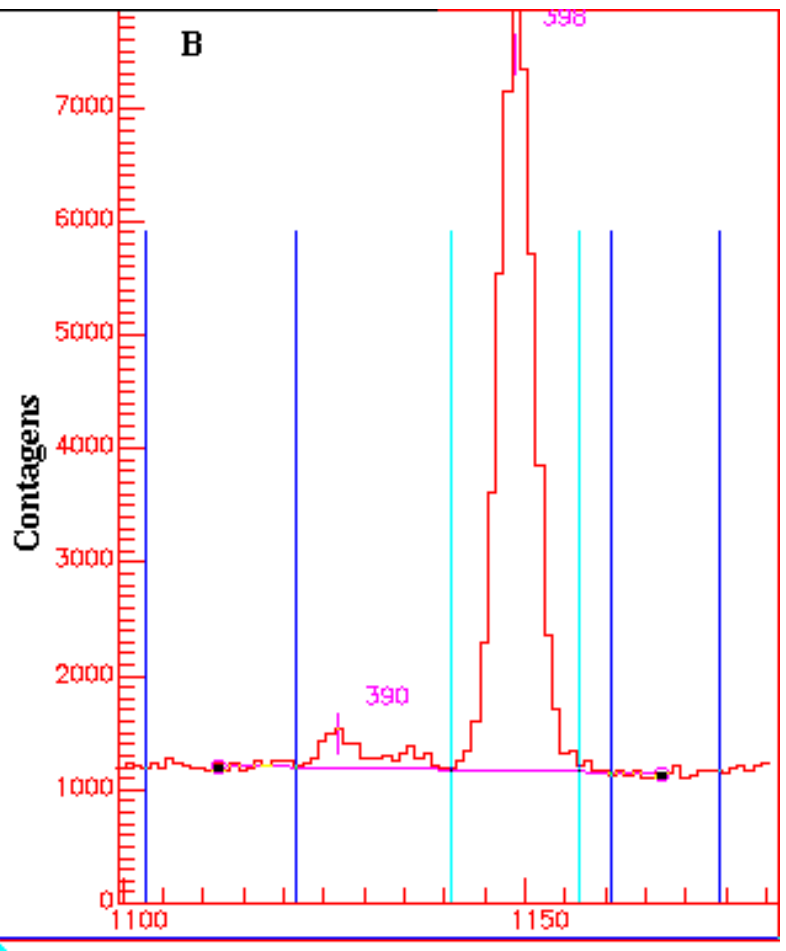

Canal

Figura 5.4: A) No método S os canais em que estão as linhas verticais definem a linha do fundo. No método A esse fundo pode ser ajustado visualmente. B)Método Ribas, com uma região em cada lado do pico que define um fundo médio.

\subsubsection{Normalização dos picos com a transição de $788 \mathrm{keV}$}

Quando se calcula a razão das contagens entre dois detectores, muitos parâmetros como variação da intensidade do feixe, eficiência de produção, etc, são canceladas. No entanto, observou-se no decorrer da experiência que aparentemente a eficiência dos detetores ou de todo o sistema de aquisição variava. Embora pequena, esta variação poderia comprometer nossos resultados, já que o efeito que procuramos medir é pequeno $(\sim 10 \%)$ e necessitamos boa precisão nas nossas medidas. Para evitar que esse tipo de mudança afetasse o resultado da experiência, decidimos normalizar nossos dados de alguma forma para cancelar esse tipo de efeito.

A solução foi usar como normalização um pico correspondente a uma transição $\gamma$ muito rápida e cujo núcleo também seja produto da reação ${ }^{16} \mathrm{O}+{ }^{56} \mathrm{Fe}$. Usando feixe pulsado de ${ }^{16} O$, adquirimos um espectro de decaimento $\gamma$ na ausência de feixe (gated). Nesse espectro, que aparece na figura 5.5, todos os picos de transições $\gamma$ que possuam vida 
média maior do que alguns $n s$. Podemos ver nosso pico de interesse de $398 \mathrm{keV}$ e $\tau=2.8$ $\mu s$ bastante intenso.

Um outro núcleo, produto da reação de fusão-evaporação é o ${ }^{70} A s$ que possui um esquema de decaimento no qual estão as transições $\gamma$ de $321 \mathrm{keV}, 485 \mathrm{keV}$ e $788 \mathrm{keV}$ que aparecem nitidamente no espectro 5.3. No entanto, o pico de $788 \mathrm{keV}$ não aparece no espectro "gated", indicando ser uma transição muito rápida, e portanto não estará sujeita à interação hiperfina podendo, portanto, ser usada como um pico de normalização .

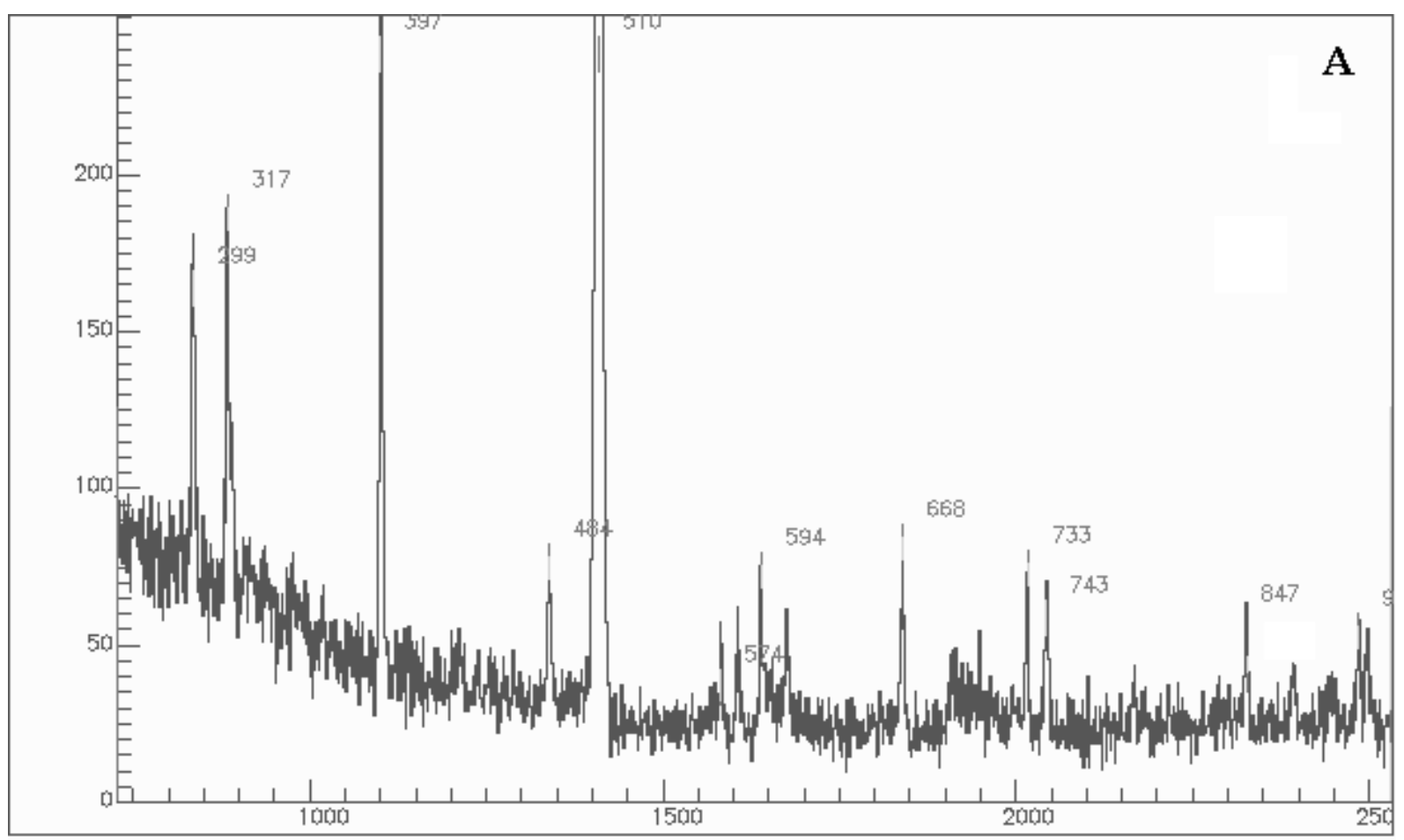

\section{Contagens $\mathrm{X}$ canais (energia)}

Figura 5.5: Espectro "gated" (na ausência de feixe) de raios gama onde notamos a ausência de contagens do pico de $788 \mathrm{keV}$, provando de que se trata de uma transição rápida que vem da própria reação ${ }^{16} \mathrm{O}+{ }^{56} \mathrm{Fe}$.

Normalizamos então o pico de $398 \mathrm{keV}$ pelo pico de $788 \mathrm{keV}$ que pode ser visto no espectro 5.3, mas não aparece no espectro 5.5. O pico de $788 \mathrm{keV}$ é produzido na reação ${ }^{56} \mathrm{Fe}\left({ }^{16} \mathrm{O}, 2 n p\right){ }^{70} \mathrm{As}$ e é uma transição rápida o suficiente (vida média $<2 n s$ ) de forma a não estar sujeito à interação hiperfina.

A consequência dessa normalização é o aumento das barras de erro no cálculo das razões, uma vez que o pico de $788 \mathrm{keV}$ tem menos contagens. Também neste caso utilizamos a demarcação do fundo com o método Ribas, como mostra a figura. Há uma 

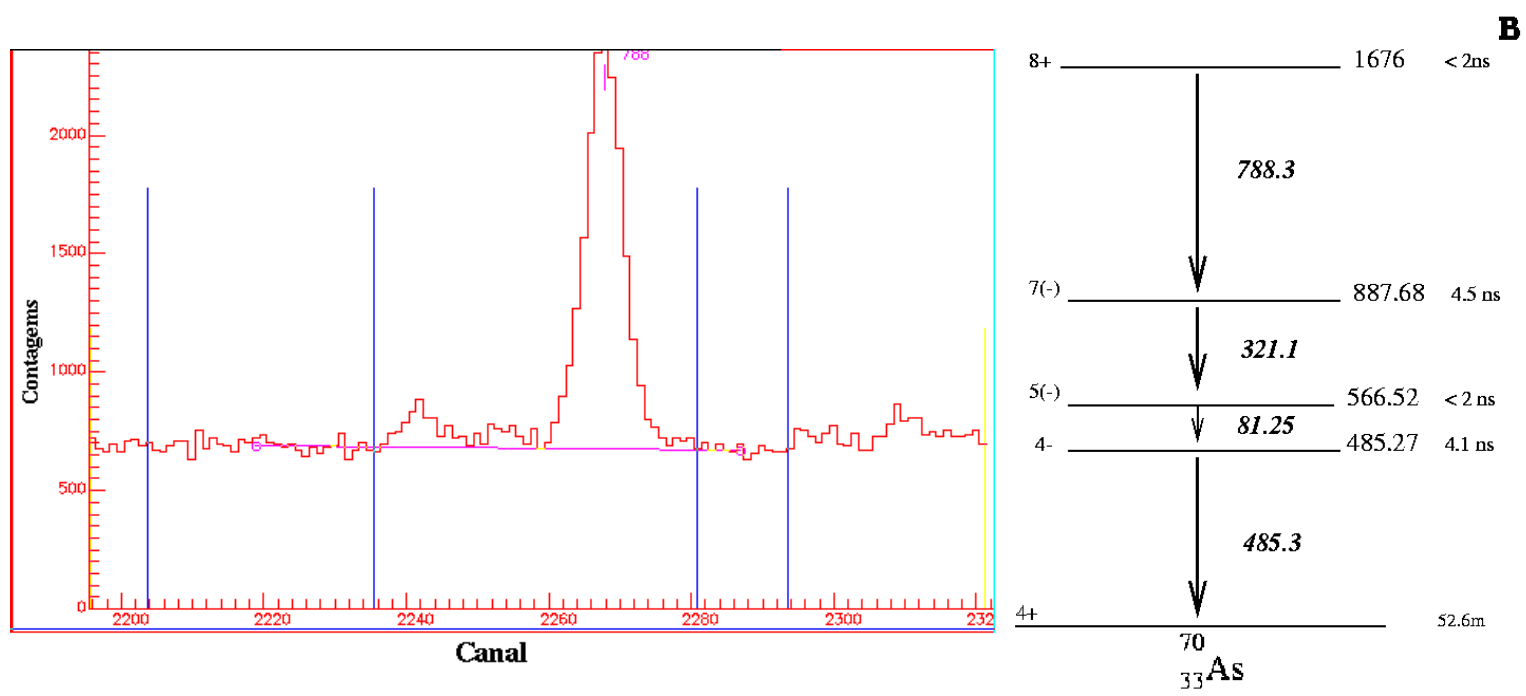

Figura 5.6: Esquma de níveis do pico de $788 \mathrm{keV}$ da transição gama do ${ }^{70} A s$, que também é formado na reação .

considerável flutuação do fundo em torno do pico, o que nos obrigou a adotar uma sistemática, na qual todos os picos são analisados usando as mesmas regiões para marcar o fundo e os limites de integração da área do pico.

Em seguida apresentamos na tabela 5.2 os resultados das medidas de anisotropia normalizada em função da temperatura do alvo.

\begin{tabular}{ccc}
\hline \hline Temperatura $($ K $)$ & Anis. $=\frac{N_{398}\left(0^{\circ}\right) / N_{788}\left(0^{\circ}\right)}{N_{399}\left(0^{\circ}\right) / N_{78}\left(90^{\circ}\right)}$ & erro \\
\hline 100 & 0.477 & 0,006 \\
150 & 0.462 & 0,012 \\
175 & 0.486 & 0,008 \\
200 & 0.493 & 0,007 \\
220 & 0.509 & 0,010 \\
240 & 0.522 & 0,008 \\
260 & 0.523 & 0,006 \\
280 & 0.526 & 0,010 \\
300 & 0.521 & 0,007 \\
\hline \hline
\end{tabular}

Tabela 5.2: Tabela de resultados experimentais da anisotropia e do seu erro em função da temperatura. 


\section{Capítulo 6}

\section{Análise e interpretação dos resultados}

\subsection{Anisotropia X Temperatura}

O resultado da análise descrita no capítulo anterior nos fornece a variação da anisotropia da radiação $\gamma$ proveniente do decaimento de estado isomérico de $398 \mathrm{keV}$ do ${ }^{69} \mathrm{Ge}$, em função da temperatura (figura 6.1). Os valores para cada temperatura representam uma média ponderada das várias medidas feitas naquela temperatura.

Podemos perceber que entre $250 \mathrm{~K}$ e $300 \mathrm{~K}$, nenhuma variação considerável da anisotropia acontece. Essa variação só é detectada a partir de $240 \mathrm{~K}$ e a anisotropia vai decrescendo até temperaturas em torno de 150K. Isto indica, à principio, que o desacoplamento das interações só tem início a partir de um valor de campo magnético alcançado à $240 \mathrm{~K}$.

No entanto, o grupo do Prof. Coussemente realizou esta mesma experiência, usando os ímãs supercondutores. Eles fixaram a temperatura do Gd hospedeiro em 450K (bem acima da temperatura de Curie $T_{C}=289 \mathrm{~K}$ ), para garantir que o campo magnético hiperfino do Gd fosse nulo, e determinaram a variação da anisotropia em função do campo magnético aplicado externamente. O resultado da experiência está na figura 6.2.

Podemos perceber nesta figura que a faixa de variação total de anisotropia é a mesma ( 10\% à 12\%). No entanto, na experiência do grupo de Leuven, com valores de campo magnético de apenas 1 Tesla, já inicia a variação da anisotropia, e que vai se estendendo até cerca de 4 Tesla. Isto indica que a interação entre campo magnético e elétrico começa a ser desacoplada com apenas 1 Tesla. 


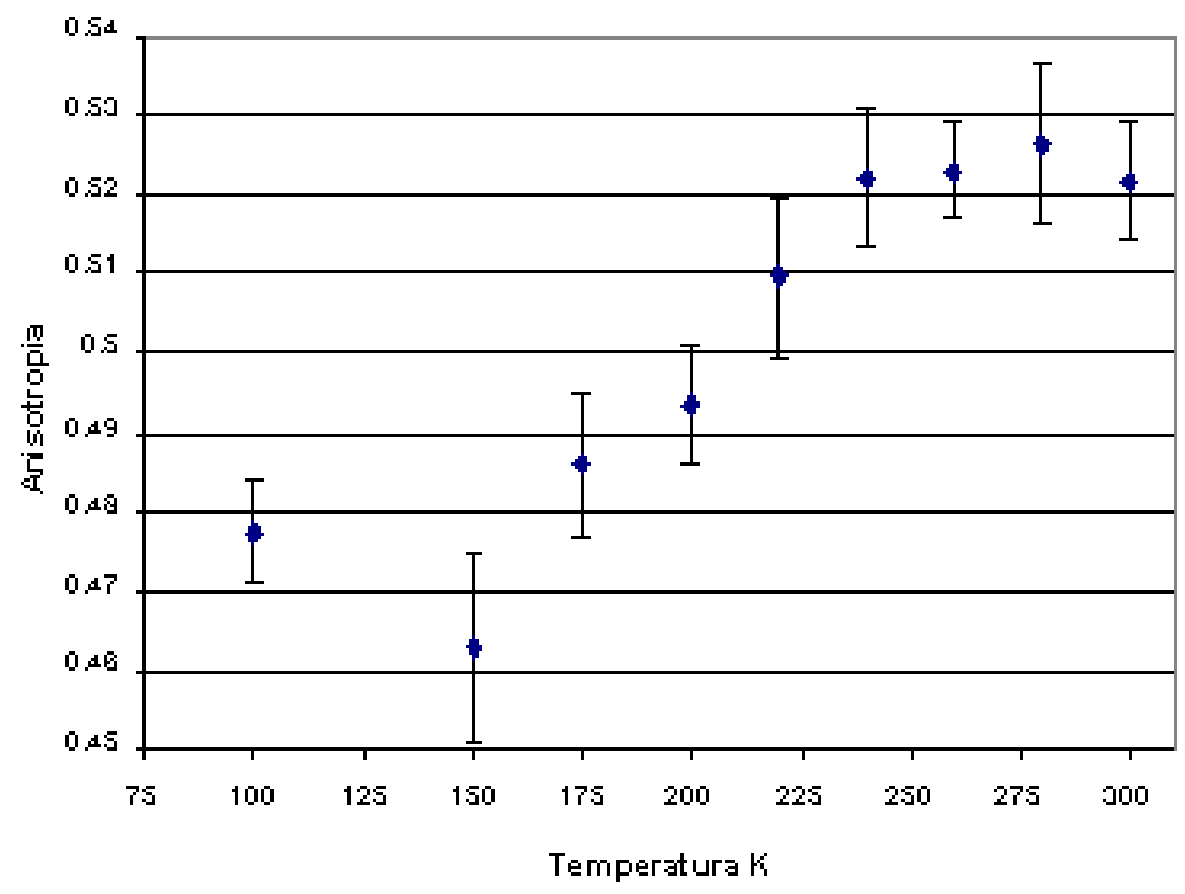

Figura 6.1: Variação da anisotropia $\mathrm{N}\left(0^{\circ}\right) / \mathrm{N}\left(90^{\circ}\right)$ em função da temperatura. O resultado aqui representa médias ponderadas de vários pontos medidos para cada temperatura.

\subsection{Comparação de resultados}

Podemos comparar o resultado de Leuven em função do campo magnético externo com o que foi obtido por nós em função da temperatura. De acordo com a curva da magnetização em função da temperatura (figura 3.1), cerca de 50\% da magnetização do Gd acontece à temperaturas em torno de 250K. Se o campo magnético hiperfino varia de forma linear com a magnetização, espera-se que campo magnético hiperfino também cresca rapidamente nessa região e consequentemente uma grande variação da anisotropia deve acontecer entre $300 \mathrm{~K}$ e $250 \mathrm{~K}$. No entanto nossos resultados não confirmam isto. Na figura 6.1 vemos que a anisotropia tem sua variação entre $150 \mathrm{~K}$ e $250 \mathrm{~K}$.

Um hipótese que foi levantada inicialmente era de um aquecimento local provocado pelo feixe incidente. No entanto, para minimizar um possível aquecimento e melhorar o contato térmico entre o alvo $(\mathrm{Fe}+\mathrm{Gd}+\mathrm{Cu})$ e o porta-alvo de cobre, evaporamos 


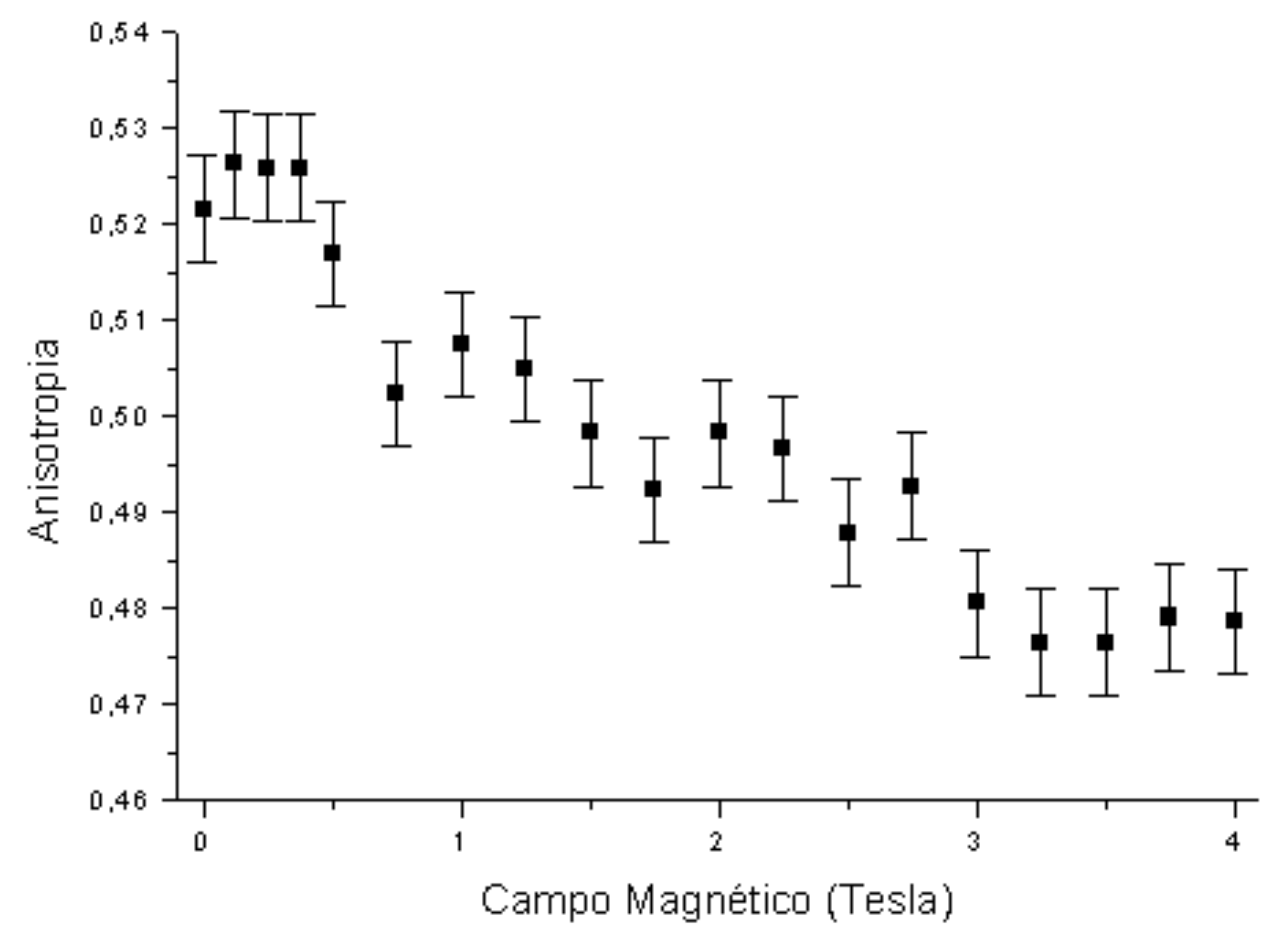

Figura 6.2: Anisotropia em função de campo magnético externo, usando uma temperatura fixa à 450K. Dados do grupo de Leuven [3]

uma camada grossa $\left(3.4 \mathrm{mg} / \mathrm{cm}^{2}\right)$ de $\mathrm{Cu}$ atrás do alvo (diretamente sobre o $\mathrm{Gd}$ ). Simulações feitas do aquecimento provocado pelo feixe incidente descartaram a hipótese do aquecimento local, uma vez que a intensidade do feixe era muito baixa $(\sim 1 \mathrm{nA})$.

É importante lembrar que com a técnica LEMS a anisotropia é sensível à razão das interações magnética e elétrica, ou seja, à razão $\omega_{B} / \omega_{Q}$.

Se consideramos que $\omega_{Q}$, ou seja, que o gradiente de campo elétrico tem um valor constante e independente da temperatura e dado apenas pela distribuição de cargas do cristal, ele será o mesmo nas nossas medidas $(100 \leq \mathrm{T} \leq 300 \mathrm{~K})$ e nas medidas de Leuven $(\mathrm{T}=450 \mathrm{~K}$ ). Neste caso a variação da anisotropia em função do campo externo B (Fig. 6.2) ou em função da temperatura (Fig. 6.1) permite correlacionar B com temperatura.

Podemos construir uma curva de campo magnético $B$ em função da temperatura $T$, e comparando com a curva de magnetização $\mathrm{M}(\mathrm{T})$, verificar uma dependência não linear da magnetização com o campo magnético (ver figura 6.5). 


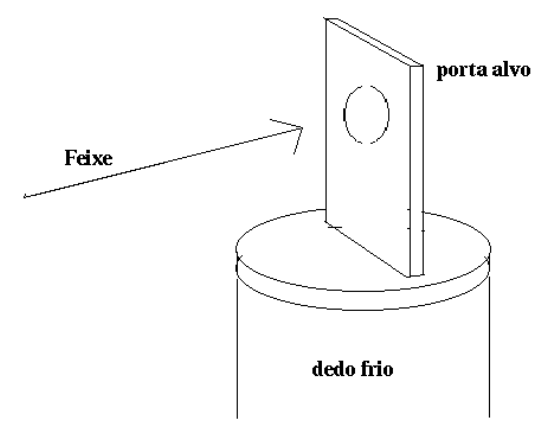

Figura 6.3: Aspecto do porta alvos usado.

Esse tipo de interpretação abre caminho para um possível campo magnético hiperfino que tem comportamento "anômalo" em função da temperatura. Ha vários desse tipo que podem ser encontrados na literatura [42].

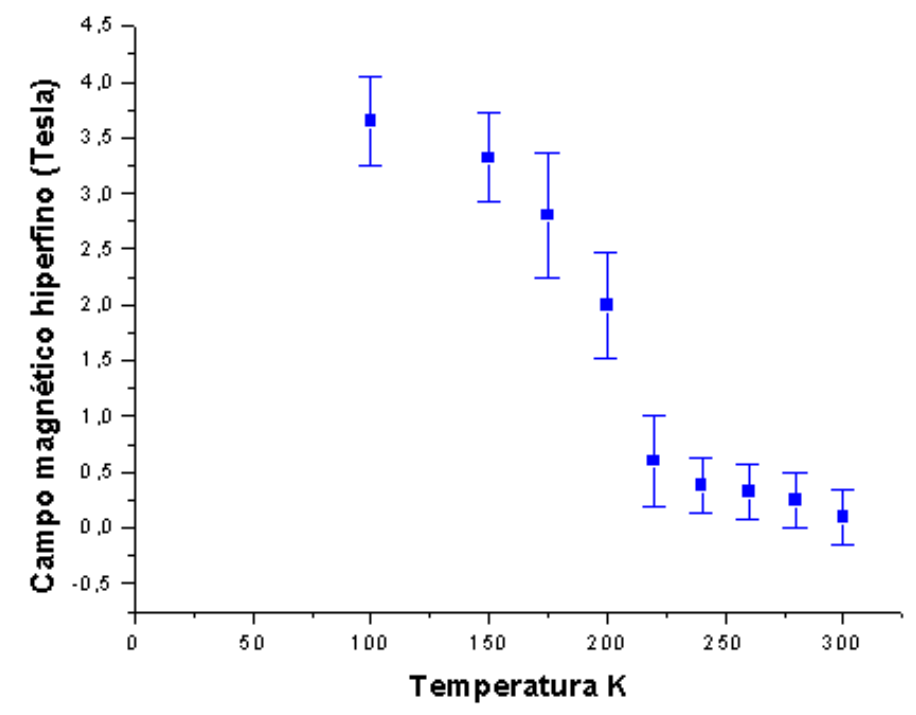

Figura 6.4: Gráfico de campo magnético hiperfino do Gd em função da temperatura.

\subsection{Campo hiperfino anômalo em Gd}

Recentemente, observaram-se campos magnéticos hiperfinos com comportamento anômalo em função da temperatura. Esses casos vêm sendo objetos de muito estudo, uma vez que 


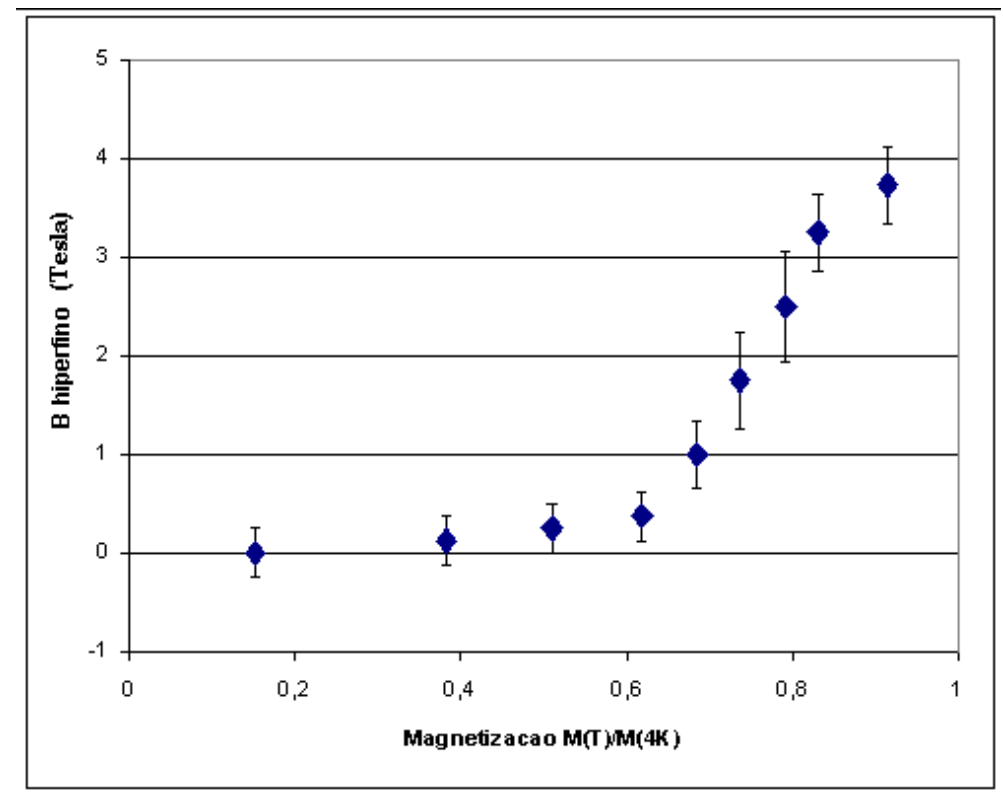

Figura 6.5: Comportamento do campo magnético em função da magnetização considerando a interação elétrica constante. Essa figura é obtida comparando o resultado da anisotropia em função da temperatura com a anisotropia em função de campo magnético externo.

as várias técnicas usam esses campos para extrair informações nucleares. Forker et al. [42] observa que essas anomalias trazem algumas dúvidas, como de que impurezas implantadas em terras raras (Gd), possam ser consideradas como impurezas diluídas em posições substitucionais. No caso de ${ }^{188} \mathrm{Os}$ em Gd [44], ${ }^{99} \mathrm{Ru} \mathrm{em} \mathrm{Gd}[45] \mathrm{e}{ }^{57} \mathrm{Fe}$ em $\mathrm{Tb}$ [46], o campo magnético hiperfino decresce abruptamente à temperaturas bem abaixo da temperatura de Curie do hospedeiro. Isto está ilustrado na figura 6.6 para ${ }^{188} \mathrm{Os}$ em Gd. Por outra lado, outras impurezas, como Cd apresentam um comportamento normal do campo hiperfino em Gd.

Vários modelos foram propostos para dar uma explicação a essa anomalia. O modelo de Jaccarino et al. [47], considera a polarização do caroço por um momento local como a única fonte para o campo hiperfino. Esse tratamento foi estendido por Low [48] para incluir os eletrons de condução. Nesses modelos, a dependência anômala da temperatura com o campo hiperfino surge se o acoplamento do momento da impureza com o hospedeiro é mais fraco do que o acoplamento "hospedeiro-hospedeiro". No modelo de Campbell [49], a anomalia reflete a transição de um momento bem localizado para um momento mal localizado. 


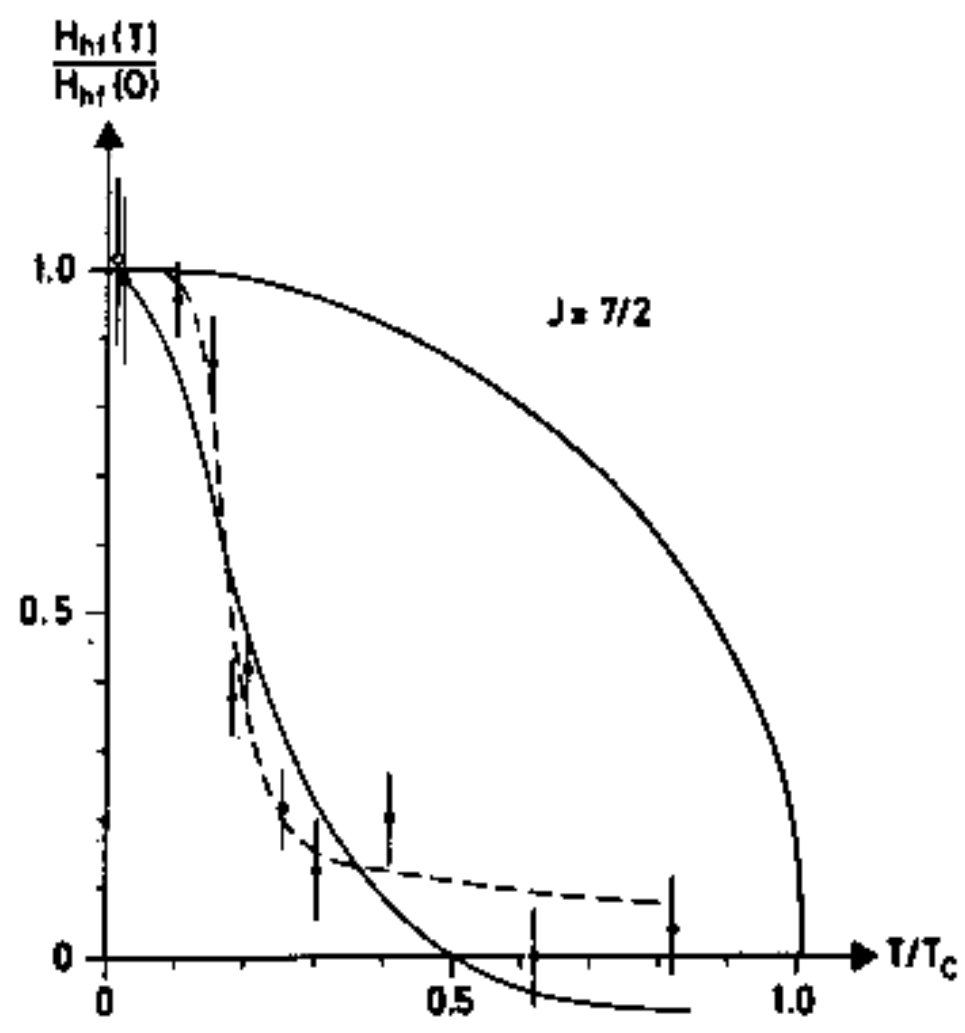

Figura 6.6: Dependência do campo magnético hiperfino em função da temperatura para Os em Gd [44]. A curva exterior é a magnetização e as linhas cheia e tracejada representam ajustes de modelos para os pontos experimentais.

Todos esses modelos são capazes de descrever um rápido decréscimo do campo hiperfino, mas não uma queda tão rápida como nos casos mencionados acima. Existem muitas explicações para os colapsos observados do campo hiperfino: Formação de um composto intermetálico em escala microscópica e que tenha uma temperatura de Curie mais baixa; mudanças da magnetização local devido à forte relaxação da rede cristalina em torno das impurezas, que são muito menores do que o volume disponível no hospedeiro, etc. No entanto, é importante lembrar que nenhuma dessas explicações foram verificadas por completo [42].

Se o campo magnético hiperfino do Gd realmente possui um comportamento anômalo, isto implica que o Gd pode não ser um bom material hospedeiro para usar na técnica LEMS. No entanto, a dependência do campo magnético hiperfino com a temperatura pode ser verificada usando a técnica TDPAD (Time Dependent Perturbed Angular Distribution). 
Fizemos ainda uma outra análise do resultado de anisotropia em função da temperatura, focando um outro ponto de vista.

\subsection{Duas frequências quadrupolares}

Como já foi mencionado anteriormente, a localização do íon implantado é um ponto importante. Ele pode ocupar uma posição substitucional ou intersticial. No nosso caso, supomos que o Ge permanece preferencialmente numa posição substitucional. Nessa posição, o Ge está na presença de um gradiente de campo elétrico bem determinado pela distribuição de cargas do Gd.

No entanto, quando a implantação é feita a temperaturas onde os defeitos se locomovem, é preciso levar em conta a probabilidade do átomo implantado (Ge) se associar com um defeito [20].

Como no caso de LEMS a anisotropia é dependente da razão $\omega_{B} / \omega_{Q}$, e a existência de defeitos na região da impureza pode induzir a um outro gradiente de campo elétrico, resultando numa outra frequência de Larmor elétrica.

O grupo de Leuven desenvolveu um programa que simula a variação da anisotropia em função do campo magnético, sendo possível inserir dois gradientes de campo elétrico distintos, com suas frações de participação .

O resultado do cálculo pode ser comparado com os dados experimentais. Podemos ver que a simulação ajusta bem os dados quando admitimos duas frequências diferentes: 45 MHz e 5 MHz. Também a fração das duas deve ficar em torno de $70 \%$ e 30\%, respectivamente (ver figura 6.7). Na figura tembém incluimos resultados dos cálculos, variando as frações respectivas entre $0 \%$ e $100 \%$.

Essa simulação indica um gradiente de campo elétrico mais intenso ( $\left.\omega_{Q}=45 \mathrm{MHz}\right)$, à qual $70 \%$ da amostra é submetida, e que deve ser o intrinseco (devido à estrutura cristalina do Gd) sentido pelo Ge em posição substitucional. A outra fração menor, sente um gradiente de campo elétrico menor $\left(\omega_{Q}=5 \mathrm{MHz}\right)$ e provavelmente é devido a defeitos próximos ao sitio onde a impureza está localizada.

Para as frequências envolvidas determinamos o valor absoluto do gradiente de campo elétrico usando: 


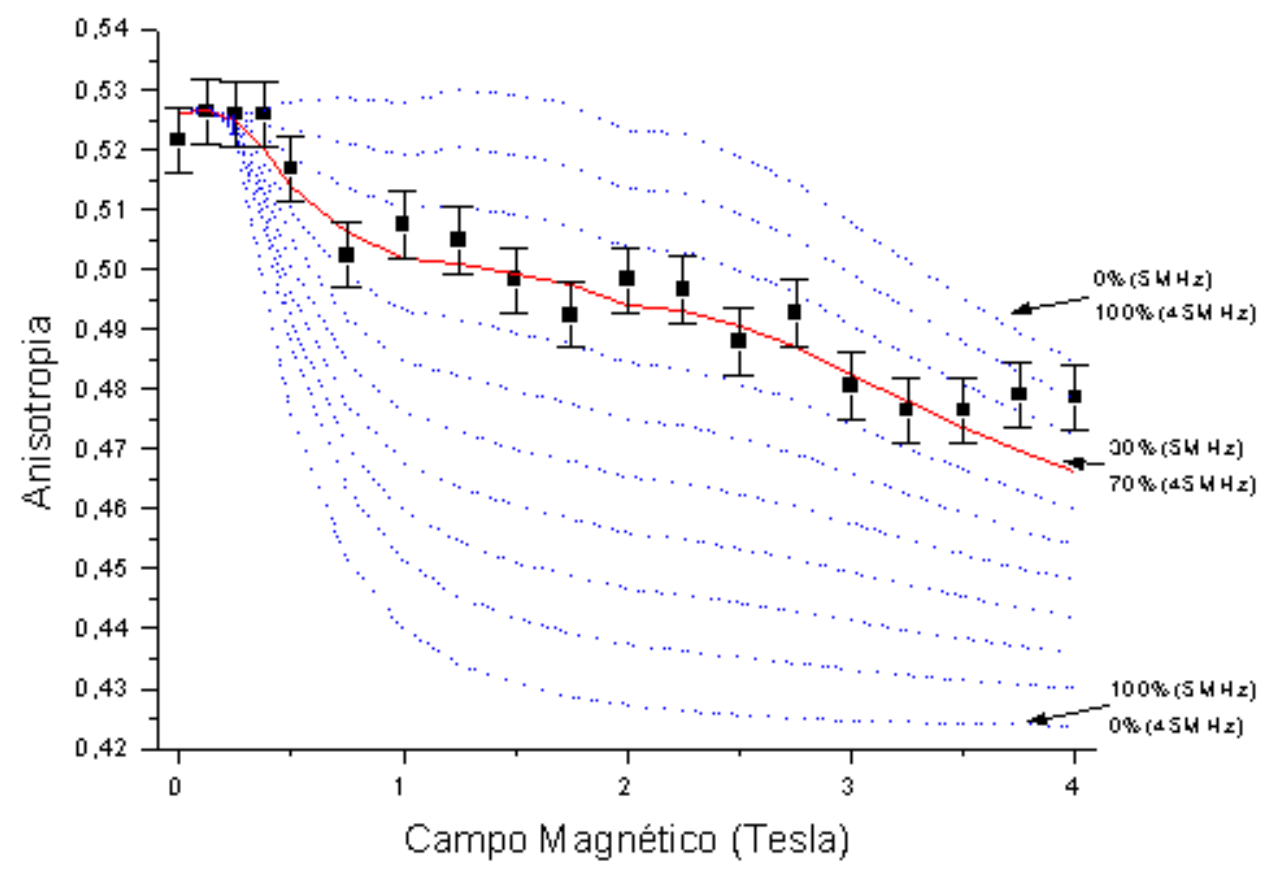

Figura 6.7: Ajuste da anisotropia em função do campo magnético para várias frações entre as duas frequências quadrupolares.

$$
\nu_{Q}=\frac{e Q V_{z z}}{\hbar}
$$

O resultado encontrado foi:

$$
\begin{aligned}
V_{z z}(45 M H z) & =(1.9 \pm 0.6) \times 10^{17} \mathrm{~V} / \mathrm{cm}^{2} \\
V_{z z}(5 M H z) & =(0.23 \pm 0.07) \times 10^{17} \mathrm{~V} / \mathrm{cm}^{2}
\end{aligned}
$$

\subsection{Interações quadrupolares dependentes de tempe- ratura}

O grande número de experimentos de interações quadrupolares encontrados na literatura, serviram para estudar também a dependência do gradiente de campo elétrico com a temperatura (ver figura 6.9). Para metais que não sejam cúbicos, ele segue a relação : 


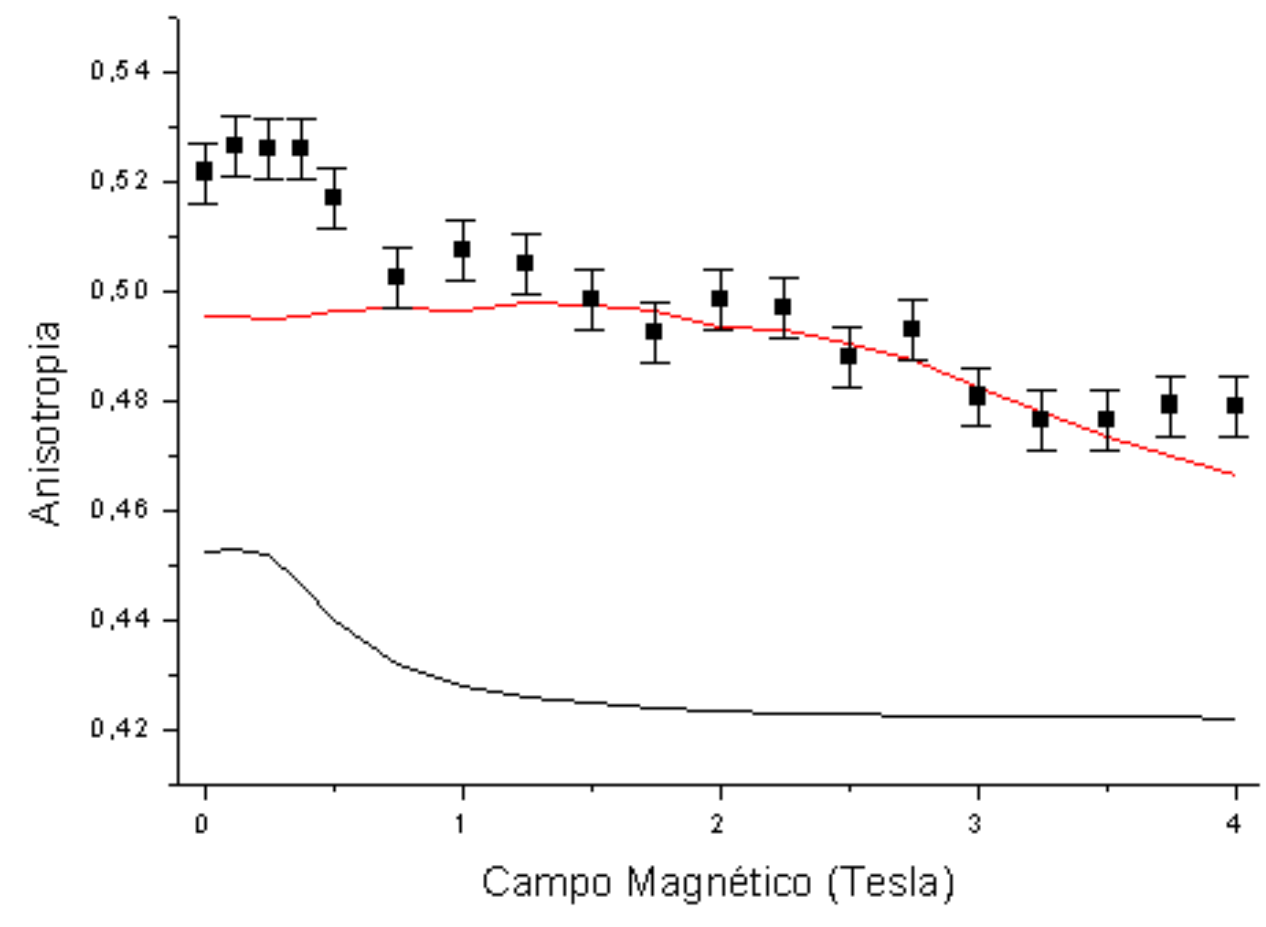

Figura 6.8: Ajuste da anisotropia em função do campo magnético onde vemos a contribuição de cada um das frequências quadrupolares.

$$
V_{z z}(T)=V_{z z}(0)\left(1-B T^{3 / 2}\right)
$$

onde B é uma constante positiva específica do sistema impureza-hospedeiro [50].

Esse comportamento não pode ser entendido como efeitos da expansão da rede cristalina [51]. Em geral, os elementos de terras raras não satisfazem completamente a dependencia $T^{3 / 2}$. Para todas as impurezas implantadas em Gd até recentemente, desvios da relação $T^{3 / 2}$ foram observados [42].

\subsection{Desacoplamento das interações}

Um ponto interessante a se notar na figura 6.7 é que a variação da anisotropia só é bem reproduzida quando supomos a presença das duas frequências distintas. Além disso, como essas frequências são bem diferentes, elas atuam sobre a anisotropia em regiões de 


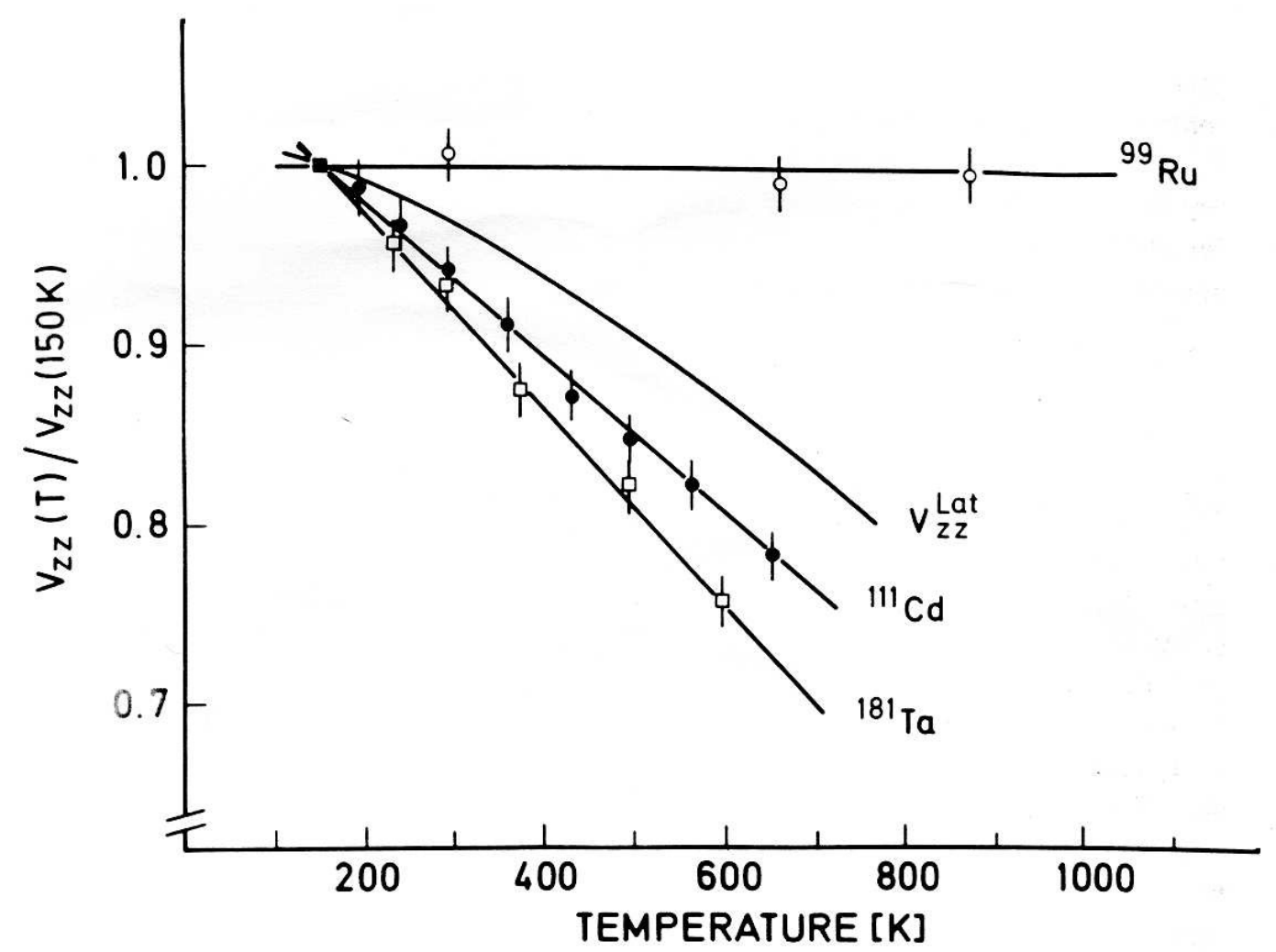

Figura 6.9: Dependência do gradiente de campo elétrico com a temperatura para as impurezas de ${ }^{99} R u$, ${ }^{111} \mathrm{Cd}$ e ${ }^{181} \mathrm{Ta}$ em Ho.

campo magnético diferentes.

Podemos entender isso da seguinte forma: para baixos campos magnéticos ( $\mathrm{B} \leq 1$ Tesla), o campo magnético é suficientemente intenso para desacoplar a interação com o gradiente de campo elétrico menor devido a defeitos. E à medida que o campo magnético vai aumentando, também a interação devido ao gradiente de campo elétrico intrinseco e maior acaba desacoplando.

Vamos então fazer uma segunda hipótese simplificadora, onde vamos supor as duas frequências quadrupolares diferentes agindo separadamente uma de cada vez e que os gradientes de campo elétrico podem depender da temperatura. Assim os gradientes de campo determinados na experiência de Leuven (fig. 6.7 e 6.8) a $\mathrm{T}=450 \mathrm{~K}$, não são os mesmos que nas medidas de São Paulo, entre 100 e 300 K. A baixas temperaturas os gradientes de campo elétrico são bem mais intensos, podendo supor a variação com $T^{3 / 2}$.

A anisotropia depende de $\omega_{B} / \omega_{Q}$, porém com a hipótese de que $\omega_{Q}(T)$, as frequências 
determinadas na experiência de Leuven são os valores de $\omega_{Q}(450 \mathrm{~K})$. Nas medidas de São Paulo, com $100 \leq \mathrm{T} \leq 300 \mathrm{~K}$, essas frequências podem ser mais altas.

Podemos calcular $\omega_{B} / \omega_{Q}$ vs. anisotropia dos dados de Leuven e determinar $\omega_{B}(T) / \omega_{Q}(T)$ a partir da comparação dos dados de Leuven com os nossos dados. Anisotropias iguais correspondem a $\omega_{B} / \omega_{Q}$ iguais.

\begin{tabular}{ccccc}
\hline \hline Campo Magnético (Tesla) & $V_{z z}(450 \mathrm{~K})\left(\mathrm{V} / \mathrm{cm}^{2}\right)$ & $\omega_{B} / \omega_{Q}$ & Anisotropia & Temp. $K$ \\
\hline 0 & 0,23 & 0 & 0,5262 & 300 \\
0,126 & 0,23 & 0,268 & 0,5266 & 280 \\
0,25 & 0,23 & 0,533 & 0,5247 & 260 \\
0,38 & 0,23 & 0,809 & 0,5199 & 240 \\
0,5 & 0,23 & 1,06 & 0,5142 & 230 \\
0,87 & 0,23 & 1,85 & 0,5040 & 210 \\
\hline 1,5 & 1,9 & 0,3551 & 0,4992 & 205 \\
2 & 1,9 & 0,473 & 0,494 & 200 \\
2,5 & 1,9 & 0,592 & 0,4904 & 175 \\
3 & 1,9 & 0,71 & 0,4824 & 165 \\
3,5 & 1,9 & 0,828 & 0,4736 & 150 \\
4 & 1,9 & 0,947 & 0,4662 & 100 \\
\hline \hline
\end{tabular}

Tabela 6.1: Tabela com os valores usados na comparação dos dados de Leuven e São Paulo.

Com estas hipóteses podemos entender, por exemplo, por que a anisotropia varía tão pouco entre 300 e $220 \mathrm{~K}$, sem precisar supor que o campo magnético hiperfino tem um comportamento anômalo com a temperatura. Se nesta faixa de temperatura $\omega_{B}$ e $\omega_{Q}$ variam rapidamente (com T), sua razão pode variar lentamente acarretando uma variação lenta na anisotropia.

Vamos tentar ajustar a variação $\omega_{B}(T) / \omega_{Q}(T)$ por nós determinado (na tabela 6.1) nas 2 faixas de temperaturas ( $300 \mathrm{~K}$ até $220 \mathrm{~K}$ e $220 \mathrm{~K}$ até $100 \mathrm{~K}$ ).

Dividimos a variação da anisotropia em duas regiões diferentes: a temperaturas entre $100 \mathrm{~K}$ e $210 \mathrm{~K}$, que corresponde a uma mesma variação de anisotropia que para valores de campo magnético entre 1 a 4 Tesla $(\mathrm{T}=450 \mathrm{~K})$ e gradiente de campo elétrico mais intenso. Da mesma forma, a região de $210 \mathrm{~K}$ a $300 \mathrm{~K}$, corresponde a uma região de campo entre 0 e 1 Tesla $(\mathrm{T}=450 \mathrm{~K})$ onde a interação elétrica é mais fraca.

Para a região entre 100 e $200 \mathrm{~K}$, ajustamos os pontos experimentais $\omega_{B}(T) / \omega_{Q}(T)$ 
considerando uma função em que $\omega_{B}$ varia com uma função $T^{3 / 2}$, semelhantemente com uma variação proporcional à magnetização (ver figura 6.10) e supondo que a interação quadrupolar elétrica permanece constante com T.

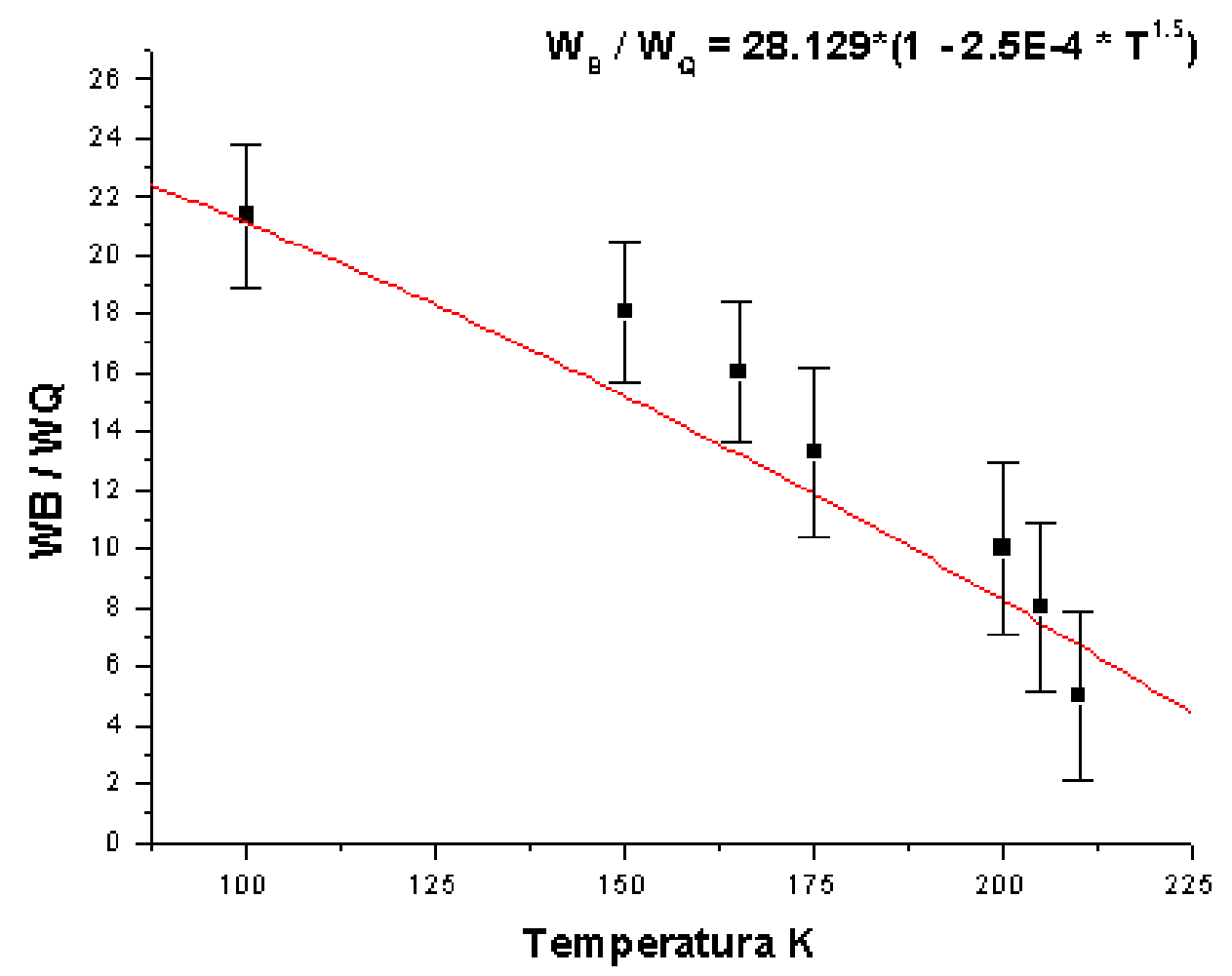

Figura 6.10: Ajuste dos dados experimentais de $\omega_{B} / \omega_{Q}$ para temperaturas entre $100 \mathrm{~K}$ e $210 \mathrm{~K}$, mantendo $\omega_{Q}$ constante.

Para ajustar os dados experimentais de $\omega_{B}(T) / \omega_{Q}(T)$ na região entre $220 \mathrm{~K}$ e $300 \mathrm{~K}$, supomos uma variação $\omega_{B}$ que segue de perto a curva da magnetização e uma variação do gradiente de campo elétrico com a temperatura, que segue de perto a relação usual $\left(T^{3 / 2}\right)\left(V_{z z}\right.$ mais baixo).

Na figura 6.11 podemos ver que o ajuste de $\omega_{B}(T) / \omega_{Q}(T)$ por uma função que descreve a razão das interações $\omega_{B} / \omega_{Q}$, com $\omega_{B}$ ajustando a curva à magnetização e $\omega_{Q}$ corresponde a uma variação da ordem de $T^{1.48}$.

Para ajustar a função devemos lembrar de alguns parâmetros importantes:

- Fizemos a hipótese de que o campo magnético hiperfino em principio é linear com 


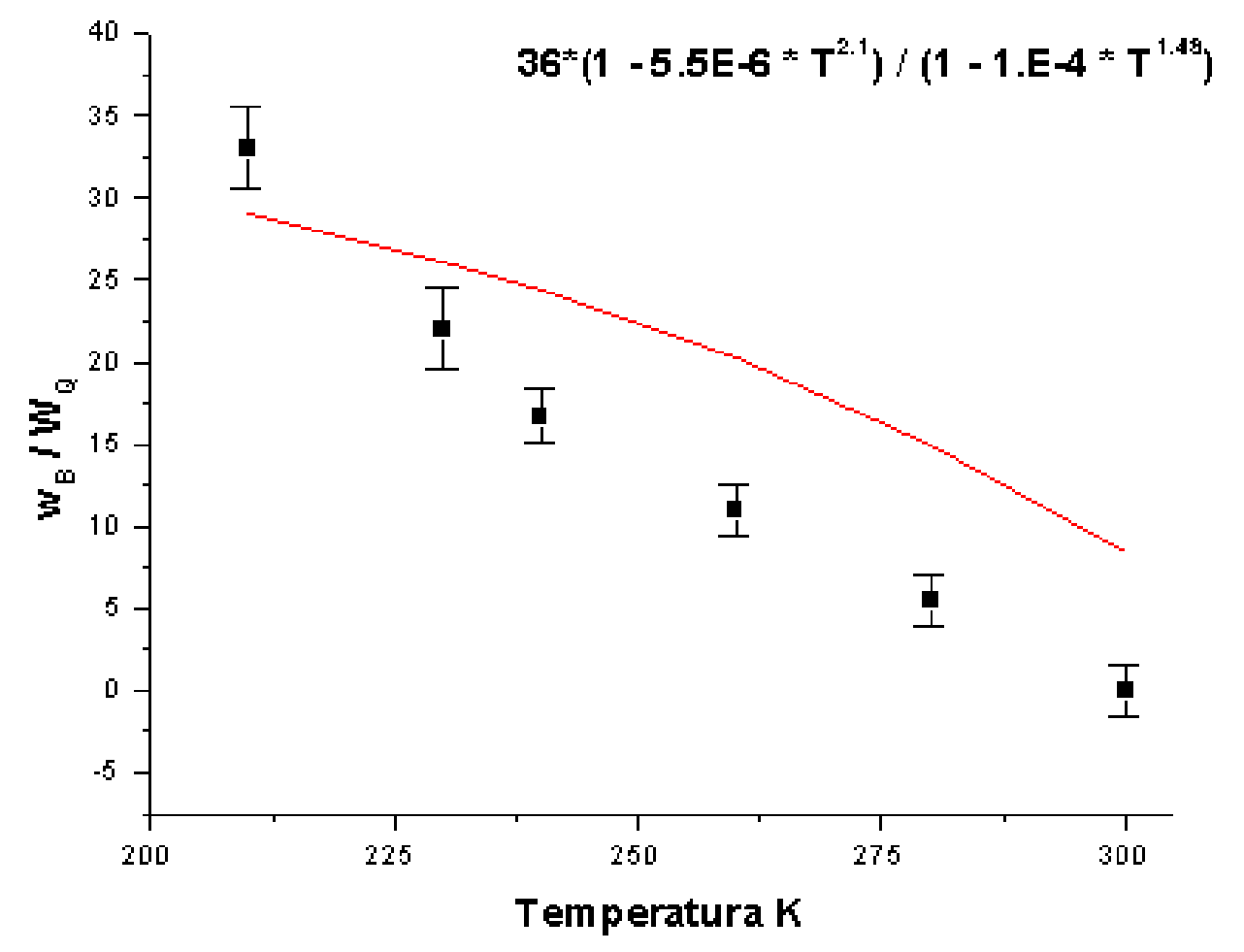

Figura 6.11: Ajuste dos dados experimentais de $\omega_{B} / \omega_{Q}$ para temperaturas entre $210 \mathrm{~K}$ e $300 \mathrm{~K}$. È necessrio impor uma variação para $\omega_{Q}$, para obter um ajuste razoável.

a magnetização. Para tal, $\omega_{B}(T)$ deve seguir o comportamento da curva da magnetização $M(T)$.

- As frequências quadrupolares obtidas da curva da anisotropia em função do campo magnético foram feitas à uma temperatura de $450 \mathrm{~K}$. Portanto, os valores das frequências quadrupolares (constantes ou dependentes da temparatura) devem tender aos mesmos valores obtidos na medida para essa temperatura.

A partir desses dados é possível extrair uma relação entre o campo magnético hiperfino (proveniente de $\omega_{B}$ ) em função da temperatura (figura 6.12). Se comparamos com a magnetização obtemos uma figura de $\mathrm{M}(\mathrm{T})$ em função de $\mathrm{B}(\mathrm{M})$ (ver figura 6.13). Nesta curva, temos uma descontinuidade entre os dois comportamentos. Isto se deve ao fato de que tratamos o problema dividindo a curva de anisotropia em duas partes, uma para cada frequência. 


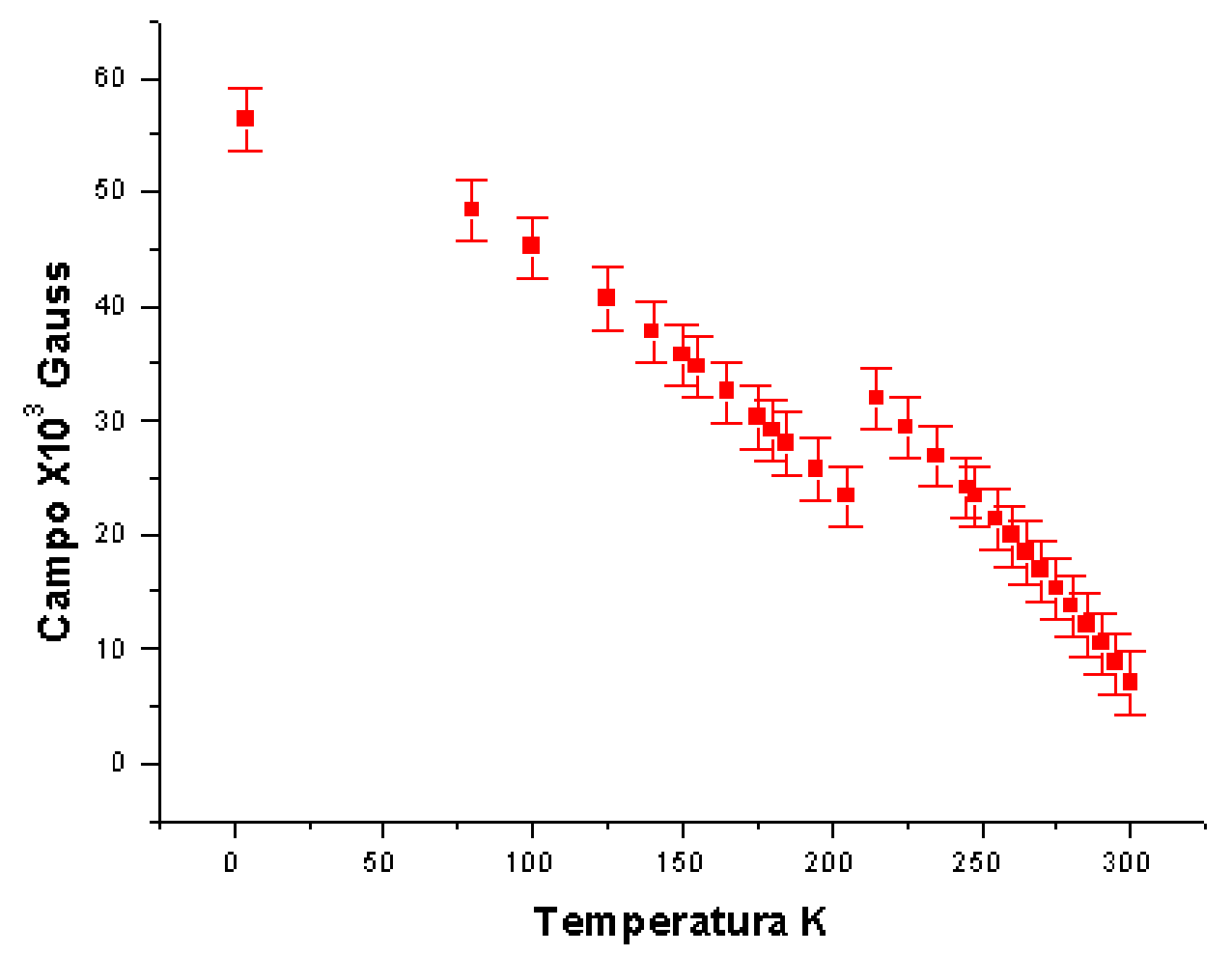

Figura 6.12: Comportamento do campo magnético hiperfino em função da temperatura. A descontinuidade é devido a separação dos dados em dois grupos de frequências distintas.

$\mathrm{Na}$ verdade o que acontece é que a anisotropia é provocada por uma mistura dessas frequências e não é totalmente correto a separação em dois regimes independentes. No entanto, para uma primeira aproximação, esse resultado mostra que é possível explicar, o comportamento da anisotropia em função da temperatura sem recorrer a um campo hiperfino anômalo, bastando levar em conta a variação do gradiente de campo elétrico com a temperatura.

Os valores de campo magnético para a figura 6.13 provêm de ajustes que certamente tem ambiguidades e não predizem o valor real com precisão. 


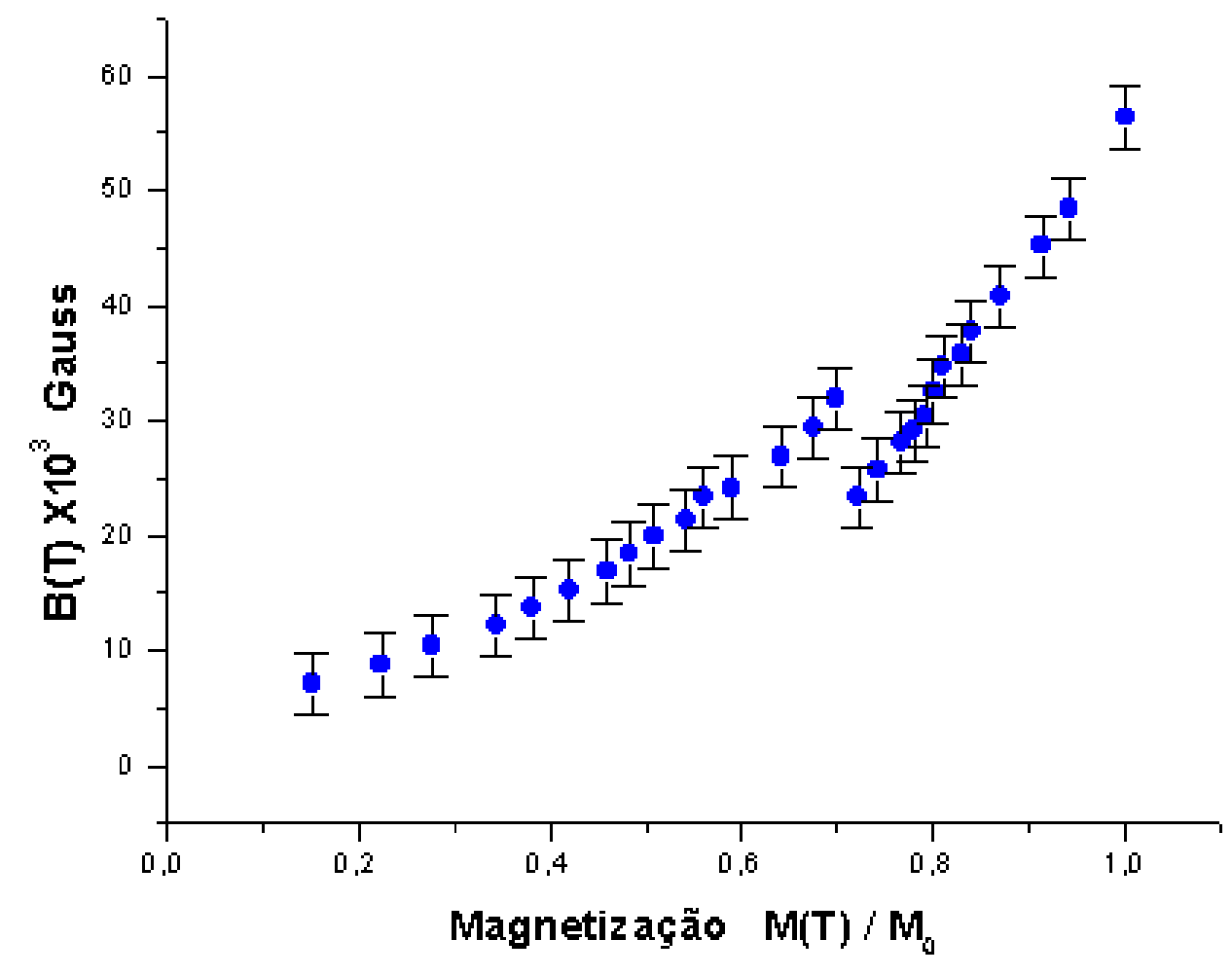

Figura 6.13: Comportamento do campo magnético hiperfino em função da magnetização . 


\section{Capítulo 7}

\section{Conclusão e perspectivas}

Neste trabalho, adaptamos o método de Espectroscopia de Mistura de Níveis (LEMS) no Laboratório Pelletron, usando como caso teste o núcleo ${ }^{69} \mathrm{Ge}$, que possui suas propriedades nucleares bem conhecidas.

Este método permite medir momentos de quadrupolo nucleares de vida média muito longa (50 ns a 100ms) ou de alto spin, caracteristicas não alcançadas por outros métodos como TDPAD (Time Dependent Perturbed Angular Distribution).

Produzimos o núcleo ${ }^{69} \mathrm{Ge}$ no estado isomérico de $398 \mathrm{keV}$ e $\tau=2.8 \mu$ s através da reação ${ }^{56} \mathrm{Fe}\left({ }^{16} \mathrm{O}, 2 p n\right){ }^{69} \mathrm{Ge}$ à $53 \mathrm{MeV}$, implantamos em um policristal de Gd e o submetemos à interação hiperfina magnética e elétrica estática simultâneamente. O resultado da perturbação foi observado por uma medida integrada no tempo da distribuição angular da radiação emitida no decaimento do isômero. A orientação inicial foi dada pela reação nuclear.

A perturbação do estado isomérico foi dada por um interação magnética produzida pelo campo magnético hiperfino do Gd, e uma interação quadrupolar produzida pelo gradiente de campo elétrico devido a assimetria na distribuição de cargas do $\mathrm{Gd}$, no qual o ${ }^{69} \mathrm{Ge}$ foi implantado. A variação da interação magnética necessária ao método, foi conseguida pela variação da temperatura do Gadolínio.

Comparamos nossas medidas da anisotropia em função da temperatura com medidas da variação da anisotropia em função de um campo magnético externo, feita pelo grupo de Leuven. Como a variação da anisotropia é função da razão das interações $\omega_{B} / \omega_{Q}$, podemos comparar as anisotropias dos dois experimentos (Leuven e São Paulo) e obter resultados sobre $\omega_{B}(T) / \omega_{Q}(T)$. 
As duas análises feitas nesse trabalho levam a interpretações diferentes. Primeiro, se o campo magnético hiperfino do Gd for anômalo e não linear à magnetização $\mathrm{M}(\mathrm{T})$, isto significa que ele não é um bom material hospedeiro para fazer medidas de momentos de quadrupolos nucleares. Entretanto, como parte do nosso projeto de doutoramento vamos fazer uma medida direta do campo hiperfino usando o método TDPAD. Para não estar sujeito à interação elétrica, vamos usar um monocristal de Gd, onde o eixo de simetria do gradiente de campo elétrico pode ser alinhado com a direção do campo magnético externo.

No que se refere à segunda interpretação, supomos que o campo magnético varia linearmente com a magnetização (campo não anômalo), e explicamos os altos campos magnéticos necessários para desacoplar as interações na medida em função da temperatura como sendo provocado por uma variação do gradiente de campo elétrico em função da temperatura. É claro que essas interpretações são simplificadas e apresentam ambiguidades. Mas elas abrem novos caminhos para o uso do método LEMS

Outra medida possível é um monocristal de Gd sem nenhum campo magnético aplicado e através do método TDPAD medir $\omega_{Q}$ em função da temperatura e determinar a variação do gradiente de campo elétrico. Uma vez conhecida essa dependência, podemos usar o método LEMS (que nos fornece a razão das interações $\omega_{B} / \omega_{Q}$ ) e extrair as propriedades da interação magnética ( $\mathrm{B}_{\text {hyp }}$ em função da temperatura).

Uma câmara maior deverá ser construída para suportar a instalação de mais um sistema de leitura de temperatura, pois um aquecimento local do alvo resultaria numa interpretação errada das medidas usando a técnica LEMS. Para tanto, vamos soldar um termopar tipo Cromel-Alumel diretamente no alvo (na parte traseira do alvo, no próprio Gadolínio) e que servirá de controle para um possível aquecimento local na posição de incidência do feixe.

A perspectiva das medidas acima propostas (TDPAD, uso de monocristal, medida em função de $B_{\text {ext. }}$ (em Leuven)) é estabelecer as variações de $B_{h y p}$ e do gradiente de campo elétrico em função da temperatura separadamente, determinando todas as características dos campos hiperfinos atuando sobre o ${ }^{69} \mathrm{Ge}$ implantado em Gd. O que se pretende verificar com estes estudos é a viabilidade da utilização do "host" de Gd na técnica LEMS. No caso de concluirmos pela viabilidade propomos determinar os momentos de quadrupolo elétricos em vários núcleos, a começar pelo ${ }^{53} \mathrm{Fe}$ e ${ }^{73} \mathrm{As}$, usando os métodos 
acima descritos. Estes núcleos têm várias de suas propriedades nucleares conhecidas (vidas médias, spins, momentos magnéticos, etc.). A vida média do estado isomérico é de $63 n s$ para o ${ }^{53} \mathrm{Fe}$ e $5,7 \mu \mathrm{s}$ para o ${ }^{73} \mathrm{As}$. Eles serão produzidos por meio das reações de fusão-evaporação . 


\section{Bibliografia}

[1] R.Coussement, P.Put, G.Scheveneels e F.Hardeman, Hyp.Int. 23 (1985)273

[2] R.M.Steffen e H.Frauenfelder "Perturbed Angular Correlations" editado por Karlsson, E.Mathias e K.Siegbahn (North-Holland, Pub.Co. 1964).

[3] S.Ternier, Tese de Doutoramento, "Extendind the Aplicability of the Level Mixing Spectroscopy Method", (1998), não publicado.

[4] S.Shibuta, M.Fujika, N.Kawamura, A.Matsumoto, S.Hayashibe, Y.Kimura, R.Coussement, M.Rots, L.Hermans e P.Put, Hyp.Int. 14 (1983)315.

[5] F.Hardeman, G.Scheveneels, G.Neyens, R.Nouwen, G.S'heeren, M.Van Den Bergh e R.Coussement Phys.Rev.C 43 nr 1 (1991)130

[6] W.Pauli, "General Principles of Quantum Mechanics" (Springer-Verlag, Berlin - Heidelberg - New York, 1980).

[7] R.Coussement, P.Put, G.Scheveneels e F.Hardeman, Hyp.Int. 24-26 (1985)1021.

[8] G.Scheveneels, F.Hardeman, G.Neyens e R.Coussement, Hyp.Int. 52 (1989)179.

[9] G.Scheveneels, F.Hardeman, G.Neyens e R.Coussement, Hyp.Int. 52 (1988)257.

[10] G.Scheneveels, Ph.D.Thesis," Toestandsmenginsspectroscopie voor In-bundel Quadrupool-interactiemetingen", (1988), no publicado.

[11] G.Neyens, R. Nouwen, R. Coussement Nuc.Instr. e Methods in Phys. Research A 340 (1994)555.

[12] H.Morinaga, T.Yamazaki "In Beam Gamma-Ray Spectroscopy" North-Holland Publishing Company 1976. 
[13] J.O.Newton, F.S.Stevens, R.M.Diamond, K.Kotajima e E.Mathias, Nucl.Phys. A95 (1967)357.

[14] D.M.Brink e G.R.Satchler em "Angular Momentum" (Clarendon Press, Oxford, 1968).

[15] G. Neyens, Ph.D.Thesis, "Ontwikkeling von een Doelgerichte LEMS-Opstelling en Bepalen van het Quadrupoolmoment van Isomere Teostanden in Radium-Isotopen", (1993).

[16] J.F.Ziegler, J.P.Biersack, U.Littmark, Stopping and Range of Ions in Solids (Pergamon Press, New York, U.S.A, 1985).

[17] R.S. Averback e Mai Ghaly, Nucl. Instr. and Meth. B 127/128(1997)1.

[18] V.V.Kirsanov, Radiat. Eff. 46(1980) 167.

[19] C.Lehmann, Interaction of Radiation with Solids and Elementary Defect Production (North Holland Publisching Company, 1977).

[20] G. Langouche e R. Coussement em Proceedings of the International Conference on the Applications of the Moossbauer Effect, Editado por Y.M.Kagan e I.S.Lyubutin, Gordon and Breach, Vol. 1, (1985) 395.

[21] J.B.Sanders, Radiat. Eff. 51(1980)43.

[22] F.Hardeman, G.Neyens, G.Scheveneels, R.Nouven, G.S'Heeren, M.Van Den Berg, R.Coussement, A.P.Byrne, R.Musseer, H.Hubel e G.Baldsiefen, Phys.Rev. C43(1991)514.

[23] G. Neyens. R.Nouwen, G.S‘Heeren, M.Van Den Berg e R.Coussement, Nucl. Phys. A $555(1993) 629$.

[24] Eisberg e Resnick, Fisica Quântica (Editora Campus 1979)624.

[25] C.Kittel, Introduction to Solid State Physics. (John Wiley and Sons, New York, Chichester, Brisbane, Toronto, 1976). 
[26] D.H.Martin, Magnetism in Solids (Iliffe Books LTD. London, 1967).

[27] R.F.Pearson, Experimental Magnetism (Editado por G.M.Kalvius e R.S.Tebble (John Wiley and Sons, New York, Chichester, Brisbane, Toronto, 1979).

[28] E.P.Wohlfarth em "Ferromagnetic Materials", Vol.1 (North-Holland Publisching Company, 1980.

[29] R.M.Steffen e K.Alder, The Eletromagnetic Interaction in Nuclear Spectroscopy, North Holland Publishing Company, Amsterdam, (1975)583.

[30] P.C.Riedi, Phys.Rev. B15(1977)5197.

[31] S.Legvold, Ferromagnetic Materials (Editado por E.P.Wohlfarth (North Holland Physics Publishing 1986).

[32] H.E.Night, S.Legvold, F.H. Spedding, Phys. Rev. 132(1963)1092.

[33] J.G.Gallant e P.Dmytrenko, Nucl. Instr. and Meth. 200(1982)127.

[34] R.Haroutunian, M.Meyer e R.Coussement, Phys.Rev.C17 (1978)292.

[35] N.Ueta e W.G.P.Engel Confecção de alvos nucleares (1996).

[36] R.V.Ribas - Manual do Sistema SPM-CAMAC para Aquisição de Dados - IFUSP/P812 (1989).

[37] CAMAC Tutorial Papers - Nucl. Sci. NS20 (1973) Num. 2

[38] Germânium Detectors Users Manual (Canberra) 5/95.

[39] N.H.Medina - Tese de doutoramento-IFUSP "Momentos magnéticos de Estados Nucleares do ${ }^{158} T b "(1992) 51$.

[40] R.V.Ribas, Nuclear Physics Department IFUSP - Annual Report (1996)64.

[41] W.T.Milner, Holifield Ion Research Facility Computer Handbook, Oak Ridge National Laboratory, USA (1987).

1955. 
[42] M.Forker, Hyp. Int. 24-26(1985)855.

[43] W.D.Hamilton, The eletromagnetic interaction in nuclear spectroscopy, NorthHolland Publishing Company, 1975.

[44] M.Forker, P.Herzog, K.Kroth, H.Schickel e W.Thomas, Z.Phys. B29(1978)223.

[45] M.Forker, S.Scholz e L.Freise, Hyp.Int. 15/16(1983)279.

[46] M.Forker, R.Trcinscki e T.Merzhauser, Hyp.Int. 15/16 (1983)273.

[47] V.Jaccarino, L.R.Walker e G.K.Wertheim, Phys. Rev. Lett 13(1964)752.

[48] G.G.Low, Phys. Lett. 21(1966)497.

[49] I.A.Campbell, J.Phys. C3(1970)2151.

[50] K.Nishiyama et al. Phys. Rev. Lett. 37(1976)357.

[51] P.Raghavan e R.S.Raghavan, Hyp. Int. 24-26(1985)855.

[52] R.L.Rasera, B.D.Dunlop e G.K.Shenoy, Phys. Rev. Lett. 41(1978)1188. 